\title{
SHORT-DISTANCE TRANSLOCATION OF THE NORTHERN PACIFIC \\ RATTLESNAKE (CROTALUS O. OREGANUS): EFFECTS ON VOLUME AND NEUROGENESIS IN THE CORTICAL FOREBRAIN, STEROID HORMONE CONCENTRATIONS, AND BEHAVIORS
}

\author{
A Thesis \\ Presented to \\ The Faculty of California Polytechnic State University \\ San Luis Obispo
}

In Partial Fulfillment

Of the Requirements for the Degree

Master of Science in Biological Sciences

By

Matthew Landon Holding

June, 2011 
(C) 2011

Matthew L. Holding

ALL RIGHTS RESERVED 
TITLE:

AUTHOR:

DATE SUBMITTED:

COMMITTEE CHAIR:

COMMITTEE MEMBER

COMMITTEE MEMBER:
Short-distance Translocation of Northern Pacific Rattlesnakes (Crotalus o. oreganus): Effects on Volume and Neurogenesis in the Cortical Forebrain, Steroid Hormones Concentrations, and Behaviors

Matthew Landon Holding

June, 2011

Emily N. Taylor, Ph.D.

Christine R. Strand, Ph.D.

Jason M. Blank, Ph.D. 


\begin{abstract}
Short-distance Translocation of Northern Pacific Rattlesnakes (Crotalus o. oreganus): Effects on Volume and Neurogenesis in the Cortical Forebrain, Steroid Hormones Concentrations, and Behaviors
\end{abstract}

Matthew L. Holding

The hippocampus of birds and mammals has been shown to play a crucial role in spatial memory and navigation. The hippocampus exhibits plasticity in adulthood in response to diverse environmental factors associated with spatial demands placed on an animal. The cortical telencephalon of squamate reptiles has been implicated as a functional homologue to the hippocampus. This study sought to experimentally manipulate the navigational demands placed on free-ranging northern Pacific rattlesnakes (Crotalus o. oreganus) to provide direct evidence of the relationship between spatial demands and neuroplasticity in the cortical telencephalon of the squamate brain. Adult male rattlesnakes were radio-tracked for two months, during which one of three treatments was imposed weekly: 225 meter translocation in a random direction, 225 meter walk and release at that day's capture site (handling control), and undisturbed control. Snakes were then sacrificed and brains were removed and processed for histological analysis of cortical features. The volume of the medial cortex was significantly larger in the translocated group compared to undisturbed controls. No differences in dorsal or lateral cortical volume were detected among the groups. Numbers of 5-Bromo-2'-deoxyuridine (BrdU) -labeled cells in the medial and dorsal cortices three weeks after BrdU injection were not affected by treatment. The activity range was larger in the translocated group compared to handled and undisturbed controls. A causal relationship between increased navigation in a free-ranging reptile and changes in brain morphology was established.

The use of translocation as a conservation strategy for reptiles is a controversial topic revisited many times. Previous studies have demonstrated the aberrant movement patterns and mortality caused by translocation and have established that short-distance translocation within an animal's home range is best for the animal. In conjunction with the neuroplasticity study, we examined the physiological impacts that repeated short-distance translocation and handling have on reptiles. This is essential knowledge if the efficacy of the technique is to be properly evaluated. Baseline and stressed concentrations of corticosterone and testosterone were assayed in blood taken immediately upon capture and following one hour of confinement in a bucket. Neither baseline nor stressed concentrations of either hormone were impacted by translocation or handling. Body condition and change in mass were not affected. Translocated animals had larger MCP activity ranges than handled and undisturbed animals at the $95 \%$, but not $100 \%$ levels, while an interaction between time and treatment impacted other movement parameters. Treatment had no effect on a number of behaviors observed during visits to each animal. We suggest that rattlesnakes are quite resistant to potential impacts on their physiology and behavior enacted by frequent short-distance translocation or handling. Additionally, studies that require frequent handling of reptilian subjects are not likely to severely alter stress physiology. 


\section{ACKNOWLEDGEMENTS}

The completion of this thesis would not have been possible without the invaluable help of several people. First, many thanks to my advisor and committee chair, Dr. Emily Taylor, who provided amazing advice, guidance, support, and research assistance throughout the course of this project. Additionally, I want to thank Dr. Christine Strand for providing advice and also much needed guidance during the laboratory portion of my study. I would like to thank my lab mates Tony Frazier and Nicholas Pollock for their assistance in the field, advice, and support. I want to acknowledge the invaluable work of Ignacio Moore on the radioimmunoassay of our blood samples and to thank him for advice on the analysis of that data and interpretation of the results. Also, I would like to acknowledge Dr. David LeBlanc and Dr. Samuel Frame for great advice on my study design and statistical analysis. Furthermore, I want to thank Sloane Henningsen, Scott Dorr, Kelsee Buskirk, Amanda Wagner, and Jordan Ahle for assistance with data collection. Lastly, this research was funded by the National Science Foundation's Graduate Research Fellowship Program, The Herpetologists' League, the Aryan I. Roest Memorial Scholarship from California Polytechnic State University, and the California Polytechnic State University Department of Biological Sciences. 
TABLE OF CONTENTS

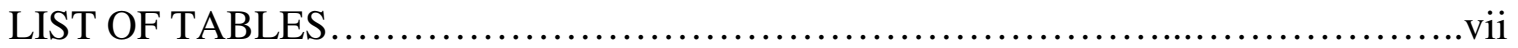

LIST OF FIGURES................................................................

GENERAL INTRODUCTION...............................................

CHAPTER

I. EXPERIMENTALLY ALTERED NAVIGATIONAL DEMANDS INDUCE CHANGES IN THE CORTICAL FOREBRAIN OF FREE-RANGING NORTHERN PACIFIC RATTLESNAKES (CROTALUS O. OREGANUS)...........5-25

II. THE HORMONAL AND BEHAVIORAL EFFECTS OF REPEATED HANDLING AND SHORT-DISTANCE TRANSLOCATION ON FREE-RANGING NORTHERN PACIFIC RATTLESNAKES (CROTALUS O. OREGANUS).............26-55

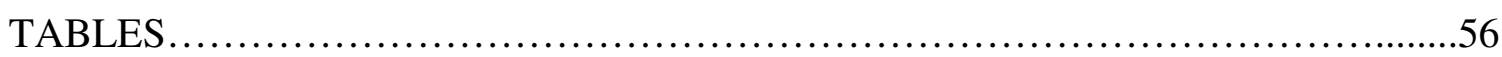

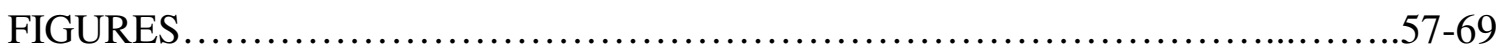

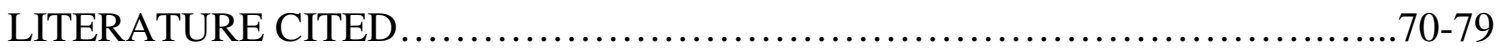




\section{LIST OF TABLES}

\section{TABLE:}

1. Mean Volumes of Each Cortical Brain Region Separated by Treatment...........56

2. Mean Values for Several Measures of Snake Movement by Treatment...........56

3. Percentage of visits during Several Snake Behaviors by Treatment..............56 


\section{LIST OF FIGURES}

\section{FIGURE:}

1. Atlas though the Brain with the Measured Regions Delineated..................57

2. Light Microscope Images of BrdU-labeled Cells in the Medial Cortex..............58

3. Minimum Convex Polygon Activity Ranges (95\%) by Treatment...............58

4. Total Distance Moved by Treatment......................................59

5. Medial Cortex Volume vs. Telencephalon Volume by Treatment................59

6. Dorsal Cortex Volume vs. Telencephalon Volume by Treatment.................60

7. Lateral Cortex Volume vs. Telencephalon Volume by Treatment................60

8. BrdU-labeled Cell Counts in Four Sub-regions of the Medial Cortex..............61

9. BrdU-labeled Cell Counts in Four Sub-regions of the Dorsal Cortex.............61

10. Minimum Convex Polygon Area (100\%) vs. SVL by Treatment...............62

11. Minimum Convex Polygon Area (95\%) vs. SVL by Treatment................62

12. Overall Total Distance Moved by Treatment...............................63

13. Total Distance Moved Separated by Time period and Treatment...............63

14. Movement Rate Separated by Time Period and Treatment......................64

15. Frequency of Movement Separated by Time Period and Treatment.............64

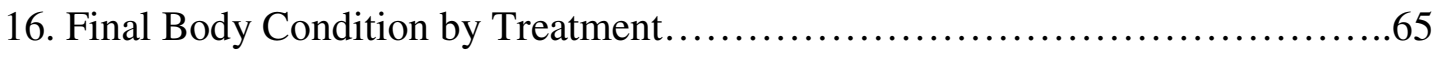

17. Change in Body Mass by Treatment...................................65

18. Wet Mass of Fat Pads vs. Snake Mass by Treatment.......................66

19. Baseline and Stressed Corticosterone During Initial and Final Capture..........66

20. Corticosterone Response to Acute Stress During Initial and Final Capture......67 
21. Baseline and Stressed Corticosterone during Final Capture by Treatment........67

22. Change in Corticosterone Conc. from Initial to Final Capture by Treatment.......68

23. Testosterone Decrease from Initial to Final Capture by Treatment................68

24. Baseline and Stressed Testosterone at Initial and Final Capture.................69

25. Baseline and Stressed Testosterone during Final Capture by Treatment..........69 


\section{General Introduction}

This chapter is intended to explain how the two parts of my research shown in Chapters 2 and 3, which at first would appear to be very distantly related, came together to be conducted within a single experiment.

Collaborative efforts by researchers from diverse fields have yielded insights into the physiology, morphology, and function of the vertebrate central nervous system. One of the great frontiers in this field is centered upon the proximate mechanisms by which the central nervous system works to interpret and store information about the environment via memory and learning. A recent line of research has revealed that parts of the brain exhibit plasticity, changing in both size and histology to meet physiological and environmental demands even in adulthood (Sherry et al. 1993; Clayton 1995; Gould et al. 1999; Sampedro et al. 2008). One method by which these changes are enacted is neurogenesis, the formation of new neurons. Many biotic and abiotic factors play a role in regulating this neuroplasticity, with steroid hormones as one likely mediators that induces the changes (Gould et al. 1990; McCormick et al. 1997; Tanapat et al. 2001, McEwen, 2007). Biotic factors include age, sex, reproductive state, and social stimuli (Clayton et al. 1997; Siwak-Tapp et al. 2007; Sampedro et al. 2008; Almli and Wilczynski, 2009), while abiotic factors such as temperature, season, and photoperiod also play crucial roles (Clayton et al. 1997, Ramirez et al. 1997; Delgado-Gonzalez et al. 2008). Although direct effects of the above factors no doubt exist, many cited examples may impact neuroplasticity indirectly by changing the degree to which learning and memory retrieval occur in an animal. The formation and retrieval of memories, such as 
the ability to navigate a maze in the laboratory or the retrieval of cached food can also stimulate changes in specific brain regions independent of other biotic or abiotic factors (Clayton, 1995; Gould et al. 1999). Spatial memory and navigational ability are among the most highly researched areas in terms of relating neuroplasticity to organismal function and ecology. Lindsey and Tropepe (2006) highlighted the importance of comparative studies using new model organisms for a better understanding of the ecological importance of neurogenesis, as well as the need to conduct studies that occur out of the laboratory and consider animals being influenced by natural conditions.

The current study was designed with such a goal in mind. The medial and dorsal cortices of reptiles have been implicated as the putative homologues of the hippocampus of mammals and birds, and are thus hypothesized to be the regions where spatial memories are stored and formed (Bruce and Butler, 1984; Butler and Hodos, 1996; Rodriguez et al. 2002). We experimentally altered the demands for navigation and spatial memory in free-ranging northern Pacific rattlesnakes (Crotalus o. oreganus) in order to observe the effects on neuroplasticity. We decided to do this via frequent shortdistance translocations, or moving an animal from place to place near or within its current home range. In snakes, such translocations have been shown to increase several movement parameters via radio-telemetry studies, such as overall range size and total distance moved, while producing no apparent ill-effects for the animals in terms of body condition and survivorship (Hardy et al. 2001; Brown et al. 2008; Brown et al. 2009). Additionally, we presumed that a snake carried from one place to another in an opaque container would need to orient itself in its environment following displacement, another potential increase to navigational demands. Hence, this technique seemed to represent an 
appropriate and controlled way in which we could increase the navigational demands placed upon a snake to observe the subsequent impacts on neuroplasticity.

Steroid hormones influence processes such as neurogenesis (Gould et al. 1990; McCormick et al. 1997; Tanapat et al. 2001, McEwen, 2007) and handling and confinement of snakes have been shown to result in acute changes in the concentrations of the steroids corticosterone (Moore et al. 1991; Dunlap and Wingfield, 1995; Schuett et al. 2004; Cartledge and Jones, 2007; Bailey et al. 2009; French et al. 2010) and testosterone (Moore et al. 1991; Manzo et al. 1994; Moore et al. 2000; Jones and Bell, 2004; Yajurvedi and Menon, 2005). Thus, data on the steroid hormones concentrations in the snakes both seemed important in terms of relating any changes we observed in the brains to increased navigational and spatial memory demands rather than altered steroid hormone concentrations resulting from the stress of repeated capture and translocation.

Upon reviewing the literature on steroid hormones, it was observed that no studies on translocation of reptiles had measured steroid hormone conentrations or the steroid response to acute stress. Given that translocation is a commonly used conservation strategy for reptiles (Dodd and Seigel, 1991; Reinert, 1991), the physiological ramifications of repeated handling and translocation seemed an important piece of information for evaluating its efficacy. Additionally, concentrations of steroids and the acute stress response to handling had not been considered over extended periods of time in free-ranging reptiles. Diverse studies on reptiles involve capturing and handling animals repeatedly during data collection. If this methodology alters the physiology and/or behavior of the study animals, then the viability of the results may come into question. Our study design, which involved translocated, handled but not translocated, 
and fully undisturbed groups of snakes is ideal for evaluating the extent to which repeated human disturbance alters physiology and related behaviors.

It was in this way that the same study design, weekly translocation, handling, or leaving snakes undisturbed, all the while tracking the animals' movements and recording associated behaviors, allowed us to examine the causes and function of neuroplasticity in the medial and dorsal cortices of the snakes' brains while simultaneously evaluating the physiological effects of handling and translocation on acute stress, chronic stress, and behaviors. We collected blood samples during the initial capture of snakes in March and April, 2010. After eight weeks of radio-telemetry and application of treatment, we collected a second set of blood samples (pre- and post-handling stress) and brought the snakes into the laboratory. Brains were then harvested from the animals for histological analysis and immunohistochemical detection of neurogenesis (Chapter 1). The blood was then assayed for concentrations of corticosterone and testosterone and certain behaviors observed in the field were tabulated and analyzed (Chapter 2). 


\section{Experimentally altered navigational demands induce changes in the cortical forebrain of free-ranging northern Pacific rattlesnakes (Crotalus o. oreganus)}

\section{Introduction}

The mammalian and avian brains have been the targets of numerous studies exploring the relationship between learning and neuroplasticity, implicating the hippocampus as a major component in spatial memory and navigation-related tasks (Clayton et al. 1997; Patel et al. 1997; Gould et al. 1999, Maguire et al. 2000; Amrein et al. 2004; Pravosudov and Omanska, 2004). Experiments utilizing mazes, enriched environments, and associative learning tasks have demonstrated that aspects of neuroplasticity can be stimulated differentially depending on the demands placed upon an animal (Kempermann et al. 1997; Gould et al. 1999). Clayton and Krebs (1994) prevented some food-storing marsh tits from caching food while allowing others to do so, resulting in marked differences in hippocampal size between the groups. Laboratory experiments like these confirm the existence of neuroplasticity that is not genetically determined or tied to seasonal cycles of activity such as reproductive cycles or active seasons, but instead that exists as a variable and readily adaptable means to cope with diverse environmental factors.

Studies using lab rats have demonstrated that adult neurogenesis is enhanced by spatial learning and navigation in Morris water mazes and enriched environments (Gould et al. 1999). In wild voles (Microtus spp.), hippocampal volume and neurogenesis are associated with sex, seasonal, and species differences that can be related to differences in spatial demands (Jacobs et al. 1990; Galea and McEwen, 1999). Maguire et al. (2000) 
showed that taxi drivers exhibit a larger hippocampal volume than control subjects and further that hippocampal size correlates positively with time spent driving a taxi. These authors concluded that environmental demands in the form of increased navigational requirements placed on taxi drivers were the likely cause of an expansion of the hippocampus.

Similar factors affecting the spatial demands of birds have been investigated and, in congruence with the mammalian literature, positive correlations between the spatial memory requirements of an animal and the size of the hippocampus have been discovered. Female brown-headed cowbirds presumably have higher demands for spatial memory than males of the species, given that they must locate and revisit the nests of the other bird species that they parasitize. The females have a larger hippocampus than the males in this species (Sherry et al. 1993). Additionally, food-caching behavior in birds can be readily manipulated in the laboratory, and as predicted, the amount of food storing allowed associates positively with both hippocampal size and rates of hippocampal neurogenesis (Clayton and Krebs, 1994; Patel et al. 1997; Biegler et al. 2001).

As one might anticipate based on their phylogenetic position in relation to mammals and birds, non-avian reptiles display neuroplasticity during adulthood. In fact, neurogenesis is much more widespread in non-avian reptile brains compared to their mammalian and avian counterparts (Pérez-Cañellas and García-Verdugo, 1996; Font et al. 2001). The reptilian medial cortex (MC) and, to a lesser extent, dorsal cortex (DC) have been implicated as both structural and functional homologues to the hippocampus of mammals and birds (Bruce and Butler, 1984; Butler and Hodos, 1996; Rodriguez et al. 2002). Again, associations with sex, season, and species-specific differences in spatial 
demands and measures of neuroplasticity have been shown (Day et al. 1997; Roth et al. 2006; Delgado-González et al. 2008; Sampedro et al. 2008). Lesioning of the MC and DC of turtles has produced deficits in spatial memory and the ability to navigate a maze (Rodriguez et al.2002, Lopez et al. 2003). In squamate reptiles, lesioning of the MC has caused similar disruption of spatial ability (Lopez-Garcia et al. 1992; but see Day et al. 2001). Day et al. (1999, 2001) suggested that relative size differences in both the MC and DC of two lizards of the genus Acanthodactylus with contrasting spatial demands may not be related to differences in the lizards' ability to carry out bird- or mammal-like spatial navigation, because no such differences were detected in their laboratory test. Holtzman et al. (1999) and Zuri and Bull (2000) showed that corn snakes (Elaphe guttata) and sleepy lizards (Tiliqua rugosa), respectively, could rapidly acquire the ability to perform a spatial task, but their spatial tasks did not require the use of distal cues as did those in Day et al. (1999). Roth et al. (2006) conducted the only to date that attempted to relate spatial requirements and cortex size in a snake. These authors showed that male cottonmouths (Agkistrodon piscivorus), which have a larger average home range than females, have a larger relative MC than females. There was not sexual dimorphism in the size of the DC in this study (Roth et al. 2006).

In spite of the overall paucity of literature on the subject, discrepancies such as those discussed by Day et al. $(1999,2001)$ have already arisen with regard to how the MC and DC each participate in spatial memory and navigation. The combination of controlled laboratory experiments and comparative neuroecological studies that relate brain morphology and neuroplasticity to selection pressures and species' life histories have begun to elucidate the trends previously discussed. Although educated inferences 
about the functional homology of the hippocampus of mammals and birds and MC-DC region of reptiles can begin to be made, more work is clearly required.

An experimental manipulation of the navigational demands placed upon a reptile would be of use in determining which brain regions play a role in navigation in reptiles, especially if this were accomplished in a natural setting on a free-ranging animal. Additionally, such an experiment would help determine whether previously observed differences in the volume and cell proliferation rates of reptiles with higher spatial demands are genetically determined or the result of cortical growth stimulated by navigation itself. Lindsey and Tropepe (2006) highlighted the need for such field-based studies in truly understanding the function of neuroplasticity and "bridging the gap" between ecology and associated changes in the brain. We chose to carry out such an experiment via short-distance translocations of free-ranging reptiles in an attempt to unite the findings from the laboratory and comparative studies. This type of field manipulation has not, to our knowledge, been carried out before, even in the more extensive mammal and bird literature.

Translocation is a commonly used management tool for the removal of nuisance snakes from areas of human contact (Reinert, 1991, Hardy et al. 2001, Brown et al. 2009). Short-distance translocations (translocations near or within an animal's home range) have been shown to increase the area over which snakes were found and the amount of movement they undertook overall, while resulting in few to no ill effects for the animal (Brown et al. 2009). We utilized short-distance translocation to experimentally increase nagivational demands of free-ranging norther Pacific rattlesnakes (Crotalus o. oreganus). We hypothesized that reptiles respond to increased navigational 
and spatial requirements with neuroplasticity in the MC, potentially via neurogenesis. We predicted that translocated snakes would have a larger MC than handled and undisturbed control snakes. Further, we predicted that translocated snakes would have higher numbers of new cells born in the MC. No such volumetric differences should occur in the DC or LC and no differences in cell birth should be observed in the DC.

\section{Materials and Methods}

\section{Field Experiment Procedures and Animal Observation}

Twenty-two adult male $C$. o. oreganus were captured during visual searches spanning a one month period from mid-March to mid-April, 2010, on the Chimineas Ranch unit of the Carrizo Plain Ecological Reserve, San Luis Obispo County, California. The site consists primarily of rolling, grassy hills with scattered rocky outcrops and blue oaks (Quercus douglasii). All snakes existed in a part of the ranch under grazing pressure from cattle and horses.

Rattlesnakes represented an excellent study organism for this experiment. They are large-bodied snakes, which permitted them to receive and carry relatively large radiotransmitters internally without impact to normal behavior. Additionally, they spend much of their time on the surface, often remain stationary upon approach, and can be repeatedly captured relatively easily. This set of features made them amicable to repeated captures, translocations, and continuous monitoring. The collection of snakes for research was carried out under the California Department of Fish and Game 
California Scientific Collection Permit \# 801072-05. The use and treatment of snakes was conducted under California Polytechnic State University IACUC protocol \#910.

Snakes were transported to the laboratory at California Polytechnic State University following initial capture. They were anesthetized via inhalation of isoflurane (Halocarbon Production Corp., U.S.A) and implanted intra-coelomically with 11g or 13.5g SI-2 radio transmitters (Holohil Systems Ltd. Carp Ontario, Canada). We defined adult males as those greater than $80 \mathrm{~cm}$ snout-to-vent length (SVL), and only those that met this requirement were placed into the study. Snakes were released at their original capture site following 1-3 days of recovery from surgery.

Each snake was randomly assigned to one of three experimental groups: translocated $(n=8)$, handled $(n=8)$, or undisturbed $(n=6)$. Translocated snakes $(\operatorname{Tr})$ were subjected to weekly (every 7-8 days) 225 meter translocations in the form of a randomly chosen, straight-line displacement in a white plastic bucket. The 225 meter distance was meant to place snake at or near the boundaries of their current home range, termed a short-distance translocation (Hardy et al., 2001). The distance was chosen using data on adult male C. o. oreganus home ranges at the study site from the three years prior to this study (Putman, unpublished data). Handled snakes (Hd) were captured weekly, carried in a white plastic bucket over a straight-line distance of 112.5 meters, and returned to the site of capture and released. These snakes were therefore carried captured and carried a distance equal to that experienced by the Tr snakes in order to control for potential effects of being handled. The undisturbed control snakes $(\mathrm{Cn})$ were radiotracked only. 
The direction of displacement for both the Tr and Hd animals was chosen via a random numbers table containing only integers between 1 and 360. These were translated to compass bearings used to move the snakes, with 360 representing due north. We wished to avoid the potential of moving a snake up to $500 \mathrm{~m}$ or more in a single direction if it happened not to move far from the previous week's release point. Therefore, a single restriction was placed on the random selection of direction for moving the snakes. Random numbers were eliminated until a bearing was selected that did not fall within $45^{\circ}$ of the previous week's bearing. The appropriate distance was then measured using a handheld GPS unit (Garmin Legend,Garmin) and Tr snakes were placed in the nearest suitable cover within 10 meters of their new location.

Treatment began on 04/23/10. All snakes were located four times weekly, on average, from $04 / 23 / 10$ to $06 / 19 / 10$. Each location was recorded to an accuracy of 10 meters with a Garmin Legend GPS unit.

From 05/29/11 to 06/02/11, all snakes were captured and received sub-dermal injections of 5 - Bromo - 2'- deoxyuridine (BrdU, MO744, Sigma-Aldrich Co., St. Louis, MO, USA) in the field at a dose of $100 \mathrm{mg} / \mathrm{kg}$. The BrdU was delivered dissolved in $0.9 \% \mathrm{NaCl}$ solution at $20 \mathrm{mg} \mathrm{BrdU} / \mathrm{ml}$. The $\mathrm{Cn}$ snakes were immediately released. The Tr and Hd snakes received their respective movement treatments following injection. Application of treatments was completed on 06/05/10, resulting in six translocations or handlings per snake. Application of treatment was planned to continue for one more week, but the onset of extremely hot weather made the prospect of capturing all snakes within a short time period unlikely. Beginning on $06 / 19 / 10$, any snake that was visible 
was captured and brought to the lab for sacrifice. Capturing commenced on 06/24/10 when the four snakes remaining were dug out of the ground.

\section{Tissue Preparation and Measurement}

Snakes were sacrificed 24-36 hours after capture. Following the onset of deep anesthesia via inhalation of isoflurane, each snake was transcardially perfused with a $0.9 \% \mathrm{NaCl}, 0.1 \% \mathrm{NaNO}_{2}, 0.1 \mathrm{M}$ Phosphate buffer (PB) wash for 10 minutes followed by $4 \%$ paraformaldehyde in $0.1 \mathrm{M} \mathrm{PB}, \mathrm{pH} 7.2$ with $0.1 \% \mathrm{NaNO}_{2}$. Paraformaldehyde perfusion lasted until the body rostral to the heart became stiffened, usually within 10 minutes. Skulls were then removed and placed in $4 \%$ paraformaldehyde for at least two hours. Brains were then carefully removed from the skull and post-fixed for 24 hours in $4 \%$ paraformaldehyde. Next, brains were transferred to a $0.1 \mathrm{M}$ PB solution for 24 hours prior to embedding in gelatin. Brains were soaked in $4 \%$ porcine gelatin for 10 minutes followed by embedding in $8 \%$ porcine gelatin. Gelatin was allowed to solidify overnight, and the block was placed into $4 \%$ paraformaldehyde for 24 hours. The block was then placed into a $30 \%$ sucrose solution until it sank, at which time it was frozen in dry ice and stored at $-80^{\circ} \mathrm{C}$.

Four series of parallel transverse sections were obtained at a thickness of $35 \mu \mathrm{m}$ using a cryostat. The first series was mounted onto slides directly from the cryostat, hydrated with mounting solution, allowed to dry, and stained with cresyl violet. The remaining series were stored in cryoprotectant at $-20^{\circ} \mathrm{C}$ until use.

Cortical brain regions in the cresyl violet-stained sections were photographed, and brain regions were measured using NIH ImageJ software. The measurement was 
conducted with the researcher blinded to the treatment group of the snake, and all measurements were carried out by one person. The medial cortex (MC), dorsal cortex (DC), lateral cortex (LC), and total telencephalon (TT) were identified in accordance with Halpern (1980). Measurement began at the first appearance of the LC cell layer and persisted until the disappearance of the telencephalon. Telencephalon rostral to first appearance of the LC cell layer was not included in the measurement of TT volume. As in Roth et al. (2006), subdivisions of the MC and DC were not considered separately. However, we did not follow Roth et al. (2006) in considering rostral and caudal MC separately. Representative photographs show the boundaries for the MC, DC, and LC as measured (Fig. 1). Volumes were calculated by summing the areas from both hemispheres of each region, then multiplying by section thickness $(0.035 \mathrm{~mm})$ and by the number of series (4). Missing or damaged sections were accounted for by using the average area of the two adjacent sections.

A subset of a second transverse series was obtained for detection of BrdU-labeled cells, such that every eighth brain section was represented. Sections were drawn from the same region in which volume was measured, beginning at the appearance of the LC cell layer. Free-floating sections were washed in phosphate-buffered saline (PBS) for three times for 5 min. prior to denaturing DNA in $4 \mathrm{~N} \mathrm{HCl}$ for 15 min. After 5 min.in PBS, acid was neutralized in $3.8 \%$ sodium borate wash adjusted to $\mathrm{pH} 8.5$ for 10 min. Sections were then washed three times for $10 \mathrm{~min}$. in PBS followed by blocking of non-specific binding and endogenous peroxidases via 1 hour in a solution of 5\% normal horse serum (S-2000, Vector Laboratories, Inc., Burlingame, CA, USA), 1\% bovine serum albumin, $0.5 \% \mathrm{H}_{2} \mathrm{O}_{2}$ in PBS $+0.3 \%$ Trition X-100 (PBST). Sections were then left shaking for 24 
hours in a 1:1000 dilution of Dako monoclonal mouse anti-BrdU (Clone Bu20a, DakoCytomation, Glostrup, Denmark) in PBST. Next, sections were washed 3 times for 5 min. in PBST and placed in a 1:200 dilution of biotinylated anti-mouse IgG affinity purified in horse (BA-2000, Vector Laboratories, Inc., Burlingame, CA, USA) for one hour.

Another three 5 min. washes in PBST was followed by 1 hour of incubation in the Vectastain avidin-biotin-peroxidase complex kit (ABC, PK-6100, Vector Laboratories, Inc., Burlingame, CA, USA). A final three 5 min. washes in PBST were followed by detection of bound peroxidase complexes by $4 \mathrm{~min}$. of incubation in a solution of Vector SG chromagen (SK-4700, Vector Laboratories, Burlingame, CA, USA), after which reaction was stopped by two 5 min. washes in PBS.

Labeled nuclei were counted in the ependymal layer (EP), inner plexiform layer (IP), cell layer (CL), and outer plexiform layer (OP) in the MC and DC (Fig. 2). Cells were said to be associated with the ependymal layer if they were within two nucleuswidths from the ventricle, and only cells on the cortical side of the ventricles were counted. Cell shape was not recorded.

\section{Data Analysis}

Arcview Version 3.3 (ESRI, Redlands, CA, U.S.A.) was used to analyze the spatial data obtained from each snake. The term activity range will replace home range for our purposes, since translocated animals were moved to areas not of their own choosing and potentially slightly outside of their home range. The activity range of each snake was measured by minimum convex polygon (MCP) at the $100 \%$ level, which 
estimates activity range by encircling all points to which a snake was tracked by a polygon with convex sides and the smallest possible area. The activity range seemed a likely estimate for the total space being mapped by the cortical forebrain of each animal. Total distance moved (TDM) was calculated as the summed distance between all successive locations, minus translocation distances for the Tr group. It is a proxy for the total distance travelled by each animal on its own throughout the study period.

The general linear model was used to analyze all of the results, with treatment as a factor and multiple potential covariates considered. The MCP activity ranges of snakes were modeled using ANCOVA with SVL as a covariate. One-way ANOVA was used to test for an effect of treatment on the TDM of the snakes once an ANCOVA model using SVL and body condition showed that these additional predictors were non-significant and did not improve the variation accounted for by the model. One snake in the Hd group received a second surgery half way through the study to replace a failing radio transmitter and was never observed to move again following this surgery. As a result, this animal's movement data are excluded from the results.

The ANCOVA procedure was used to test for differences in volume in the MC, DC, and LC and numbers of BrdU-labelled cells in the MC and DC among the three experimental groups. Following Roth et al. (2006), the volumetric analyses were carried out by creating a unique covariate to analyze the volumes of each cortical region. Covariates were calculated by subtracting the region of interest (MC, DC, or LC) from the total telencephalon volume. This is the most appropriate way to build this ANCOVA model, as not doing so would result in a covariate partly made up by the response of interest itself and a falsely inflated R-sq. value. Using these unique covariates instead of 
overall TT volume did not change the results of any tests. SVL was used as a covariate in all tests on the BrdU-labeled cell counts.

All models were chosen based on their ability to model the response in terms of significant covariates and the change in the adjusted R-sq brought about by adding or subtracting covariates suspected of affecting the response. The MCP activity range areas were log-transformed to meet the assumptions of normality and equal variance of the residuals in the ANOVA and ANCOVA models, but the results are presented in terms of the original variables. Alpha was set at 0.05 for all tests. The default procedure used for making pair-wise comparisons among treatments when the F-test yielded a significant pvalue was Tukey's procedure. All analyses were conducted with Minitab statistical software (Version 16, Minitab, Inc., State College, PA, USA).

\section{Results}

\section{Snake Ranges and Movement}

Our choice of translocation distance appeared to satisfy the description of a shortdistance translocation. Snakes never displayed the concentric circling behaviors observed during long-distance translocations that are believed to be attempts at located familiar areas (Reinert and Rupert, 1999; Nowak et al. 2002). Snakes navigated back to the exact site of the capture by the day after translocation on a number of occasions. On multiple other occasions a previously translocated snake was found moving directly toward its previous site of capture. 
The activity ranges of $\mathrm{Cn}$ snakes in this study were much larger than those from previous years that had been used in choosing the distance for translocation (current study mean: 12.16 ha, previous study mean: 5.03 ha, Putman et al., unpublished data). Despite this discrepancy and in concurrence with the results of another study that used short-distance translocation (Brown et al. 2008), the MCP activity range of $C . o$. oreganus was significantly impacted by treatment $\left(\mathrm{F}_{2,15}=9.10, \mathrm{p}=0.003\right.$, Fig. 3$)$. While SVL did not have a significant main effect on activity range size $\left(F_{2,15}=1.35, p=0.263\right)$, it interacted significantly with treatment to affect activity range size $\left(F_{2,15}=9.17, p=\right.$ 0.003). Post-hoc analysis revealed that Tr snakes had larger activity ranges than $\mathrm{Cn}$ snakes $(p=0.0297)$ while Hd snakes did not differ significantly from $\operatorname{Tr}(p=0.0619)$ or Cn snakes $(\mathrm{p}=0.8826)$. The TDM was not affected by treatment (ANOVA: $\mathrm{F}_{2,19}=0.76$, $\mathrm{p}=0.482$, Fig. 4)

\section{Cortical Volumes}

The TT volume with the respective region of interest subtracted was a highly significant predictor of the size of each region $(\mathrm{p}<0.0001$ for all cortical regions analyzed). The MCP size and TDM were not significant predictors of MC, DC, or LC volume ( $\mathrm{p}>0.3)$. ANCOVA using TT volume (minus MC volume) as a covariate to control for overall brain size revealed that treatment caused significant changes in MC volume $\left(F_{2,18}=7.77, p=0.004\right.$, Fig. 5). Treatment did not affect DC volume $\left(F_{2,18}=1.30\right.$, $\mathrm{p}=0.297$, Fig. 6) or LC volume $\left(\mathrm{F}_{2,18}=0.89, \mathrm{p}=0.429\right.$, Fig. 7$)$. Tukey's procedure revealed that $\operatorname{Tr}$ snakes possessed significantly larger MCs than $\mathrm{Cn}$ snakes $(\mathrm{T}=3.933, \mathrm{p}$ $=0.0027)$, while Hd snakes did not differ significantly from $\operatorname{Tr}$ snakes $(\mathrm{T}=2.087, \mathrm{p}=$ 
0.1207) or $\mathrm{Cn}$ snakes $(\mathrm{T}=2.034, \mathrm{p}=0.1327)$. Table 1 shows the average size of each brain region by treatment group.

\section{BrdU-labeled Cells}

An ANCOVA using SVL as a covariate revealed that the numbers of BrdUlabeled cells were not affected by treatment in the MC (Fig. 8) or DC (Fig.9). The TDM and MCP size did not impact any facet of BrdU-labeled cell counts ( $p>0.25$ in all cases). The numbers of BrdU-labeled cells showed a significant negative correlation with SVL of the snake in all layers of all cortical regions ( $\mathrm{p}<0.01$ in all cases), while TT volume was always a non-significant predictor of BrdU-labeled cell count. The TT volume also never improved the adjusted R-sq value of the ANCOVA models in conjunction with SVL. This may seem perplexing, as SVL and TT volume are significantly positively correlated $(T=2.41, p=0.026, R$-sq $=18.6 \%)$. The relatively small $R$-sq value here suggests that other factors may come into play in determining SVL, and thus, that using it in a model for BrdU-labeled cell counts may be accounting for snake size as well as some other factors. Snake age is one that immediately presents itself, especially given that other studies have shown that age impacts rates of neurogenesis in the brains of mammals (Amrein et al. 2004, Siwak-Tapp et al. 2007) and that the age and SVL of C. o. oreganus are positively correlated (MaCartney et al. 1990; Diller and Wallace, 2002). Interestingly, both SVL and TT volume were always negatively related to BrdU-labeled cell counts, suggesting that younger snakes may have higher rates of cell birth in the cortices. 


\section{Discussion}

In partial support of our hypothesis that reptiles respond to increased navigational demands with neuroplasticity in the MC, Tr snakes had significantly larger MCs than Cn snakes. Also as predicted, such differences were not observed in the DC or LC. Furthermore, the spatial demands of the animals followed the same pattern as the observed MC volume differences, as Tr snakes had larger MCP activity ranges than $\mathrm{Cn}$ snakes. These results are in agreement with the finding that male A. piscivorus have larger MCs than females, in addition to larger home ranges (Roth et al. 2006). It may be that the increased navigation of male snakes in that study due to searching for females was the cause of larger relative MC volumes in males compared to females. Our study suggests that such sex differences are not a genetically determined dimorphism, but something brought about by the formation of spatial memories, the act of navigating, or both. The C. o. oreganus studied here did not move further due to translocation, but instead carried out their movements over a larger activity range.

Clayton (1995) suggested that hippocampal size in food-storing birds is determined in large part by the act of storing food. However, the actual amount of foodstoring allowed did not correlate positively with hippocampal size and it is suggested that a threshold for the effect of storing on hippocampal size may exist (Clayton and Krebs, 1994). In this study, Tr snakes had larger MCP activity ranges than Cn snakes, but TDM was not affected by translocation, nor did MCP size or TDM show a significant positive correlation with MC volume. Thus, Tr snakes carried out the same amount of movement as $\mathrm{Cn}$ snakes, but did so over a larger are. It may be that traveling over a larger area 
caused a threshold change that did not differ depending on how much area a snake actually traversed. Alternatively, the act of orienteering and navigating, especially if the area is novel or somewhat unfamiliar, could be the stimulus for MC growth, regardless of activity range size or TDM. As all Tr snakes were translocated the same number of times, they were equal in terms of the demand to emerge from hiding, determine exactly where they were, and begin moving to where they wished to be next.

It is important to note that while the differences in both the MCP activity range results and the $\mathrm{MC}$ volumes did not turn out as predicted, the relationships among the groups were the same for both variables. The Hd snakes had activity ranges and MC volumes that were not significantly different from that of $\operatorname{Tr}$ or $\mathrm{Cn}$ snakes. The position of Hd snakes in terms of MC volume means that the support for our hypothesis is partial, but the similar relationship between activity ranges and $\mathrm{MC}$ volumes is encouraging. If navigational demands were somehow being impacted by our handling treatment and translocation was a further extension of that increase, this could help explain the position of the Hd snakes.

However, additional explanations for the MC volumes of $\mathrm{Hd}$ animals must be considered. Given that $\operatorname{Tr}$ and $\mathrm{Cn}$ snakes were shown to have significantly different relative MC volumes, a Type II statistical error must have been made in regard to the true effect of handling alone on MC volume. Thus, the unresolved position of Hd snakes was likely a product of small sample size and the presence of uncontrollable variability that is the downside of a field experiment like this one. Another potential explanation is that the stress related to capture, handling, and translocation had a positive effect on MC volume in both translocated and handled animals, and that the additional stress of translocation 
further increased MC size in the Tr group. Snyder et al. (2009) showed that restraint stress causes a transient increase in the survival of newly born hippocampal neurons in mice. In contrast to these results however, Gould et al. (1991) showed that treatment with the stress hormone corticosterone decreased rates of both cell birth and cell survival in rat pups. Likewise, Heine et al. (2004) found that both acute and chronic stressors suppress proliferation and stimulate apoptosis in the hippocampus of adult rats. Furthermore, natural stressors, such as the stress of losing a territorial conflict, have also been shown to result in marked decreases in neurogenesis (Gould et al. 1997).

Since different stressors appear to affect the brain differently, it is impossible to tell whether or not our captures and translocations impacted MC volumes via a stressrelated pathway. Such repeated acute stressors could have led to increases in brain volume, although this would contradict the bulk of the mammalian literature. Studies examining the effect of stress on the cortical forebrain of squamate reptiles would be most informative, but have not been carried out thus far. Evidence to suggest that stress did not play a role in MC size of $C$. o. oreganus in this study was obtained in the form of baseline concentrations of corticosterone upon final capture of the animals in the field before sacrifice. Treatment did not significantly affect baseline concentrations of corticosterone (see chapter 2 results). Thus, the differences observed in MC volume are unlikely to be due to differences in circulating corticosterone concentrations indicative of a chronically stressed state.

A confounding factor such as stress may have indeed played a role in the final MC volume of Tr and Hd snakes. Still, Tr snakes differed further in that following a dive into a hole or shrub near their point of release, they presumably had to emerge and orient 
themselves. As Tr snakes often were found at their original capture locations, they were receiving repeated stimuli in the form of navigational demands. Specifically, they had to find their way back to wherever they wanted to be after being translocated in an opaque bucket. Handled snakes did not have to orient themselves in the environment before embarking on their next movement, as their original location had not changed. Since corticosterone concentrations did not differ among treatments, we conclude that the increase in MC size in the $\operatorname{Tr}$ snakes compared to $\mathrm{Cn}$ snakes was due to the navigational demands incurred through translocation.

The BrdU injection was carried out in the field, followed immediately by application of the appropriate treatment. The labeling period following BrdU injection lasts about 2 hours in mammals (Phuphanich and Levin, 1985). It may be longer in a rattlesnake, a large-bodied, drought-tolerant ectotherm with a generally low standard metabolic rate (Beaupre, 1993). Still, we do not suspect that labeling lasted for more than 1-2 days. Given a sacrifice time of around three weeks post-injection, the numbers of BrdU-labeled cells observed in this study were likely a product of both rates of cell proliferation and cell survival.

Our hypothesis that altered navigational demands would result in differential rates of neurogenesis was not supported, as no effect of treatment on numbers of BrdU-labeled cells was observed in any layer of the MC. This is particularly interesting in light of the fact that volumetric differences were generated in the MC as a result of translocating snakes. Other potential means by which the MC could have grown include synaptogenesis and size and spacing changes in existing neurons. Learning has been shown to increase synaptogenesis in rats, and the link between spatial memory and 
synaptogenesis is well-established (Black et al. 1990; Moser et al. 1998; Ramírez-Amaya, 2001). Quantification of synaptic density in mature neurons in the MC of these snakes represents a potential future direction to help explain the means by which the MC increased in size. Such an analysis would also provide valuable information regarding neuroplasticity in reptiles, as no studies of reptilian synaptogenic capacity are currently available.

Marchioro et al. (2005) showed that most of the BrdU-labeled cells in the tropical iguanid lizard Tropidurus hispidus were fated to become neurons, especially in lizards with survival times longer than a few days post-injection. If this trend holds across all squamate reptiles, then we can safely say that it was rates of neuronal recruitment that did not differ significantly among the treatment groups. If this is not the case, the possibility that rates of neurogenesis and/or neuronal survival actually did differ between the treatments is not fully excluded. A double-labeling study using anti-BrdU and anti-beta tubulin III or double-cortin (DCX), both markers of immature neurons, would be useful in determining exactly how many neurons were born during the BrdU labeling pulse. Additionally, due to inclement weather conditions during the last few weeks of the study, the snakes went between 14 and 19 days without receiving treatment prior to sacrifice. Clayton and Krebs (1994) showed that in marsh tits, hippocampal growth stimulated by food storing ceased when food storing was brought to a halt, and a reduction in hippocampal size followed such that halted food storers had hippocampi whose volumes were not significantly different from those that were never allowed to store food. If this type of attrition can occur in snakes in a two week period with no treatment and little movement as occurred in this study, then the potential effects of treatment on neuronal 
recruitment may have been masked. Further, if overall MC volume regressed during this period, then the effect of translocation on MC volume may actually be greater than reported. Also, the unresolved position of the Hd snakes with respect to MC size may be partly due to the extended period without application of treatments.

Quantifying the actual spatial demands of a free-ranging vertebrate represents a unique approach to relating spatial demands, brain morphology, and the ecological significance of neuroplasticity. We have demonstrated that it is possible to experimentally manipulate those spatial demands in a manageable fashion in rattlesnakes. Although experiments such as ours do carry the limitation of reduced control, we believe that these costs are offset by gaining the valuable ability to elucidate cause and effect in a natural setting. Foremost among our goals in exploring brain function should be to understand the functional significance and adaptive value of a particular trait for the organisms in which it occurs. It is in this light that we suggest that these results have greatly aided in solidifying the role of MC neuroplasticity in responding to the varying spatial demands reptiles encounter naturally, such as those related to seasonal differences in spatial ecology. Additional studies that attempt to manipulate spatial demands in freeranging vertebrates would be most useful in fine-tuning our understanding of neuroplasticity and its role in navigation and spatial memory. The discovery of adequate mammalian and avian models, along with additional reptilian models, would greatly expand the knowledge we can gain from field-based neuroecological experiments.

Short-distance translocation during breeding and non-breeding seasons using both sexes may provide an invaluable degree of additional information regarding how neuroplasticity is stimulated by navigational demands and the formation of spatial 
memory. Does it occur in response to simple changes in spatial ecology only, or would season and sex interact with translocation treatment such that the capacity for neuroplasticity is different in a conditional manner? We greatly encourage future studies using Crotaline snakes that seek to manipulate the snakes' spatial demands in these and other ways and to note the subsequent impacts on morphology in the brain. 


\section{The hormonal and behavioral effects of repeated handling and short-distance translocation on free-ranging northern Pacific rattlesnakes (Crotalus o. oreganus)}

\section{Introduction}

Many studies of the life histories, behaviors, and physiological processes of reptiles have employed repeated capture and subsequent handling during the process of data collection. Human disturbance is necessary in many cases and kept to a functional minimum in all sound study designs. Nonetheless, the possibility that the results of such studies could be affected merits a consideration of the physiological and behavioral effects that repeated capture and handling might induce. Burger (2001) demonstrated that simply stopping to observe a snake at a distance elicits a different behavioral response compared to walking past the animal without stopping. Bailey et al. (2009) found that baseline concentrations of the stress hormone corticosterone (CORT) were not significantly elevated in free-ranging cottonmouths (Agkistrodon piscivorus) subjected to 30 minutes of quiet observation. However, a strong significant relationship between time to blood draw and CORT concentrations that existed in the immediately bled animals of that study was non-existent in the animals that were bled following observation.

Stress induced via capture and handling has been widely studied via assay of the circulating concentrations of "stress" hormones, most often CORT. A marked increase in CORT concentrations in response to stress has been widely documented in reptiles (Moore et al. 1991; Dunlap and Wingfield, 1995; Schuett et al. 2004; Cartledge and Jones, 2007; Bailey et al. 2009; French et al. 2010). The acute CORT stress response has been characterized as a contributing factor through which an organism enters an 
"emergency life history stage" when energy stores are mobilized, reproductive behaviors may be down-regulated, and behaviors involved with alleviating the effects of the stressor may be enacted (Wingfield et al. 1998). The hypothalamo-pituitary-adrenal (HPA) axis is the neuro-endocrine control center through which CORT release is modulated and can be regulated by a diverse array of potential factors. Normal concentrations of CORT prior to acute stress (hereafter referred to as baseline) are affected by season, reproductive status, feeding, sex, age, and time of day (Summers and Norman, 1988; Dauphin-Villemant et al. 1990; Klukowski and Nelson, 1998; Cree et al. 2000; Moore et al. 2001; Cease et al. 2007; Wada et al. 2007; Cote et al. 2010; Lind et al. 2010). The circulating CORT concentration following the application of an acute stressor by humans (hereafter referred to as stressed concentration) and the change in concentration from baseline to stressed (hereafter referred to as the CORT stress response) are also impacted by diverse factors including, but not limited to, season (Dunlap and Wingfield, 1995; Moore et al. 2001), population (Dunlap and Wingfield, 1995; Moore et al. 2001, French et al. 2008), sex (Grassman and Hess, 1992; Cree et al. 2003; Cartledge and Jones, 2007) and reproductive status (Cree et al. 2000; Woodley and Moore, 2002; Cartledge and Jones, 2007). Many of these studies have utilized somewhat different techniques and time periods for their acute stressors, and these also appear to have profound influences on the stress response (Schuett et al. 2004; Bailey et al. 2009; Langkilde and Shine, 2006).

One potential human-induced stressor whose potential impacts on stress physiology have not yet been studied is translocation, or the intentional movement of an animal from place to place by human action. Translocation is a popular conservation 
strategy used for reptiles that are in areas subject to impending development, for moving reptiles to areas from which they were previously extirpated, and for removing "nuisance" reptiles from areas of human conflict, the latter applying especially to venomous snakes that represent a perceived threat to humans (Dodd and Seigel, 1991; Reinert, 1991; Fisher and Lindenmayer, 2000; Nowak et al. 2002). Numerous field experiments have been conducted to assess the efficacy of translocation as a conservation strategy in reptiles (Reinert and Rupert, 1999; Plummer et al. 2000; Nowak et al. 2002; Brown et al. 2008; Brown et al. 2009). Common trends observed among the aforementioned studies regarding the effects of translocation include increases in several movement parameters (home range size, total movement, frequency of movement, movement rate), roaming behavior, and increased mortality. T. Brown et al. (2008) and J. Brown et al. (2009) have shown that short-distance translocation, or translocation at distances near or within an animal's current home range (Hardy et al. 2001), imparted fewer negative impacts on rattlesnake (Crotalus spp.) behavior and survival than longdistance translocation, or translocation far beyond the boundaries of the animal's home range.

Reptiles subjected to long-distance translocations experience such extreme negative consequences that it is almost ubiquitously discouraged as a management tool. However, they have not been shown to return to the area from which they were removed (Reinert and Rupert, 1999; Nowak et al. 2002). Short-distance translocates, on the other hand, experience little to no fitness consequences but can return to the area from which they were removed in a matter of days (Brown et al. 2008, Brown et al. 2009). Thus, a short-distance translocation policy may mean that an animal could receive many such 
translocations during its lifetime, or even during a single season. It is possible that such a translocation regime could result in chronic elevations of CORT, which can have serious negative effects on immune function and reproduction (Guillette et al. 1995; Moynihan, 2003). Elevated CORT concentrations have been shown to result in a depression of the hypothalamo-pituitary-gonadal (HPG) axis, resulting in a decrease in circulating concentrations of testosterone (Knapp and Moore, 1997, Tokarz, 1987; DeNardo and Licht, 1993; Yajurvedi and Nijagal, 2000), the primary male reproductive hormone regulating mating behaviors such as aggression, mate searching, and courtship behaviors (Moore and Marler, 1987; Haenel et al. 2003; Watt et al. 2003). Furthermore, as a metabolic hormone, CORT elevation can result in weight loss and an overall decline in body condition (Cote et al. 2010) and reduced wound healing rates (French et al. 2007) In spite of the importance of fully evaluating the efficacy of translocation for conservation biology, no study to date has examined the physiological implications of repeated translocation in terms of potential impacts on baseline CORT concentration and the stress response. Since translocation may be repeated and its effects long-lasting, it may represent both an acute stressor in the form of the capture and translocation event, and a chronic stressor via repeated translocations and the lasting effects of arriving in a potentially unfamiliar area and having to navigate back to familiar territory. Such factors make the hormonal response to translocation a particularly interesting subject, as implications exist for conservation biology and in the form of a novel anthropogenic stressor for which the stress response can be quantified exist. Furthermore, a study on the physiological ramifications of translocating reptiles would require long-term monitoring of animals in the field. Such a study could provide broad insight for many studies during 
which free-ranging reptiles are followed and repeatedly handled over extended periods, with respect to the extent to which the physiology of those animals has been potentially altered.

In order to provide such insights, we carried out an experiment to assess the hormonal response to repeated translocation and handling on the northern Pacific rattlesnake (Crotalus o. oreganus) by obtaining baseline and stressed blood samples upon initial capture of a snake (pre-treatment) and final capture of a snake (following 8 weeks of repeated translocations or handlings). These rattlesnakes are found along the west coast of North America, ranging from central California into parts of Washington and British Columbia. At the northern extent of their range in British Columbia, Brown et al. (2009) carried out repeated 500 meter short-distance translocations on C. o. oreganus that increased several movement parameters, but did not alter survivorship or an index of body condition when compared to non-translocated controls. We decided to conduct our study in a similar fashion, collecting data on hormones (CORT and testosterone) along with data on movements, snake health, and snake behaviors to facilitate comparisons with other studies on translocation of reptiles.

The snakes we studied are likely to have had little if any contact with humans. In Galapagos marine iguanas (Amblyrhychus cristatus), populations in heavily touristed sites showed a greater CORT stress response than populations in undisturbed areas, but did not display differences in baseline CORT concentrations (French et al. 2010). In tree lizard (Urosaurus graciosus) populations existing across an urban-rural gradient, differences in the CORT stress response were not observed, while baseline CORT was lower in animals in less natural environments (French et al. 2008). One explanation for 
the observed baseline differences in the baseline CORT concentrations of $U$. graciosus suggested by French et al. is that the HPA axis may be depressed as part of acclimatizing to the more frequent stressors encountered in urban life. A small collection of behavioral studies have examined the abilities of different snake species to habituate to human interaction. Plains garter snakes (Thamnophis radix) are unable to retain habituation in their response to a passing shadow for more than 24 hours (Fuenzalida, 1975). Herzog et al. (1989) studied two closely related species, Butler's garter snake (T. butleri) and the Mexican garter snake (T. melanogaster), and found that T. melanogaster could retain habituation of decreased striking behavior to human interaction over a period of five days, while T. butleri could not. Additionally, A. piscivorus habituates to human encounters over a five day period by showing fewer aggressive behaviors, but this effect disappeared when snakes were handled again 9 days later (Glaudas, 2004). These behavioral studies appear to represent the only examples of attempts to quantify the response to multiple human-induced stressors over time. To our knowledge, no studies have examined the same animals over time periods longer than a few days while attempting to quantify the adrenocortical effects of repeated, human-induced stressors. Additionally, the relationship between testosterone (T) and CORT has been well established, such that $\mathrm{T}$ concentration commonly declines in response to stress (Moore et al. 1991; Manzo et al. 1994; Moore et al. 2000; Jones and Bell, 2004; Yajurvedi and Menon, 2005) and often is negatively correlated with CORT concentration (Knapp and Moore, 1997) or directly lowered by experimental elevation of CORT (Tokarz, 1987; DeNardo and Licht, 1993; Yajurvedi and Nijagal, 2000). This phenomenon has been explained as a tradeoff between reproductive activities and mitigating the negative 
impacts of stressors. To address this issue in terms of repeated translocation and handling of free-ranging reptiles, we also measured $\mathrm{T}$ in the C. o. oreganus in our study. We hypothesized that repeated handling and translocation represent a chronic stressor to reptiles. Such chronic stress could manifest itself as a down-regulation of the HPA and HPG axes and heightened sensitivity to an acute stressor.

\section{Materials and Methods}

\section{Experimental Procedure}

Twenty-two adult male $C$. o. oreganus greater than $80 \mathrm{~cm}$ snout-vent length (SVL) were captured during visual searches spanning a one month period from midMarch to mid-April, 2010, on the Chimineas Ranch unit of the Carrizo Plain Ecological Reserve, San Luis Obispo County, California. The site consists primarily of rolling, grassy hills with scattered rocky outcrops and blue oaks (Quercus douglasii). All snakes were captured in a part of the ranch under moderate grazing pressure from cattle and horses. The collection of snakes for research was carried out under the California Department of Fish and Game California Scientific Collection Permit \# 801072-05. The use and treatment of snakes was conducted under California Polytechnic State University IACUC protocol number 910.

Snakes were transported to the laboratory at California Polytechnic State University following initial capture. They were anesthetized via inhalation of isoflurane (Halocarbon Production Corp., U.S.A) and implanted intracoelomically with 11g or 13.5g SI-2 radio transmitters (Holohil Systems Ltd. Carp Ontario, Canada). During 
anesthesia, mass and snout-to-vent length (SVL) were obtained. Snakes were released at their original capture site following 1-3 days of recovery in the lab.

Each snake was randomly assigned to one of three experimental groups: translocated $(n=8)$, handled $(n=8)$, or undisturbed $(n=6)$. Translocated $(\operatorname{Tr})$ snakes received weekly (every 7-8 days) 225 meter translocations in the form of a randomly chosen, straight-line displacement in a white plastic bucket. The 225 meter distance was meant to place snakes at or near the boundaries of their current home range, termed a short-distance translocation (Hardy et al., 2001). The distance was chosen based data on adult male $C$. o. oreganus home ranges at the study site gathered three years prior to this study (Putman et al., unpublished data). Handled (Hd) snakes were captured weekly, carried in a white plastic bucket over a straight-line distance of 112.5 meters, and returned to the site of capture and released. These snakes were therefore captured and carried a distance equal to that experienced by the translocated snakes, but did not receive translocation themselves. The undisturbed control snakes $(\mathrm{Cn})$ were radio-tracked only, but not captured.

The direction of displacement for both the Tr and Hd animals was chosen via a random numbers table containing only integers between 1 and 360. These were translated to compass bearings used to move the snakes, with 360 representing due north. We wished to avoid the potential of moving a snake up to $500 \mathrm{~m}$ or more in a single direction if it happened not to move far from the previous week's release point. Therefore, a single restriction was placed on the random selection of direction for moving the snakes. Random numbers were selected and eliminated until a bearing was selected that did not fall within $45^{\circ}$ of the previous week's bearing. The appropriate distance was 
then measured using a handheld GPS unit (Garmin Legend, Garmin) and Tr snakes were placed in the nearest suitable cover within 10 meters of their new location.

Treatment began on 04/23/10. One snake's radio signal displayed early signs of impending transmitter failure in mid-May and had to be brought back into the lab for a second surgery to replace the transmitter. The change in this snake's body condition from initial to final capture was the greatest of all the snakes and its movements following the second surgery were essentially none. Thus, we chose to exclude this animal from data analysis, leaving the Hd group with 7 snakes. Application of treatments ended on 06/05/10, resulting in six translocations/handlings per snake. Beginning on 06/19/10, any snake that was visible was captured and brought to the lab for sacrifice as part of the study described in Chapter 1. Capturing commenced on 06/24/10 when the four snakes remaining were dug out of the ground. Mass and SVL were obtained prior to sacrifice of the snakes. The presence or absence of stomach contents and the wet mass of fat pads were determined during post-mortem dissections.

\section{General Statistical Analysis}

Some variables were log-transformed to meet the assumptions of normality and equal variance of the residuals in ANOVA and ANCOVA models, but the results are always presented in terms of the original variables. Covariates were chosen or eliminated based on significance or contribution to the adjusted R-squared value of the model. Alpha was set at 0.05 for all tests. The default procedure used for making pair-wise comparisons among treatments when the ANOVA F-test yielded a significant p-value 
was Tukey'sprocedure. All analyses were performed using Minitab version 16 (Minitab, Inc.)

\section{Snake Movement}

All snakes were located by radio telemetry four times weekly, on average, from 04/23/10 to 06/19/10. Each location was recorded to an accuracy of 10 meters with a Garmin Legend GPS unit. Arcview Version 3.3 (ESRI, Redlands, CA, U.S.A.) was used to analyze the spatial data obtained from each snake. The term activity range will replace home range for our purposes, since translocated animals were moved to areas not of their own choosing and potentially slightly outside of their home ranges. The activity range of each snake was estimated by minimum convex polygon (MCP) at the 100\% and $95 \%$ levels. Total distance moved (TDM) was calculated as the summed distance between all successive locations, minus translocation distances for the Tr group. Movement rate was calculated as the total distance moved by each snake divided by the total number of days they were tracked. Movement frequency was calculated as the percentage of tracking days on which a snake had moved from the previous point at which it had been located. In calculating movement frequency, we considered successive points greater than 10 meters apart to represent a movement in order to account for GPS error. Post-hoc observation suggested that snakes moved less toward the end of the year, and we wished to discover whether there was an interaction between the number of weeks passed in the study and treatment. The TDM, movement rate, and movement frequency were calculated for the periods spanning 04/23/10 - 05/12/10, 05/13/10 - 05/31/10 and 06/01/10 - 06/19/10, in order to consider the potential impact that season and/or duration 
of treatment might have on movement and potential interactions with the aforementioned factors and treatment. This separated the entire study into three equal 19 day periods over which movement parameters were considered was considered.

\section{Statistical Analysis: Snake Movement}

The 100 and 95\% MCP areas of snake activity ranges were modeled using ANCOVA. Body condition and stomach contents at capture were eliminated as nonsignificant predictors of activity range, while SVL was found to be significant as a covariate in an interaction with treatment and was therefore included in the model. The overall TDM of snakes over the course of the study was modeled using one-way ANOVA, once body condition and SVL were found to be non-significant as covariates. The study period was then subdivided into three equal time intervals to consider TDM, movement rate, and movement frequency of snakes with repeated-measures ANOVA (RMANOVA). The result was a RMANOVA that considered the effects of treatment and time over three 19-day time intervals. Both the main effects of treatment and time and the interaction of the two were considered in these models.

\section{Snake Behaviors during Location}

Each time a snake was located, a series of behavioral data were collected. First, we recorded whether or not a snake was located visually or not. Given that visual search of the area to which a snake was tracked was extensive and location could be pinpointed via telemetry, the proportion of times a snake was seen represents a good estimate of the proportion of time a snake was above ground. If a male was found in contact with a 
female, this event was recorded as a courting event. Additionally, whether or not a snake rattled at the observer prior to any handling or manipulation, whether it was moving or stationary, and the percent of the dorsum that was sunlit were recorded.

\section{Statistical Analysis: Snake Behaviors during Location}

Analysis of covariance on the recorded behaviors yielded no significant covariates among SVL, body condition and baseline CORT concentrations. Thus, one-way ANOVA was used to test for effects of treatment on the frequency of all behaviors recorded during the location of each snake. The behavioral data presented are the proportion of visits during which a snake was visually detected and that particular behavior was observed.

\section{Snake Condition and Statistical Analysis of Condition}

Mass and SVL were obtained at both initial and final capture. The mass of any stomach contents observed during dissection was weighed and removed from the final mass values. The change in snake mass over the course of the study was then obtained and analyzed using the general linear model with treatment and presence or absence of stomach contents as factors. Additionally, body condition was calculated as the residuals from a regression of mass vs. SVL that included all of the snakes from this study, along with 68 other males that had been previously weighed and measured in the same population over the past five years. The body condition at final capture was analyzed in the general linear model with treatment and the presence or absence of stomach contents as factors and SVL as a covariate. Lastly, the wet mass of fat pads was obtained during 
dissection by removing and weighing the fat pads. Then the gut contents were fully extruded and the fat-free mass of the snake was obtained. The fat pad mass was analyzed in the general linear model with treatment as a factor and SVL as a covariate.

\section{Hormone Sampling and Radioimmunoassays}

The first time a snake was located via visual search $(03 / 23 / 10-04 / 18 / 10)$, it was captured and blood was taken from the caudal vein via a heparin-treated syringe as quickly as possible in order to ascertain baseline concentrations of CORT and T. The time to obtain this initial samples was recorded in minutes. The snake was then placed in a white 2.5 gallon white plastic bucket for one hour before being bled once again. The second sample shows stressed hormone concentration following the acute stressor of capture, handling, and one hour in a container. This procedure was repeated again at the end of the study period when snakes were collected (06/19/10 - 06-24/10). Blood samples were stored in at $4{ }^{\circ} \mathrm{C}$ within 24 hours of sampling and centrifuged to obtain plasma within 48 hours. Transporting blood for one day at high field temperatures is unlikely to impact steroid hormone concentrations (Taylor and Schuett, 2004). Plasma was frozen at $-20^{\circ} \mathrm{C}$ until radioimmunoassay.

We predicted that translocated and equally handled but non-translocated $C . o$. oreganus would have lower baseline CORT concentrations and a more pronounced CORT stress response than undisturbed controls following many weeks of repeated translocations or handlings, with these differences being more pronounced in translocated snakes. Furthermore, we predicted that the change in both baseline CORT and the CORT stress response from the initial capture to the final capture of the animals would be 
significantly more negative and positive, respectively, for translocated and handled snakes. In regard to $\mathrm{T}$ concentrations, predicted that repeatedly translocated and handled C. o. oreganus would have lower baseline $\mathrm{T}$ concentrations than undisturbed controls after many weeks of treatment. Furthermore, since previous studies of this population indicated that we could expect $\mathrm{T}$ concentrations to decrease naturally from the beginning to the end of our study (early to late spring; Lind et al. 2010), we predicted that the magnitude of this drop in baseline $\mathrm{T}$ would be larger for handled and translocated animals, with the greatest decrease among translocated snakes.

Concentrations of CORT and $\mathrm{T}$ were measured by standard radioimmunoassay techniques following extraction and chromatographic separation (Wingfield and Farner 1975; Moore et al. 2000; Husak et al. 2007, Lind et al. 2010). Based on the studies conducted by Taylor et al. (2004) on C. atrox and Lind et al. (2010) on this species, we used $20 \mu 1$ of plasma when steroid concentrations were predicted to be high (such as following acute stress) and $50 \mu \mathrm{l}$ of plasma when steroid concentrations were predicted to be low (such as $\mathrm{T}$ concentrations during the June sampling period). For individual extraction efficiency determination, we equilibrated each sample overnight with 2,000 cpm of tritiated steroid. Each sample was extracted with $5 \mathrm{ml}$ of distilled dichloromethane with the dichloromethane phase removed and dried in a warm water bath, under a stream of nitrogen gas, and re-suspended in $10 \%$ ethyl acetate in isooctane. For the removal of neutral lipids and isolation of individual steroids, all samples were transferred to diatomaceous earth (Celite, Sigma) columns for chromatographic separation. Neutral lipids and other steroids were eluted with $2 \mathrm{ml}$ of isooctane and discarded. Testosterone and CORT were eluted with $2 \mathrm{ml}$ of $20 \%$, and $2.5 \mathrm{ml}$ of $50 \%$ 
ethyl acetate in isooctane, respectively, and saved. After this, samples were dried in a $40^{\circ}$ $\mathrm{C}$ water bath under nitrogen gas, re-suspended in $600 \mu \mathrm{l}$ phosphate buffered saline, and maintained overnight at $4^{\circ} \mathrm{C}$.

Individual extraction efficiency for each steroid was determined from $100 \mu \mathrm{l}$ of the sample while $200 \mu \mathrm{l}$ of the sample was allocated to each of two duplicates for the assay. Mean recoveries were $63 \%$ for T and $61 \%$ for CORT. Serial dilutions for the standard curves were performed in triplicate (T curve range $=500-1 \mathrm{pg}$; CORT curve range $=2000-4 \mathrm{pg})$. All samples were incubated overnight with $100 \mu$ of antiserum $(\mathrm{T}$ : T-3003, Wien Laboratories, Succasunna, NJ; CORT: Esoterix Endocrinology, Calabasas Hills, CA) and $100 \mu \mathrm{l}$ of tritiated steroid. Unbound steroid was separated using dextrancoated charcoal and the bound steroid decanted into scintillation vials. Samples were counted on a liquid scintillation counter and final concentrations corrected for individual extraction efficiency. Average intra-assay coefficients of variation (CV) were $6.0 \%$ for $\mathrm{T}$ and $8.3 \%$ for CORT.

\section{Statistical Analysis: Hormone Concentrations}

Since hormones, especially CORT, exhibit complex interactions with other life history factors, we attempted to consider as many facets of the hormone concentrations of the snakes as possible to best evaluate potential effects of handling and translocation treatments on hormone concentrations. All analyses of T concentrations required logtransformation of the $\mathrm{T}$ values. The change in baseline $\mathrm{T}$ and CORT, the change in stressed $\mathrm{T}$ and CORT, and the change in the magnitude of the $\mathrm{T}$ and CORT response to acute stress between the initial and final captures were compared with one-way ANOVA 
once SVL, body condition, and the presence or absence of stomach contents were found to be non-significant as covariates. The baseline and stressed concentrations of $\mathrm{T}$ and CORT were compared using RMANOVA during the final capture, with T or CORT concentration as the response, and treatment, time (baseline or stressed) and their interaction as the model. The interaction was non-significant and was removed from the model for both hormones. The magnitude of the acute response to stress during final capture was compared using one-way ANOVA once baseline CORT concentration, SVL, body condition, and the presence or absence of stomach contents were eliminated from the model. Finally, hormone concentrations between baseline and stressed periods and between captures were compared with paired-t tests when no differences were found due to treatment.

\section{Results}

\section{Snake Movement}

Treatment significantly impacted the area of the MCP activity ranges of the snakes $\left(100 \%\right.$ MCP: $F_{2,15}=10.04, p=0.002 ; 95 \%$ MCP: $\left.F_{2,15}=9.10, p=0.003\right)$. While SVL alone did not significantly impact MCP size (100\% MCP: $\mathrm{F}_{1,15}=1.69, \mathrm{p}=0.213$; 95\% MCP: $\left.\mathrm{F}_{1,15}=1.35, \mathrm{p}=0.263\right), \mathrm{SVL}$ interacted significantly with treatment to affect MCP size (100\% MCP: $F_{2,15}=10.17, p=0.002$, Fig.10; 95\% MCP: $F_{2,15}=9.17, p=$ 0.003, Fig.11). Post-hoc analysis revealed that Tr snakes had larger 100\% MCPs than Cn snakes $(\mathrm{p}=0.0297)$, but that Hd snakes did not differ significantly from either $\operatorname{Tr}(\mathrm{p}=$ 0.0619) or Cn snakes ( $\mathrm{p}=0.8826)$. The Tr snakes had larger 95\% MCPs than both Hd ( $\mathrm{p}$ 
$=0.05)$ and $\mathrm{Cn}$ snakes $(\mathrm{p}=0.0166)$, and the $95 \%$ MCPs of $\mathrm{Hd}$ and $\mathrm{Cn}$ snakes did not differ significantly $(\mathrm{p}=0.7882)$.

There was not a significant effect of treatment on overall $\operatorname{TDM}\left(\mathrm{F}_{2,18}=0.60, \mathrm{p}=\right.$ 0.557, Fig. 12). Treatment did not interact significantly with time period $\left(\mathrm{F}_{4,36}=1.83, \mathrm{p}\right.$ $=0.144)$, nor did it have a significant main effect on TDM $\left(\mathrm{F}_{2,40}=0.60, \mathrm{p}=0.557\right)$. However, the TDM of snakes was significantly impacted by time period $\left(\mathrm{F}_{2,40}=6.57, \mathrm{p}=\right.$ 0.003, Fig. 13). Post-hoc analysis revealed that snakes moved farther during the period of $04 / 23 / 10-05 / 12 / 10$ than they did from $06 / 01 / 10-06 / 19 / 10(p=0.0024)$. No other pair-wise comparisons revealed significant differences between time periods.

Overall movement rate was not significantly different among treatment groups $\left(F_{2,18}=0.70, p=0.509\right)$, and was then subjected to similar consideration over time via RMANOVA. There was no significant main effect of treatment $\left(\mathrm{F}_{2,18}=0.12, \mathrm{p}=0.885\right)$, but there was a significant main effect of period when comparing 04/23/10 - 05/31/10 vs. $06 / 01 / 10-06 / 19 / 10\left(F_{1,18}=10.76, p=0.004\right)$ and a significant interaction between time period and treatment $\left(\mathrm{F}_{2,18}=5.10, \mathrm{p}=0.018\right)$. Post-hoc comparisons revealed that $\mathrm{Tr}$ snakes moved at a greater rate during the early period than $\mathrm{Hd}$ or $\mathrm{Tr}$ snakes in June and that overall, movement rate was higher during the early period (period main effect, Fig. 14). Movement frequency was not impacted by treatment $\left(\mathrm{F}_{2,40}=0.52, \mathrm{p}=0.596\right)$ or time period $\left(\mathrm{F}_{2,40}=0.33, \mathrm{p}=0.717\right.$, Fig. 15$)$.

\section{Snake Behaviors}

Translocation did not have any discernible impact on the behaviors we recorded in C. o. oreganus. Translocation did not affect the detectability of snakes as estimated by 
the proportion of visits during which the snake was seen $\left(F_{2,18}=0.12, p=0.890\right)$, the percent of the a snake's dorsum sunlit when seen $\left(\mathrm{F}_{2,18}=0.14, \mathrm{p}=0.870\right)$, the proportion of visits during which a snake was found on the move $\left(F_{2,18}=0.41, p=0.669\right)$, the proportion of visits during which a snake was seen and found to be courting a female $\left(\mathrm{F}_{2,18}=2.09, \mathrm{p}=0.153\right)$, or the proportion of visits during which the snake was seen and the observer received a rattling response to approach $\left(F_{2,18}=0.46, p=0.641\right)$. See Table 3 for the mean values for the behaviors discussed above.

\section{Body Condition, Change in Mass, and Stored Fat}

Treatment did not significantly affect body condition (BC) at final collection $\left(\mathrm{F}_{2,16}=1.43, \mathrm{p}=0.268\right.$, Fig 16$)$. The only significant predictors of body condition were whether the snake was found with stomach contents at collection $\left(\mathrm{F}_{1,16}=18.17, \mathrm{p}=\right.$ $0.001)$ and $\operatorname{SVL}\left(\mathrm{F}_{1,16}=6.66, \mathrm{p}=0.020\right)$. Change in mass was also not affected by treatment group $\left(\mathrm{F}_{2,16}=0.26, \mathrm{p}=0.772\right.$, Fig, 17), but there was a significant impact of the presence of stomach contents at final collection $\left(\mathrm{F}_{1,16}=4.93, \mathrm{p}<0.041\right)$. The mass of fat pads was positively correlated with snake size $(\mathrm{p}=0.002)$. Treatment did not have a significant main effect on the mass of fat pads in a snake $\left(F_{2,15}=2.76, p=0.095\right)$, but did interact significantly with the fat-free body mass of the snake to affect the fat pad mass $\left(\mathrm{F}_{2,15}=4.40, \mathrm{p}=0.031\right.$, Fig. 18$)$

\section{Corticosterone: Circulating Baseline and the Acute Stress Response}

We were unable to obtain blood from one animal during initial capture because it was in the act of copulating with a female. Hence, the initial capture data include only 20 
males. During the final capture period four snakes had to be dug up due to time constraints on the duration of the study. Even though these animals had baseline CORT concentrations below average and stressed CORT concentrations close to mean concentrations, all analyses were performed with and without these animals to attempt to identify any effects of digging up the snakes. Removing these animals did not change any of our conclusions, and only the full data set is presented in this section.

Baseline CORT, stressed CORT, and the stress response were not significantly impacted by time to bleed, time of day, or body condition of the snake during the initial or final bleeds $(\mathrm{p}>0.05)$. Corticosterone concentrations were significantly higher after our stressor compared to concentrations immediately following capture during both the initial capture $(T=-5.28, \mathrm{p}<0.001)$ and final capture $(\mathrm{T}=-9.65, \mathrm{p}<0.001$, Fig. 19). Baseline CORT concentrations did not differ significantly between the initial and final capture periods $(T=0.53, p=0.602)$, while stressed CORT concentration was significantly higher during the final capture period $(\mathrm{T}=3.58, \mathrm{p}=0.002)$. The magnitude of the acute stress response (stressed CORT minus baseline CORT) was therefore significantly larger during the final capture period $(T=-3.67, p=0.002$, Fig. 20).

Treatment did not significantly impact any facet of CORT physiology measured in our study. Variables that did not differ significantly among the treatments include baseline CORT concentration during the final capture $\left(\mathrm{F}_{2,18}=0.17, \mathrm{p}=0.844\right)$, CORT concentration following the acute stressor during final capture $\left(F_{2,17}=0.63, p=0.545\right)$, and the magnitude of the acute stress response during final capture $\left(\mathrm{F}_{2,18}=0.43, \mathrm{p}=\right.$ 0.43, Fig. 21). Treatment also did not significantly impact the way CORT concentrations changed from initial capture to final capture, including change in baseline CORT 
concentration $\left(\mathrm{F}_{2,17}=0.94, \mathrm{p}=0.411\right)$, change in the stressed CORT concentration following the acute stressor $\left(\mathrm{F}_{2,17}=0.61, \mathrm{p}=0.557\right)$, or the change in the magnitude of the CORT stress response $\left(\mathrm{F}_{2,17}=0.42, \mathrm{p}=0.666\right.$, Fig. 22$)$.

A high amount of variability was present in CORT concentrations. Baseline CORT ranged from 43.9 to $242.2 \mathrm{ng} / \mathrm{ml}$ during the initial capture and 5.1 to $305.9 \mathrm{ng} / \mathrm{ml}$ during final capture. The magnitude of the change in CORT during stress varied from a decrease of $28.7 \mathrm{ng} / \mathrm{ml}$ to an increase of $236.3 \mathrm{ng} / \mathrm{ml}$ during initial capture, while final capture CORT response varied from a rise of 31.2 to $282.6 \mathrm{ng} / \mathrm{ml}$.

\section{Testosterone: Circulating Baseline and the Response to Stress}

The concentrations of CORT and $\mathrm{T}$ at baseline, stressed CORT and $\mathrm{T}$, and the magnitude of the CORT and T stress responses were not significant related $(p>0.05$ in all cases). Baseline $\mathrm{T}$ concentration decreased significantly from initial to final capture (paired-T $=11.02, \mathrm{p}<0.001$ ). The magnitude of this drop was not affected by treatment $(\mathrm{F}=2.04, \mathrm{p}=0.161$, Fig. 23$)$. The drop in $\mathrm{T}$ from initial to final capture, $45.84 \pm 4.16$ $\mathrm{ng} / \mathrm{ml}$, is congruent with previous studies of seasonal hormonal variation in this population of C. o. oreganus (Lind et al. 2010). Acute stress did not affect T concentration during initial capture (paired-T $=-1.90, \mathrm{p}=0.073$ ), but did coincide with a significant decrease in $\mathrm{T}$ concentration during final capture (paired-T $=2.13, \mathrm{p}=0.046$, Fig. 24). Since treatment did not significantly impact this decrease (RMANOVA, F = $0.35, p=0.707)$, the data are shown irrespective of treatment. Additionally, the increased variability in $\mathrm{T}$ concentration during the stressed bleed of the initial capture was due in large part to a single individual whose $\mathrm{T}$ concentration increased by $61.5 \mathrm{ng} / \mathrm{ml}$, a very 
large increase. This same animal's T concentration increased following stress during the final capture by $12.51 \mathrm{ng} / \mathrm{ml}$, making it the sole extreme outlier in this dataset as well. The data were analyzed with and without this extreme outlier. None of the conclusions were changed, with the p-value for the initial capture comparison of baseline vs. stressed T becoming higher $(\mathrm{p}=0.119)$ and the $\mathrm{p}$-value for the final capture comparison of baseline vs. stressed $\mathrm{T}$ becoming more significant in favor of decreasing $\mathrm{T}$ after stress ( $\mathrm{p}$ $=0.003)$. This animal's T concentrations are included in the following results. During the final, post-treatment capture of the snakes, treatment did not significantly affect baseline $T$ concentrations $\left(F_{2,18}=0.49, p=0.620\right)$, stressed $T$ concentrations $\left(T_{2,18}=\right.$ $0.24, \mathrm{p}=0.789$ ), or the magnitude of the change in $\mathrm{T}$ experienced while in the bucket (stressed T- baseline $\mathrm{T} ; \mathrm{F}_{2,18}=0.24, \mathrm{p}=0.788$, Fig. 25).

\section{Discussion}

\section{Baseline Corticosterone and the Stress Response}

Our hypothesis repeated handling and translocation represent a chronic stressor to reptiles was not supported, as baseline CORT during final capture and the magnitude of the change in baseline CORT from initial to final capture were not significantly affected by treatment. It appears that $C$. o. oreganus are generally robust to the physiological impacts of a fairly frequent stress regime. While $C$. horridus show seasonal difference in baseline CORT concentrations (Lutterschmidt et al. 2009), Lind et al. (2010) did not detect seasonal differences in baseline CORT in this population of C. o. oreganus, and our results agree with this finding. Baseline CORT concentrations during initial capture, 
which spanned mid-March to mid-April, appear similar in both their means and amount of variability to those described in Lind et al. (2010). Our final capture baseline CORT concentration during June, however, appears to be of somewhat higher concentration (average 98.8 vs $53.4 \mathrm{ng} / \mathrm{ml}$ ) with similar variability in CORT concentrations. One potential explanation for this apparent increase is that the snakes in the current study were visited more often than those in Lind et al. (once weekly) and that even the snakes in the undisturbed control group were under chronic stress from the human visitations four times weekly. Thirty minute observation on one occasion did not impact baseline CORT concentrations in A. piscivorus (Bailey et al. 2009), and this is far longer than any of the snakes in this study were observed at a given time. However, the impacts of such observation periods chronically, in combination with occasional captures ( 9 captures for the $\operatorname{Tr}$ and $\mathrm{Hd}$ animals, 3 captures for the Cn animals) is unknown and could account for the higher average baseline CORT in our snakes in June compared to those of Lind et al. (2010). The only studies of the effect of chronic stress on baseline CORT involve confinement studies where an animal is brought from the wild and kept in captivity for an extended period. Moore et al. (1991) reported a significant positive correlation between baseline CORT and time in captivity, although the actual baseline CORT concentrations of the $U$. ornatus in their study were not significantly different between animals held in captivity for 1 day, 1 week, or 3 weeks. In the skink Egernia whitii, captivity resulted in a similar initial increase in baseline CORT concentrations, but a decrease in baseline CORT was detected 4 weeks post-capture (Jones and Bell, 2004). In water snakes (Nerodia sipedon), 5 to 8 days of confinement resulted in a significant increase in both baseline CORT concentration and CORT concentration after one hour of confinement in 
a bag (Sykes and Klukowski, 2009). These studies are important for comparison with our own as they represent the only other studies of chronic stress in reptiles. However, our snakes were free-ranging, whereas captivity represents a non-natural condition, which could actually reduce the overall stress load of an animal via absence of predators, ad libitum food, and stable environmental conditions. Thus, comparison between these studies and our own is difficult. An alternative explanation to chronic stress is that this study took place during a wet year that broke nearly four years of drought during which time the study of Lind et al. (2010) took place. It is likely that food was much more abundant during our study, and snakes spent much more time above ground (E. Taylor, pers. comm.). As CORT plays a large role in energetics and metabolism and has been shown to relate to thermoregulatory behaviors (Cree et al. 2003) and diurnal activity cycles (Jones and Bell, 2004), it seems likely that such yearly variation could produce differences in the mean CORT concentrations of snakes exposed to the differing environmental conditions.

We also predicted that the CORT response to the acute stressor of capture and one hour of confinement would be heightened by handling and translocation. Our data did not yield support for our hypothesis either. Although our male C. o. oreganus did display a significant elevation in CORT concentration during both initial and final capture, no aspects of the stress response were impacted significantly by treatment. Given that proximity to humans has been shown to impact the CORT stress response in another squamate reptile (A. cristatus) it seems that 1) species differences in susceptibility to anthropogenic stressors exist, 2) proximity to humans results in stressors other than direct human contact and capture (predators, altered food sources, etc.) or 3) a combination of 
the previous factors may play a role. Our snakes likely received little to no interaction with humans prior to this study. Although we predicted that the CORT stress response would be elevated in the Tr and Hd groups, it could have been depressed. This would agree with other literature demonstrating that Crotaline snakes can habituate behaviorally to human interaction (Glaudas, 2004). However, physiological habituation in terms of a down-regulation of the stress response following repeated capture and translocation was not observed here.

Since no effect of treatment on CORT physiology was observed, we pooled the CORT data to compare initial versus final capture. Although baseline CORT did not change between initial and final capture, the magnitude of the CORT stress response and the peak stressed CORT concentration were higher during final capture than initial capture. We could, again, explain this in terms of some effect of the fact that all snakes underwent some captures, surgery and manipulation in the lab, and repeated observation, and the effect was simply not heightened by the additional stressors applied to the $\operatorname{Tr}$ and Hd snakes. Such an explanation would be in partial concurrence with the results of Rödl et al. (2006), who showed that some populations of A. cristatus display an altered CORT stress response to chasing and capture if they have been chased and captured in the past. However, their results did show a graded response that varied with the relative threat of predation in each of the three populations tested. Their results would lead to a prediction in our study that all snakes should show an elevated CORT response during final capture, but that Hd and $\operatorname{Tr}$ snakes should have a greater increase than $\mathrm{Cn}$ snakes. This pattern was not detected in our study, although the high amount of variability in CORT responses in our study resulted in an estimated $20 \%$ power to detect even a difference of $30 \mathrm{ng} / \mathrm{ml}$ 
in elevated CORT given our sample size. Conversely, the stress response may show seasonal variation in this population of $C$. o. oreganus. Seasonal modulation of the stress response is well established in reptiles, especially in accordance with reproductive activities in males. Late March through April represents the primary breeding season for C. o. oreganus in our population (Lind et al. 2010, pers. obs.). Suppression of the CORT stress response during the breeding season has been demonstrated in a number of male reptiles including timber rattlesnakes $C$. horridus (Lutterschmidt et al. 2009), western fence lizards (Sceloporus occidentalis, Dunlap and WIngfield, 1995) and E. whitii (Cartledge and Jones, 2007), while the complete absence of a CORT stress response during the breeding season has been demonstrated in garter snakes ( $T$. sirtalis, Moore et al. 2001) and bearded dragons (Pogona barbatta, Cree et al. 2000). While the rattlesnakes studied here mounted significant CORT responses to capture and confinement during all seasons, they appear to have modulated their stress response between capture periods. Further study of this phenomenon in C. o. oreganus would be useful in determining whether our results were produced by human interaction or were an effect of season and/or reproductive activity.

\section{Baseline Testosterone and the Stress Response}

Neither baseline $\mathrm{T}$ concentration during final capture, nor the magnitude of the predicted drop in baseline $\mathrm{T}$ from initial to final capture were significantly impacted by treatment, yielding no support for our hypothesis. Egernia whitii showed no detectable change in T during 28 days of captivity compared to wild-caught control concentrations (Jones and Bell, 2004), while U. graciosus displayed a substantial initial drop in T 
following capture that was not exacerbated by three weeks of captivity (Moore et al. 1991). Our results appear to agree with these other studies in suggesting that reptiles are fairly robust against the effects of low impact chronic stress on $\mathrm{T}$ concentrations.

We detected a difference in the $\mathrm{T}$ response to acute stress between our initial and final captures. During initial capture, $\mathrm{T}$ concentrations did not change significantly and the raw value for mean $\mathrm{T}$ concentration was actually higher after one hour of confinement. At final capture, T concentrations decreased significantly in response to capture and confinement. In $C$. horridus season also affects the T response to stress, such that $\mathrm{T}$ levels increase during stress in the spring and fall only (Lutterschmidt et al. 2009). Among garter snakes, $T$. sirtalis parietalis at the northern extent of their range, T. concentrations do not change in response to acute stress during the spring breeding season, but decreased in response to acute stress during summer and fall (Moore et al. 2001). The effects of stress on the HPG axis appear to be highly context-dependent, and are likely shaped by differing selective pressures on reproduction and avoidance of stressful situations.

A negative relationship between CORT and $\mathrm{T}$ has been widely supported in the reptilian literature, such that when CORT is elevated, $\mathrm{T}$ concentration often declines (Tokarz et al. 1987; Moore et al. 1991; DeNardo and Licht, 1993; Knapp and Moore 1997; Jones and Bell 2004; Moore et al. 2001). While acute stress did result in reduced T concentrations during our final capture, no significant relationships between baseline CORT and $\mathrm{T}$, stressed CORT and $\mathrm{T}$, or the CORT and $\mathrm{T}$ response existed for the initial or final captures. This result suggests that in C. o. oreganus CORT and T concentrations are not tightly linked. 
Physical Condition, Movements, and Behaviors: Comparability with other

\section{Translocation Studies}

Our results appear to be comparable to those of other translocation studies in that short-distance translocation altered several movement parameters in our snakes but produced no adverse impacts on body condition and mortality. Short-distance translocation did not impact the body condition of $C$. o. oreganus at the northern extent of their range (Brown et al. 2009), while long distance translocation did not affect body condition in C. atrox (Nowak et al. 2002) and C. horridus (Reinert and Rupert, 1999). Feeding events were only observed for $\operatorname{Tr}$ (two snakes ) and Cn (two snakes) animals. The two Tr snakes that fed did so in ground squirrel burrows in which they were placed during translocations in the last three weeks of the study. If translocation into a fresh burrow system actually helped these snakes get a meal, then this may be evidence of a potential benefit of translocation, especially given that $\mathrm{Hd}$ snakes were not observed to feed. The best support for this explanation is the significant interaction between fat pad mass and fat-free snake mass in which Tr snakes had more fat than Hd snakes at larger overall sizes. Mackessy (1988) showed that C. o. oreganus display an ontogenetic shift in prey preference from reptiles to larger and larger mammals as they grow in size. This could indicate why large animals benefited from being moved into ground squirrel burrows, while smaller snakes did not. This difference, however, was driven in large part by two snakes and is thus weak evidence for such an effect. Studies focused on the effects of translocation on snakes of different sizes would be interesting.

The $100 \%$ MCP estimate of male C. o. oreganus home range size for our population (Putman, unpublished data) that was used to choose our translocation distance 
of $225 \mathrm{~m}$ was far smaller than the average male $100 \%$ MCP size in this study for $\mathrm{Cn}$ animals (Putman: 5.03 ha; this study: $12.16 \mathrm{ha}$ ). This discrepancy is likely attributable to drought conditions during the 2007-2008 seasons when the data of Putman et al. were collected. Our MCP estimates of activity range would have led to a choice of much larger distances for our short-distance translocations, likely around $500 \mathrm{~m}$. Still, our shorter distance translocation had an impact on several movement parameters. Translocation treatment affected activity range and movement rate in $C$. o. oreganus in our study. At the northern extent of their range, $500 \mathrm{~m}$ translocations increased TDM but not MCP size. Here, activity range was affected, with differences in the relationship between treatment groups depending on whether 100\% MCPs or 95\% MCPs were analyzed. The Tr and Hd snakes were not significantly different in their 100\% MCP activity ranges. This effect may have been due to the fact that Hd snakes made a few long distance movements, potentially during searches for females (pers. observation) after which they returned to core activity ranges. The 95\% MCP did not include those long, short-duration forays, while the repeated translocations incurred by $\operatorname{Tr}$ snakes were not all eliminated by $95 \% \mathrm{MCP}$ because there were many of them. Our further subdivision of movement rate into an early, cool period during 04/23/10 - 05/31/10 and a late, hot period in June yielded the result that translocated animals moved at a greater rate earlier in the season compared to $\mathrm{Hd}$ and $\mathrm{Cn}$ animals and moved at a slower rate in June. We could speculate that Tr snakes were getting fatigued toward the end of the study by the repeated translocations followed by having to move to locate preferred habitats. However, the CORT and body condition data do not support this conclusion. We may have been reaching a physiological limit during which the Tr snakes could no longer 
maintain similar performance to $\mathrm{Cn}$ and $\mathrm{Hd}$ animals, especially in combination with the onset of hot, dry conditions. Future studies over a longer time period may be useful in elucidating these effects.

None of the behaviors observed at each location were impacted by treatment. We believed that behaviors such as rattling upon approach and the amount of the dorsum in shade versus sun might relate to habituation or sensitization of the snakes in response to repeated captures, handlings, and translocations. However, it appears that C. o. oreganus is relatively resistant to behavioral adjustments to its response to repeated human interactions. Basking behavior in lizards has been shown to relate to both food availability and CORT concentrations in such a way that lizards made a tradeoff between potential exposure to predators and food acquisition (Cote et al. 2010). Our rattlesnakes did not alter their exposure in terms of the percent of their dorsum that was sunlit, which is related to the amount of cover beneath which they were sheltering, nor did they alter their overall time spent above ground, as evidenced by the probability of detection results.

Reproductive behaviors in translocated snakes have been observed in other studies (Reinert and Rupert, 1999; Plummer and Mills, 2000; Brown et al. 2008). We observed courting behaviors among all groups of snakes in our study, although the only observed copulation involved a $\mathrm{Cn}$ male. The frequency with which males were found in courtship with females was not affected by treatment, so we posit that short-distance translocation is not a large constraint on reproduction in C. o. oreganus. Males were translocated away from females which they had been courting on several occasions, but often returned to those females shortly afterward. In fact, all occasions in which a 
translocated male returned to the exact spot from which it was translocated within one day or less involved that snake being pulled off of a female, and the male was found with what appeared to be the same female again the next day.

\section{Translocation as a Conservation Strategy}

The importance of physiological ecology to conservation biology has been highlighted previously (Tracy et al. 2006). We were able to assay a quantifiable measure of stress, CORT concentrations at both acute and chronic timescales. The effects of our short-distance translocations on body condition and movement appear to be fairly comparable to those of Brown et al. (2008) and Brown et al. (2009). Thus, the results of our hormone measurements may be extrapolated to the broader literature on shortdistance translocation. Our results add more information to the translocation literature in terms of the physical and behavioral robustness of rattlesnakes to translocation, while providing new evidence that they are also robust physiologically to the impacts of translocations in terms of CORT and T concentrations and thus, the effects on the HPA and HPG axes. The frequency of translocations in our study is likely far more than would be necessary in a management program. As in other studies, our snakes were able to find their way back over the 225 meters distance to the same location from which they were removed. This occurred sometimes within periods as short as one day. Therefore, short-distance translocation is likely a better mitigation strategy in less populated areas, where the chances of finding a snake again, even when it returns, are lower. We suggest that, should a snake return and be repeatedly discovered and removed, the potential impacts to its physiology and even behavior towards humans will be minimal. 
Table 1.Mean volumes $\left(\mathrm{mm}^{3}\right) \pm \mathrm{SE}$ of the cortical regions and total telencephalon for adult male $C$. o. oreganus in each treatment group. Significantly different means are emboldened.

\begin{tabular}{lllll}
\hline Treatment & medial cortex & dorsal cortex & lateral cortex & telencephalon \\
\hline Control & $\mathbf{1 0 . 1 2 7} \pm \mathbf{0 . 4 9 2}$ & $5.884 \pm 0.304$ & $5.326 \pm 0.303$ & $52.27 \pm 2.36$ \\
Handled & $11.303 \pm 0.631$ & $6.419 \pm 0.406$ & $5.520 \pm 0.360$ & $54.81 \pm 2.30$ \\
Translocated & $\mathbf{1 2 . 3 4 3} \pm \mathbf{0 . 5 5 0}$ & $6.701 \pm 0.337$ & $5.601 \pm 0.243$ & $56.79 \pm 2.56$ \\
\hline
\end{tabular}

Table 2. Means \pm SE for minimum convex polygon activity ranges (ha), total distance moved $(\mathrm{m})$, movement rate $(\mathrm{m} / \mathrm{day})$, and frequency of movement for male $C$. o. oreganus in each treatment group for the entire period of $04 / 23 / 10-06 / 19 / 10$.

\begin{tabular}{llllll}
\hline Treatment & $100 \%$ MCP & $95 \%$ MCP & TDM & Rate & Frequency \\
\hline Control & $12.16 \pm 4.65$ & $10.55 \pm 3.93$ & $2016 \pm 294$ & $35.36 \pm 5.15$ & $0.692 \pm 0.04$ \\
Handled & $14.51 \pm 4.28$ & $13.41 \pm 4.28$ & $2175 \pm 370$ & $38.16 \pm 6.50$ & $0.732 \pm 0.04$ \\
Translocated & $27.33 \pm 5.74$ & $25.56 \pm 5.40$ & $2537 \pm 350$ & $45.29 \pm 6.35$ & $0.668 \pm 0.07$ \\
\hline
\end{tabular}

Table 3. Means \pm SE for percentage of visits during which a snake was detected, percent of the dorsum sunlit, percentage of visits during movement, percentage of the visits during courtship, and percentage of visits during which a rattling response to approach was elicited of male $C .0$. oreganus in each treatment group for the period of 04/23/10 - 06/19/10.

\begin{tabular}{llllll}
\hline Treatment & Detectability & $\%$ Sunlit & \% Moving & \% Courtship & \% Rattling \\
\hline Control & $71.34 \pm 6.33$ & $37.67 \pm 3.83$ & $8.80 \pm 2.14$ & $18.44 \pm 4.15$ & $12.13 \pm 4.87$ \\
Handled & $73.38 \pm 3.77$ & $34.84 \pm 4.46$ & $5.86 \pm 1.11$ & $7.69 \pm 4.45$ & $11.38 \pm 4.12$ \\
Translocated & $70.93 \pm 1.34$ & $35.73 \pm 2.79$ & $6.42 \pm 1.91$ & $8.30 \pm 3.45$ & $16.62 \pm 4.11$ \\
\hline
\end{tabular}




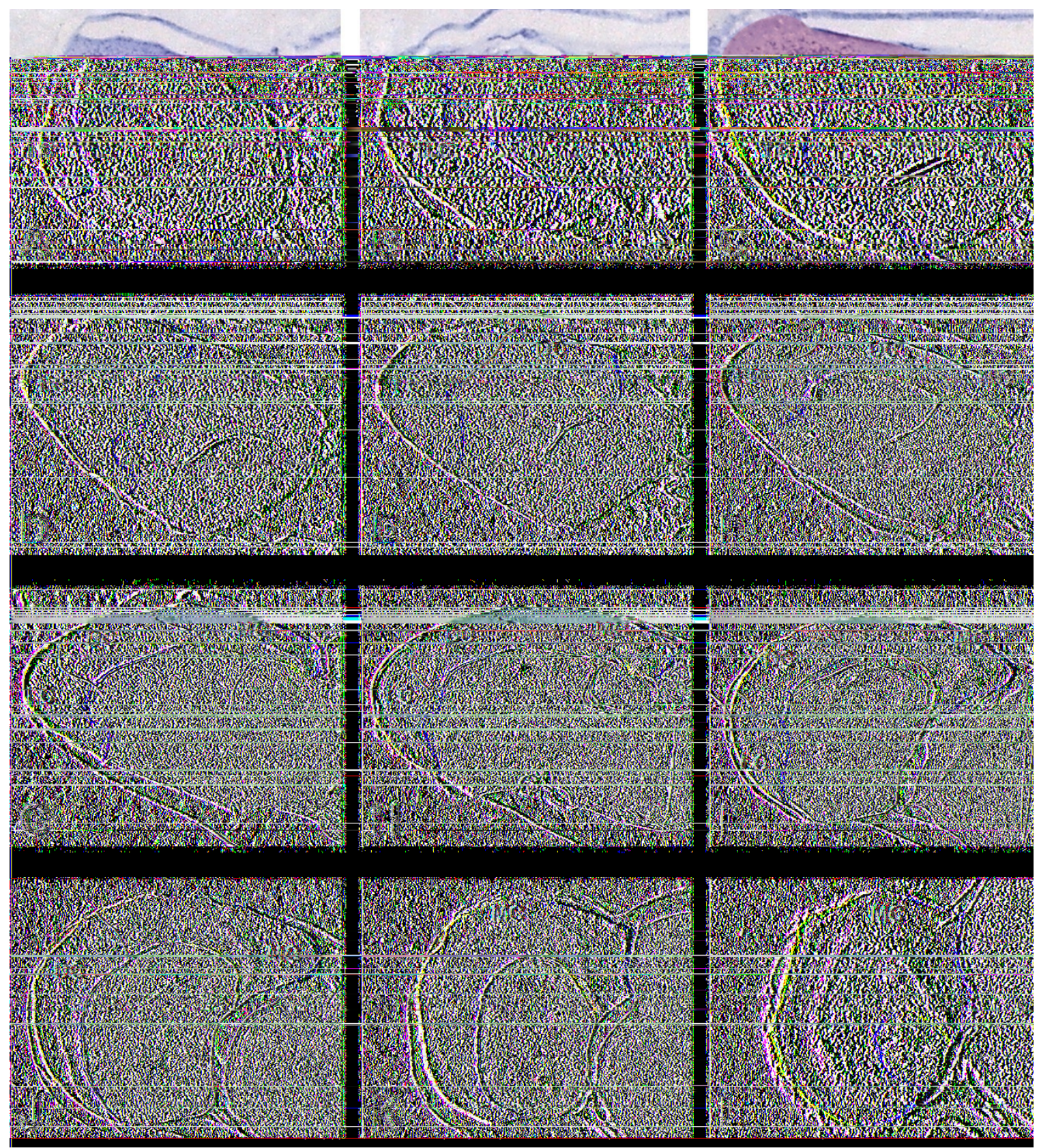

Figure 1: Images of cresyl violet-stained sections moving caudally from A-L through one hemisphere of the telencephalon of $C$. o. oreganus. The images represent areas where major changes occur in morphological features of the cortical regions under consideration. The area outlined in translucent pink represents the area measured during volumetric analysis and the black lines show the divisions between the MC, DC, and LC. A) Measurement began here, when the first cells of the cell layer of the LC become visible. B) The LC expands dorsally and ventrally. C) The LC expands medially. D) The DC is present but difficult to discern from the anterior dorsoventricular ridge and retrobulbular region. E) Measurement of the $\mathrm{DC}$ began at the point where the lateral extension of the lateral ventricle first became visible. F) The MC cell layer first appears. G-I)The MC expands laterally, while the DC expands ventrally in conjuction with the lateral ventricle. J) The lateral ventricle completely encircles the dorsoventricular ridge and nucleus sphericus. K) The disappearance of the medial superposition marks the disappearance of the DC. All cortical area was now attributed to the MC. L) The disappearance of the nucleus sphericus marks the point at which all remaining telencephalon was attributed to the MC. 

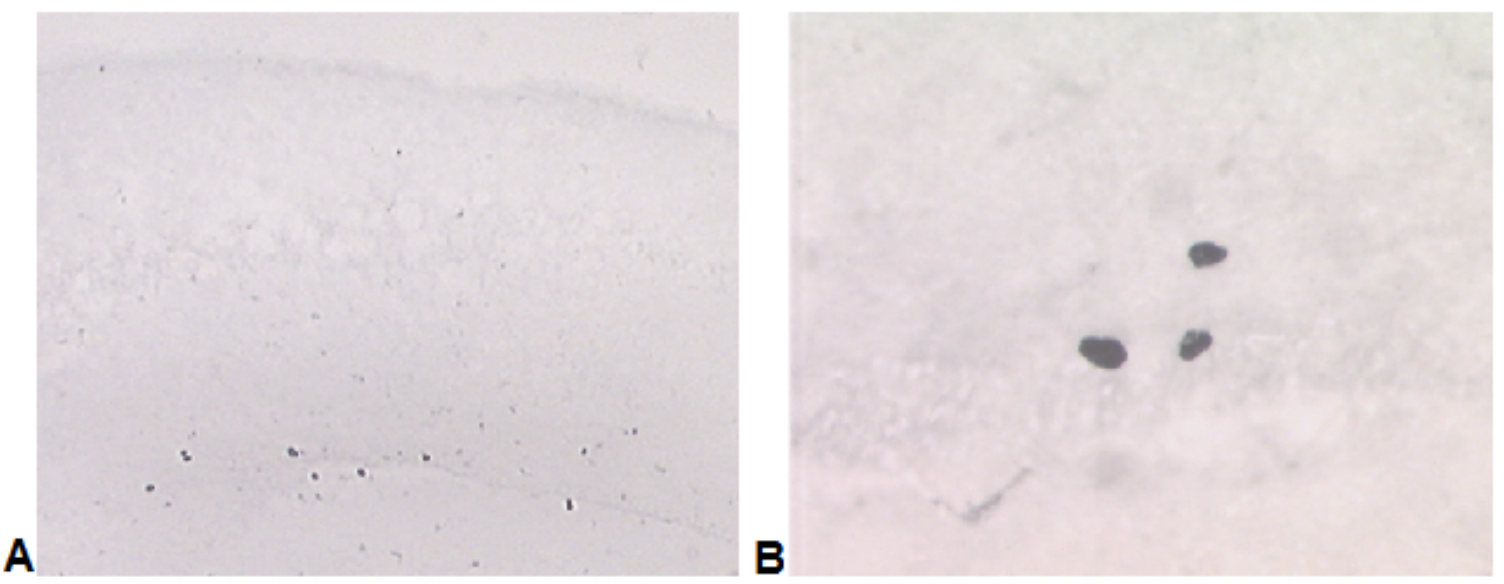

Figure 2: A) The medial cortex of $C$. o. oreganus containing BrdU-labeled cells. Cells were characterized by dark nuclei that were round, oval, or fusiform in shape. Background stained objects seen on this image were not counted, and were very small with long projections not characteristic of cell nuclei. B) Image of two labeled cells in the EP and one in the IP of the MC.

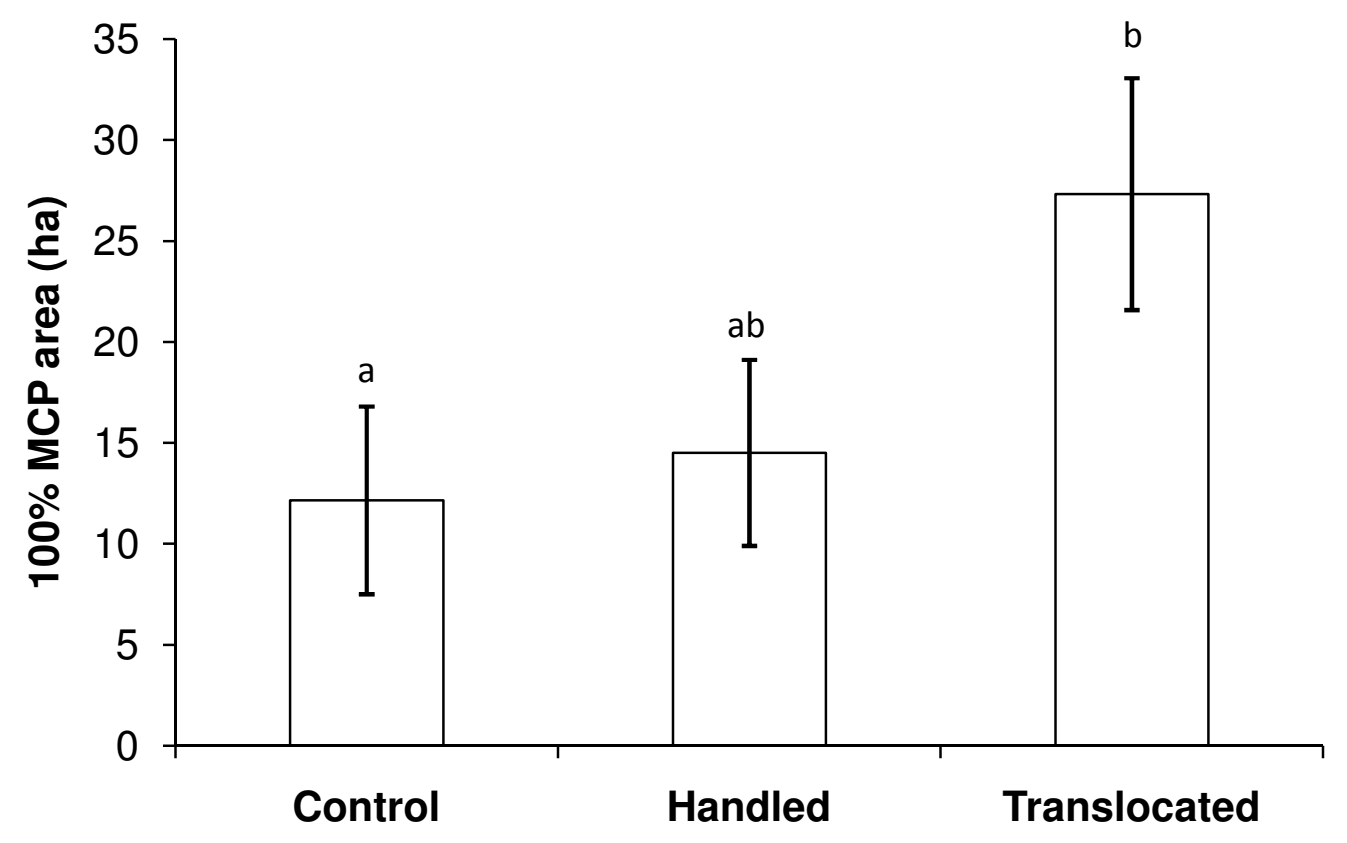

Figure 3: Activity range size estimated by $100 \%$ minimum convex polygons of translocated, handled, and undisturbed adult male C. o. oreganus tracked from April $23-$ June 19, 2010 is shown as means \pm SE. Different letters indicate significant differences. 


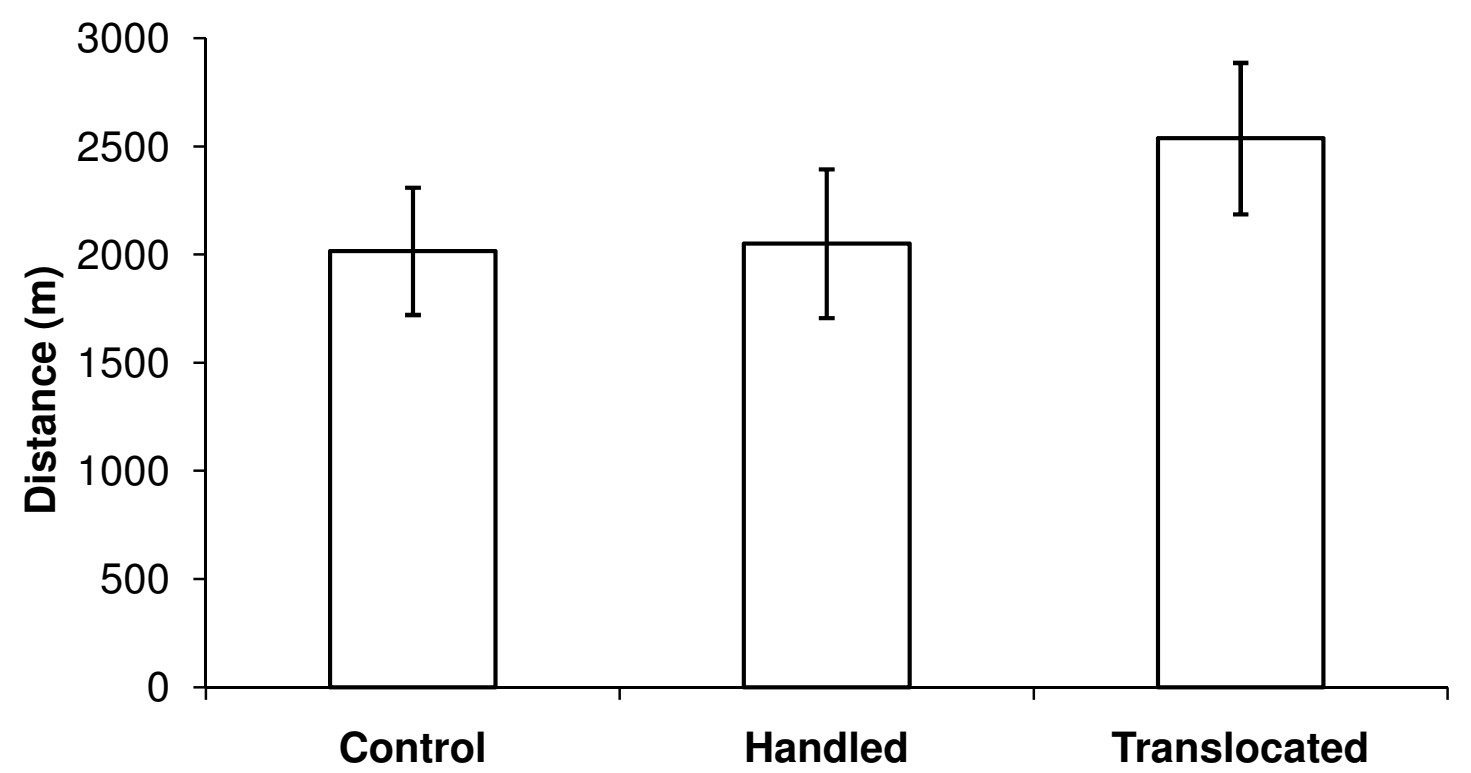

Figure 4: Total distance moved by translocated, handled, and undisturbed adult male C. $o$. oreganus from April 23 - June 19, 2010 is represented as means \pm SE This total excluded the distance of each of six 225 meter translocations carried out on individuals in the translocated group and, thus, considers only the movements made voluntarily by the snakes themselves. Treatment had no significant effect on total distance moved $\left(F_{2,19}=0.76, p=0.482\right)$.

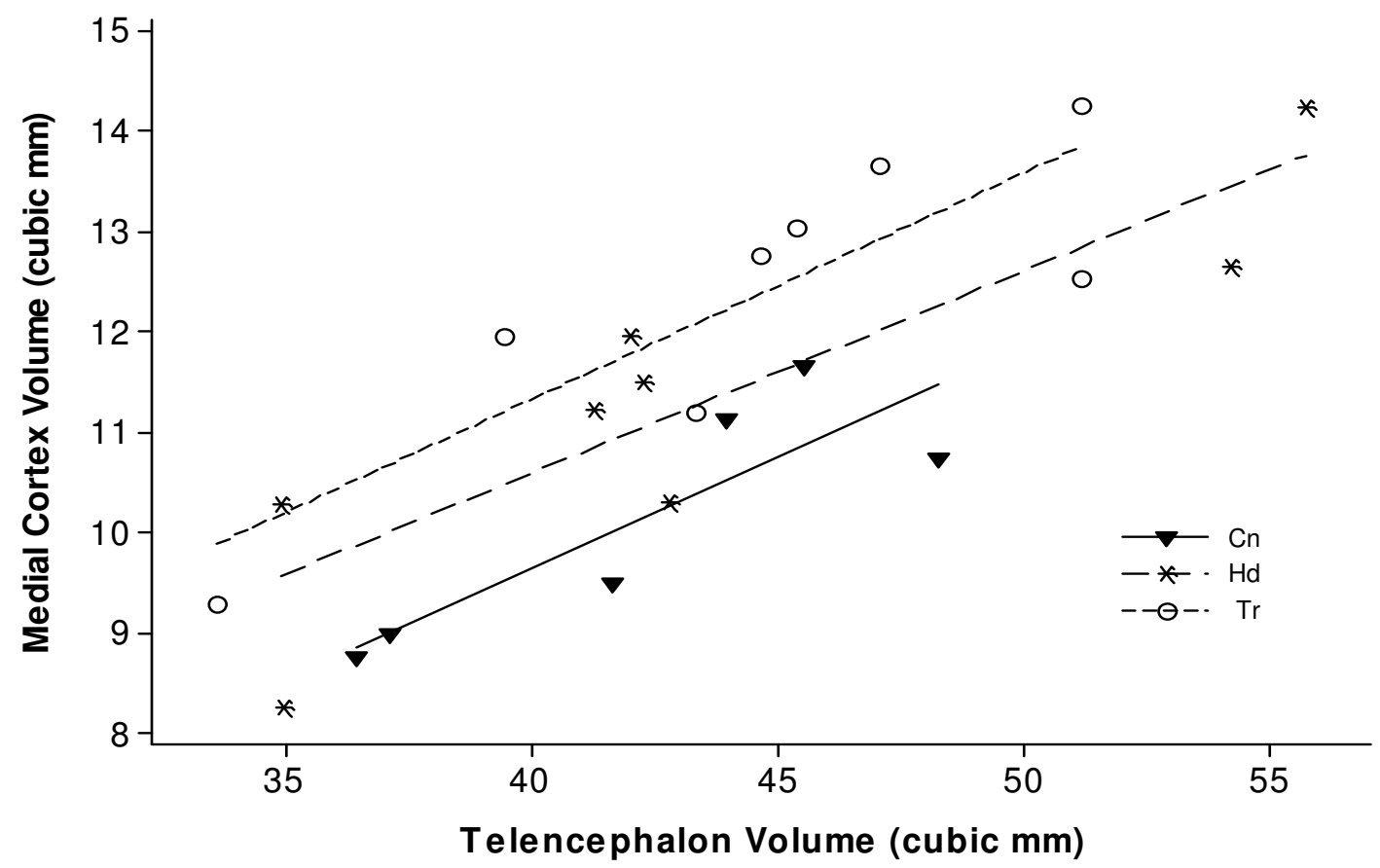

Figure 5: Medial cortex volume for each snake is plotted in relation to total telencephalon volume (minus MC volume) and separated by treatment group. Translocated snakes had significantly larger medial cortices compared to $C n$ snakes $(p=0.0027)$. Handled snakes did not differ significantly from $\operatorname{Tr}(p=0.1207)$ or Cn snakes $(p=0.1327)$. 


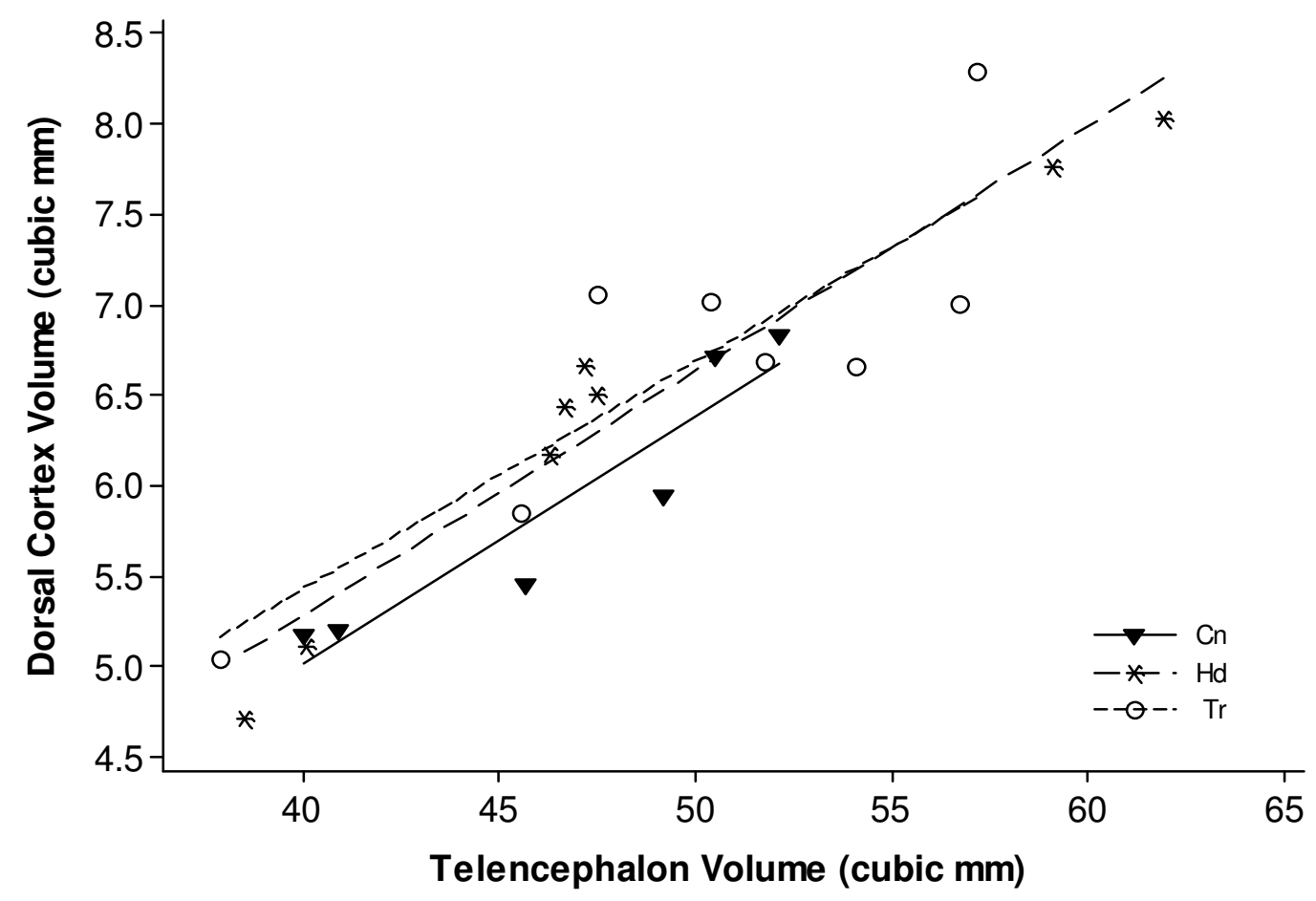

Figure 6: Dorsal cortex volume for each snake is plotted in relation to total telencephalon volume (minus DC volume) and separated by treatment group. Treatment did not significantly affect $D C$ volume $(p=0.319)$.

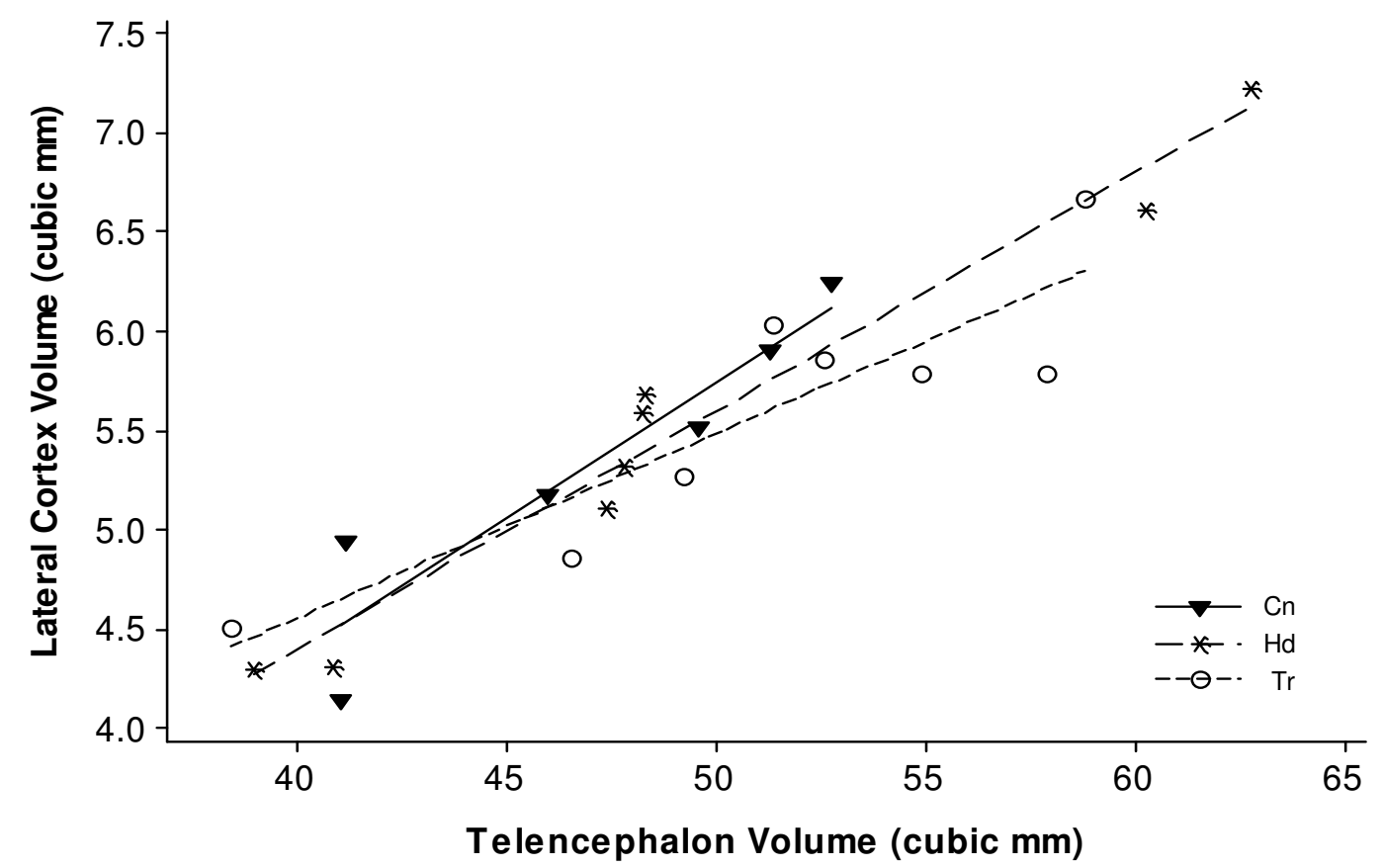

Figure 7: Lateral cortex volume for each snake is plotted in relation to total telencephalon volume (minus LC volume) and separated by treatment group. Treatment did not significantly affect $L C$ volume $(p=0.409)$. 


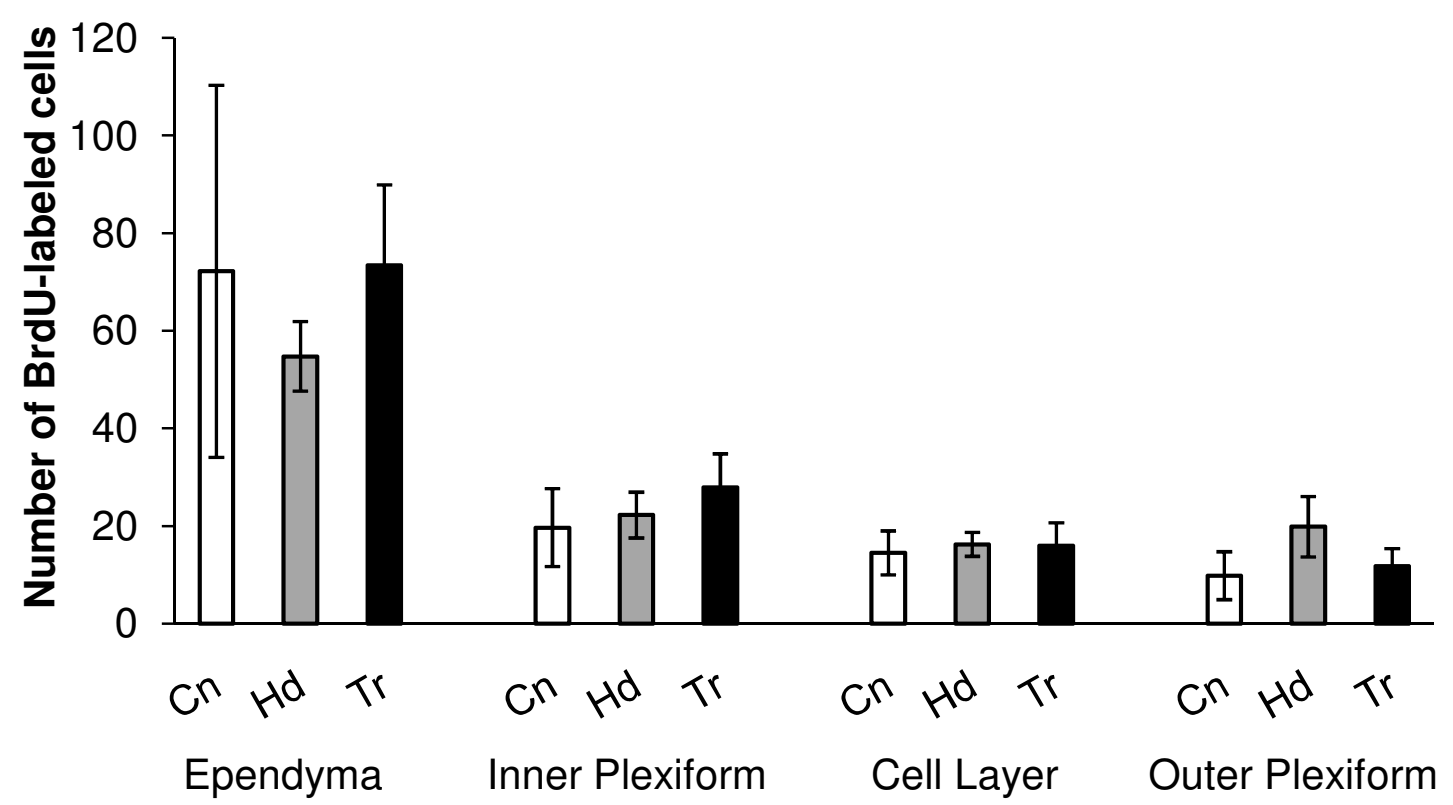

Figure 8: Number of BrdU-labeled cells in different regions of the medial cortex of $\mathrm{Cn}, \mathrm{Hd}$, and $\mathrm{Tr}$ adult male $C$. 0 . oreganus three weeks after BrdU injection. The data are means \pm SE. ANCOVA using SVL as a covariate revealed no effect of treatment on the number of BrdUlabeled cells in any region of the medial cortex (Ependymal Layer: $F=0.67, p=0.525$; Inner Plexiform Layer: $F=1.05, p=0.369$; Cell Layer: $F=0.16, p=0.85$; Outer Plexiform Layer: $F=1.77$, $\mathrm{p}=0.199$ ).

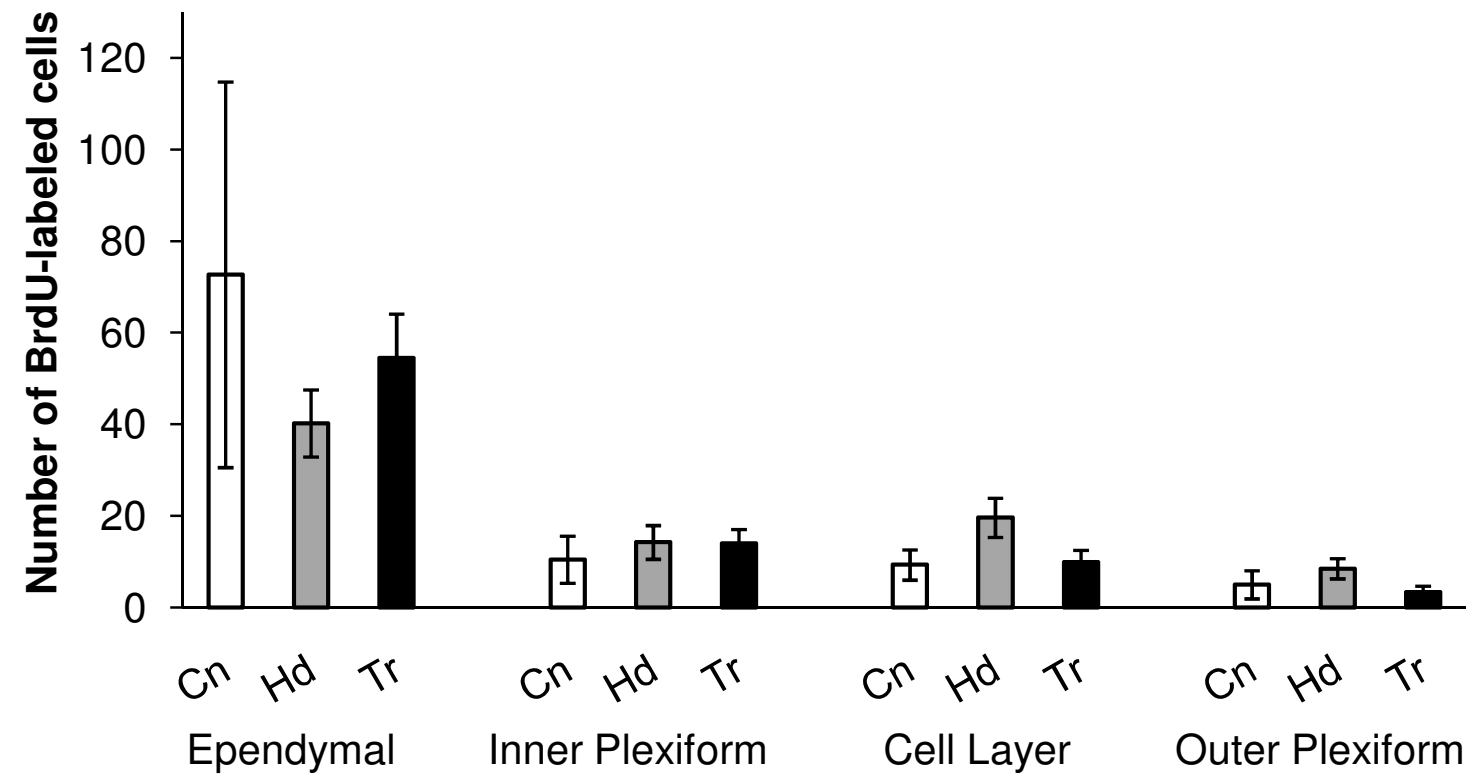

Figure 9: Number of BrDU-labeled cells in different regions of the dorsal cortex of $\mathrm{Cn}, \mathrm{Hd}$, and Tr adult male $C$. o. oreganus three weeks after BrdU injection. The data are means \pm SE. ANCOVA using SVL as a covariate revealed no effect of treatment on the number of BrdUlabeled cells in any region of the dorsal cortex (Ependymal Layer: $F=0.62, p=0.551$; Inner Plexiform Layer: $F=0.60, p=0.560$; Cell Layer: $F=3.41, p=0.056$; Outer Plexiform Layer: $F=2.51$, $\mathrm{p}=0.109$ ). 


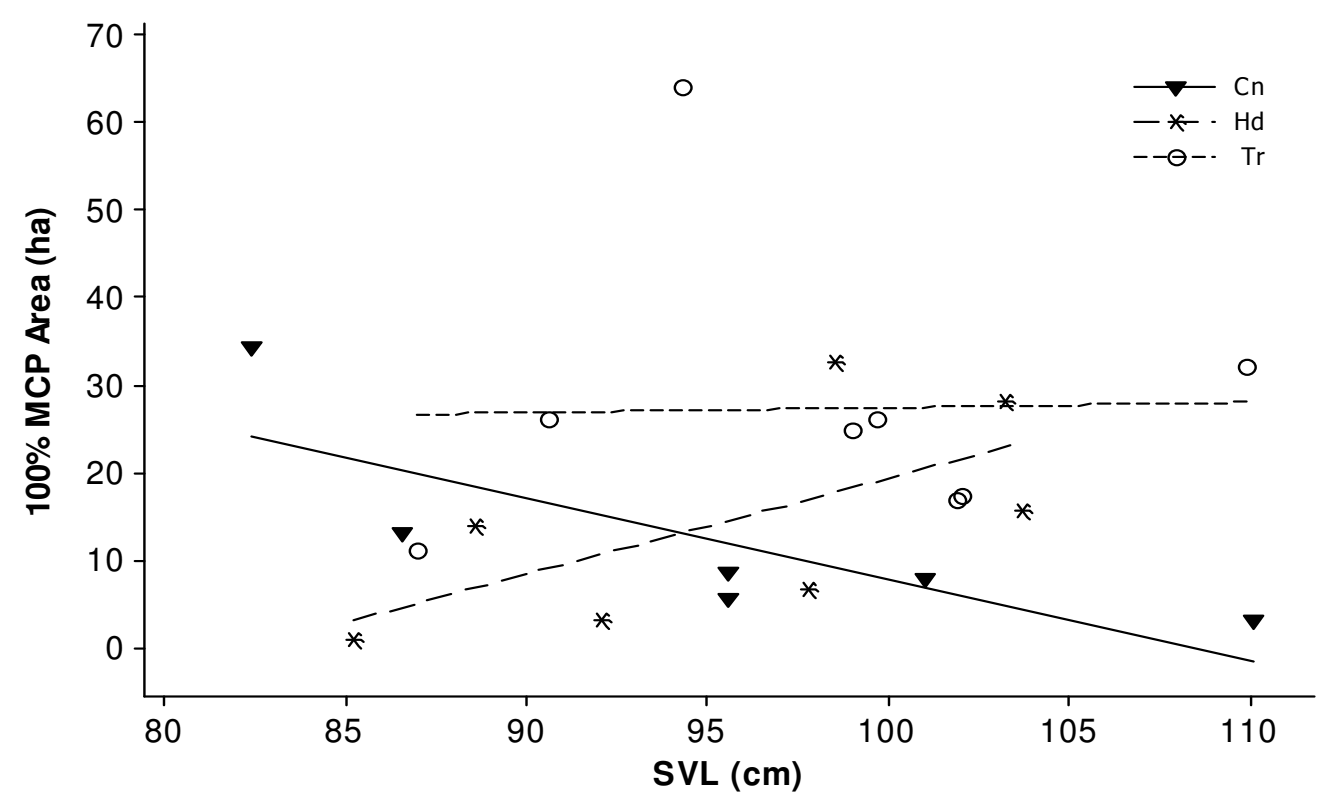

Figure 10: The area of the $100 \%$ MCP activity range of $\mathrm{Tr}, \mathrm{Hd}$, and $\mathrm{Cn}$ C. o. oreganus is plotted in relation to the SVL of each animal. Translocated snakes had significantly larger $100 \%$ MCPs than Cn snakes, but not Hd snakes, which did not differ significantly from either group. Treatment interacted significantly with SVL to affect MCP size. Length did not affect MCP size in the $\operatorname{Tr}$ snakes, while longer snakes occupied smaller activity ranges in the $\mathrm{Cn}$ group and larger areas in the Hd group.

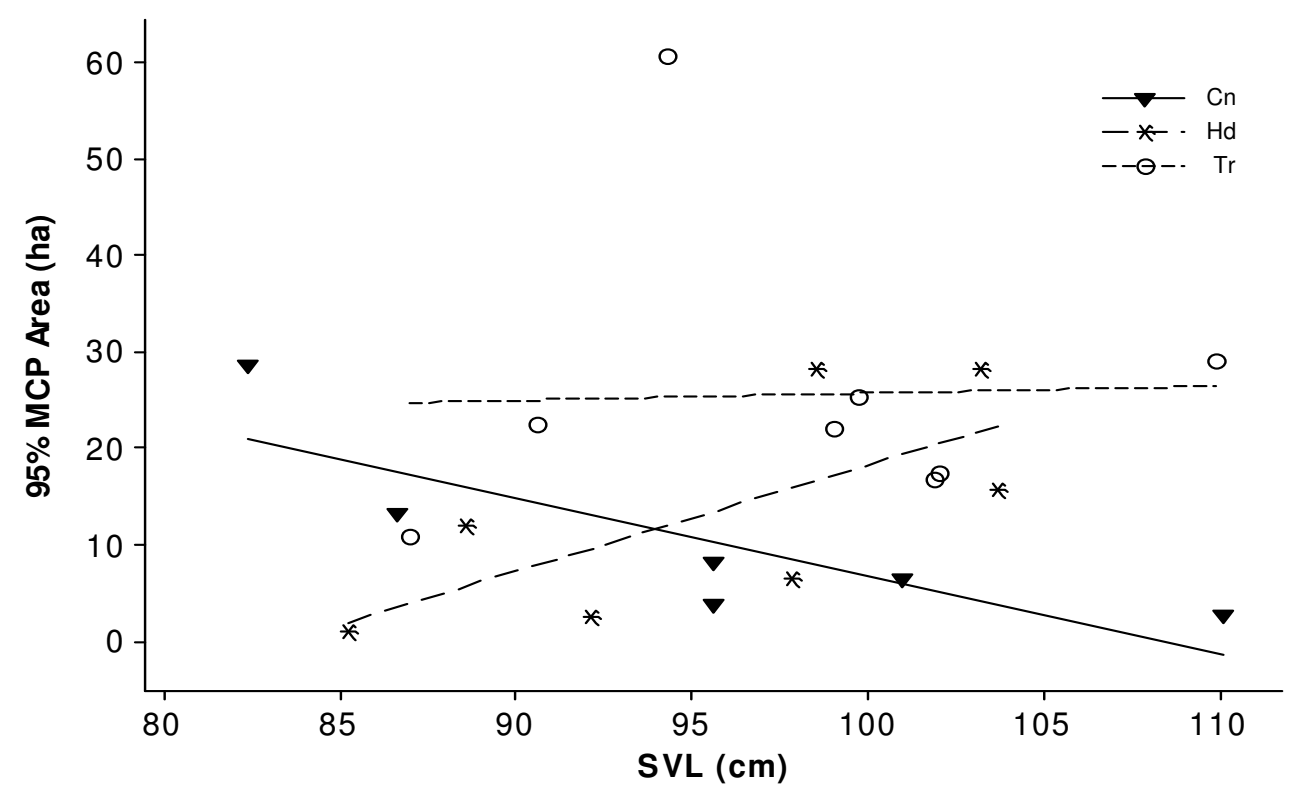

Figure 11: The area of the 95\% MCP activity range of $\mathrm{Tr}, \mathrm{Hd}$, and $\mathrm{Cn}$ C. o. oreganus is plotted in relation to the SVL of each animal. Translocated snakes had significantly larger 95\% MCPs than $\mathrm{Cn}$ and Hd snakes, which did not differ significantly from one another. Treatment interacted significantly with SVL to affect MCP size. Length did not affect MCP size in the $\mathrm{Tr}$ snakes, while longer snakes occupied smaller activity ranges in the Cn group and larger areas in the Hd group 


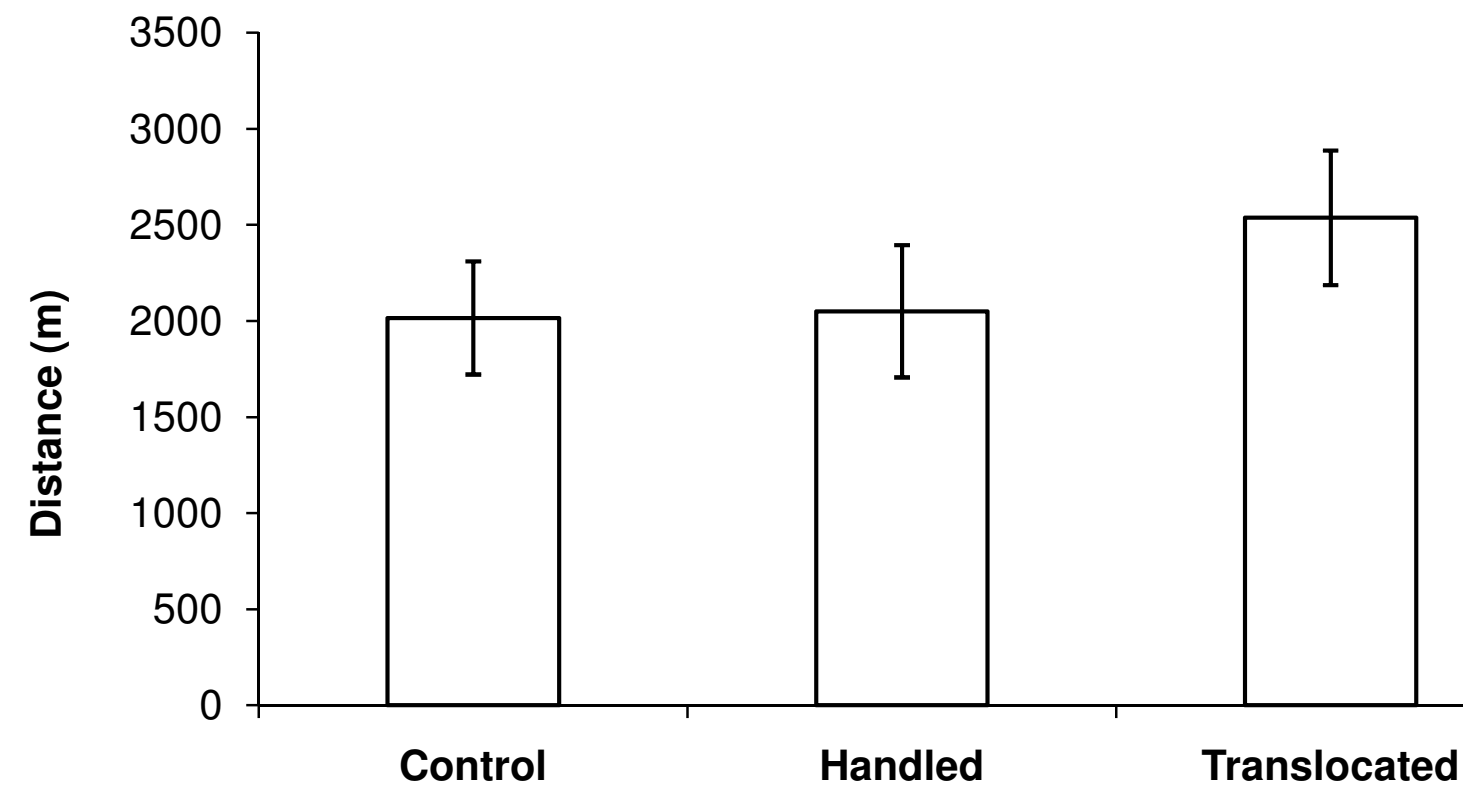

Figure 12: Total distance moved by translocated, handled, or undisturbed adult male C. 0 . oreganus from April 23 - June 19, 2010. This total excluded the distance of each of six 225 meter translocations carried out on individuals in the translocated group and, thus, considers only the movements made voluntarily by the snakes themselves. The data are means \pm SE. Total distance moved did not differ significantly among the groups.

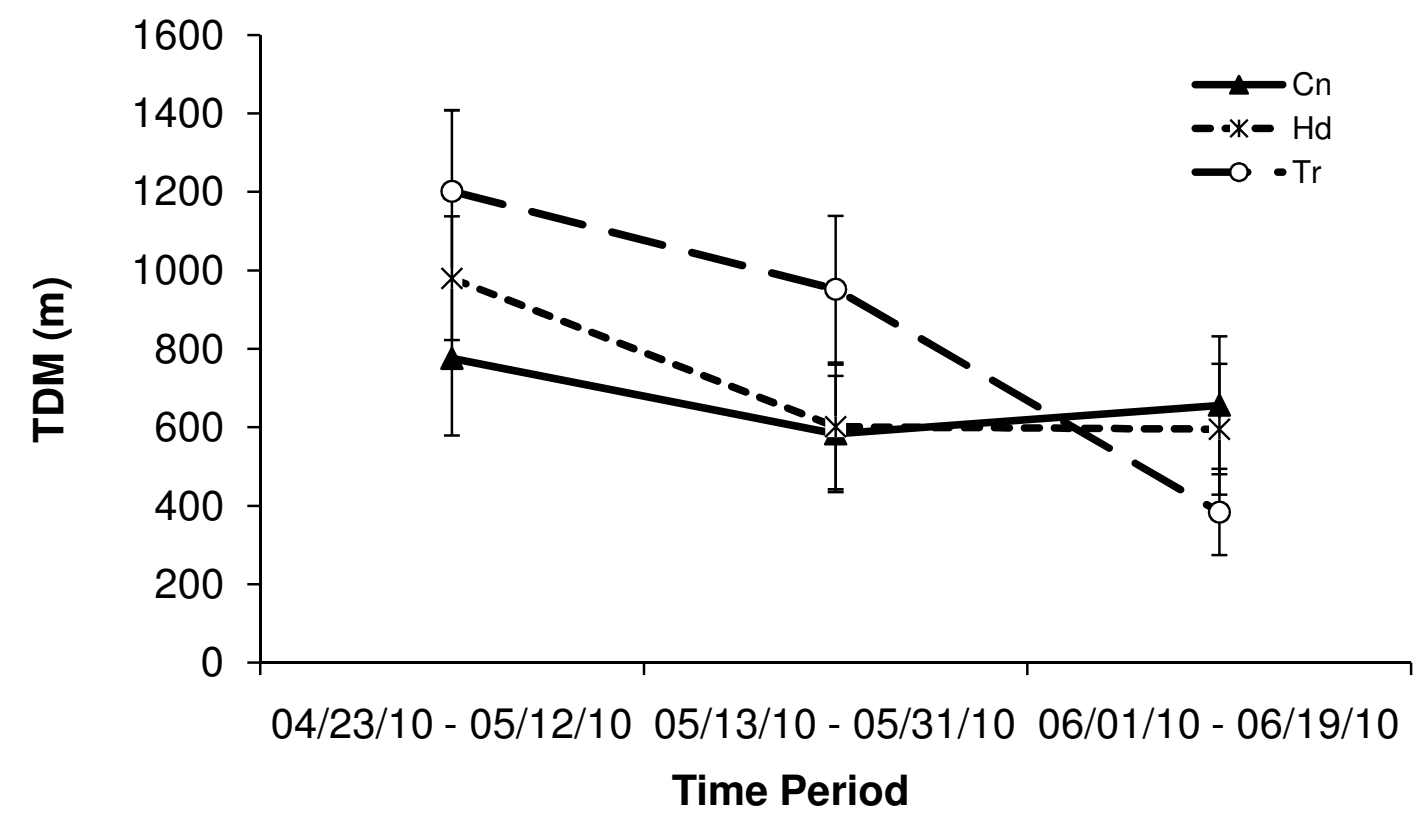

Figure 13: Total distance moved by translocated, handled, or undisturbed adult male C. 0 . oreganus separated into three 19 day intervals in order to consider potential effects of season on movement. This total excluded the distance of each of seven 225 meter translocations carried out on individuals in the translocated group and, thus, considers only the movements made voluntarily by the snakes themselves. The data are means \pm SE. Treatment did not significantly impact TDM, but time period did. 


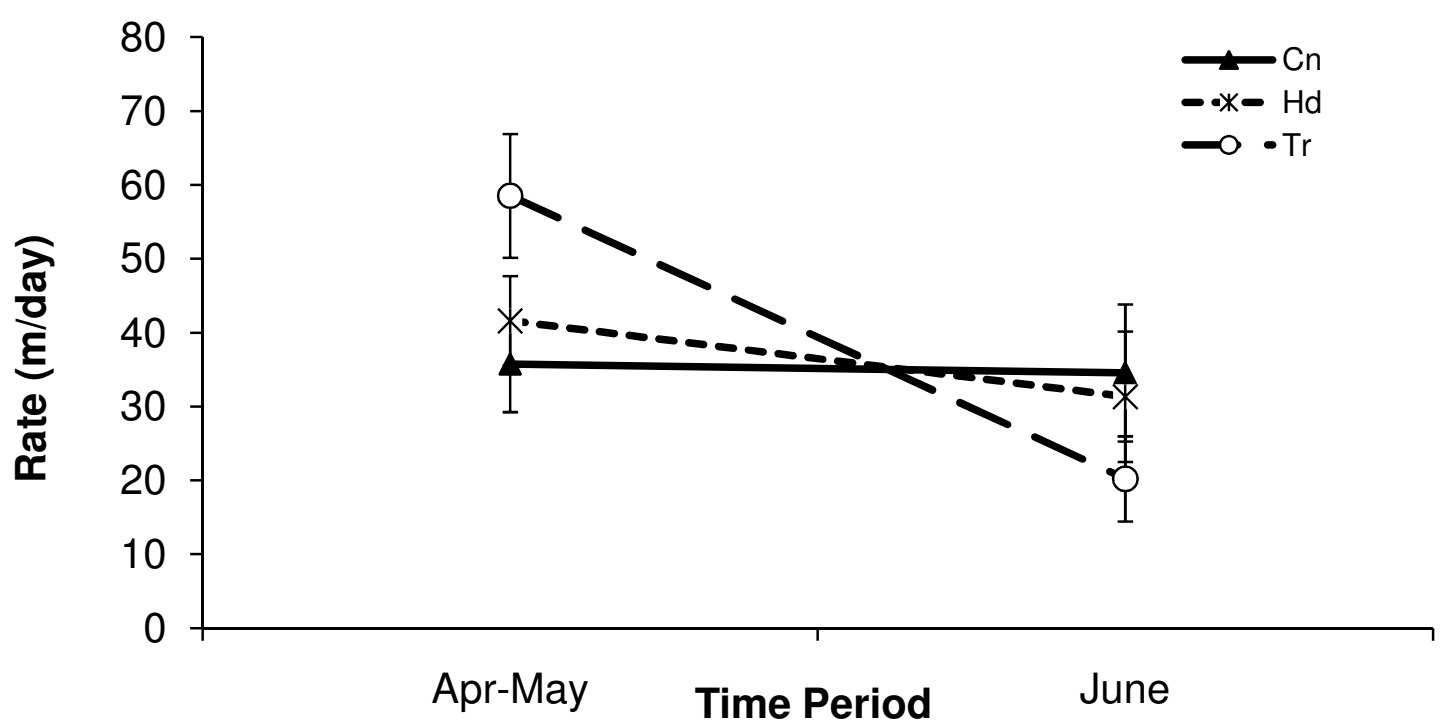

Figure 14: The movement rate of translocated, handled, or undisturbed adult male $C$. 0 . oreganus separated into two periods (end-of-April through May and June) in order to consider potential effects of season on movement. This calculation of rate excluded the distance of each of seven 225 meter translocations carried out on individuals in the translocated group and, thus, considers only the movements made voluntarily by the snakes themselves. The data are means \pm SE. Treatment did not significantly impact rate, but time period affected rate via a main effect and a significant interaction with treatment.

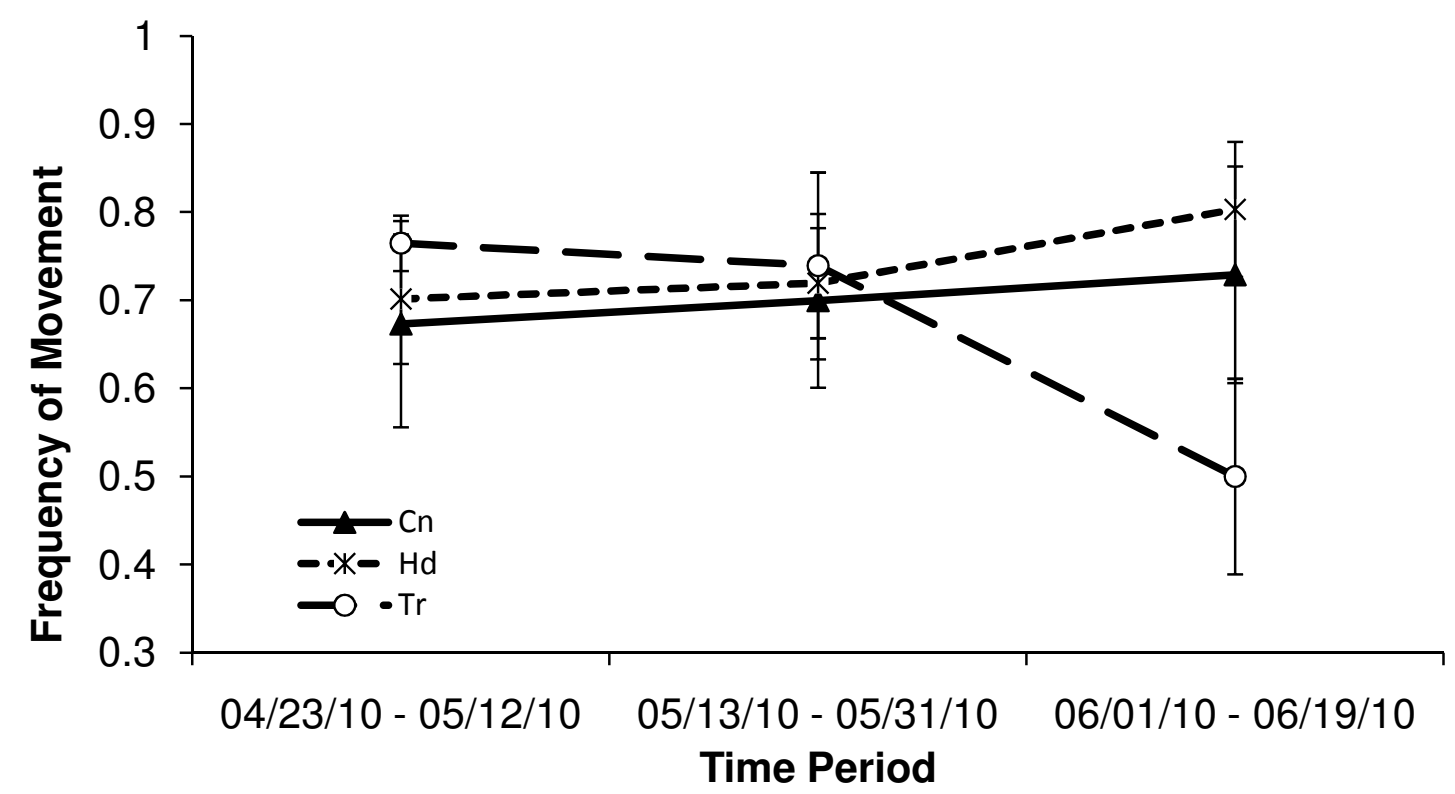

Figure 15: The frequency of movement of translocated, handled, or undisturbed adult male $C$. o. oreganus separated into 19-day time periods in order to consider the potential effects of season on movement. This calculation excluded the distance of each of seven 225 meter translocations carried out on individuals in the translocated group and, thus, considers only the movements made voluntarily by the snakes themselves. The data are means \pm SE. Treatment and time period were not significant predictors of movement frequency, nor did these two variables interact significantly to impact movement frequency. 


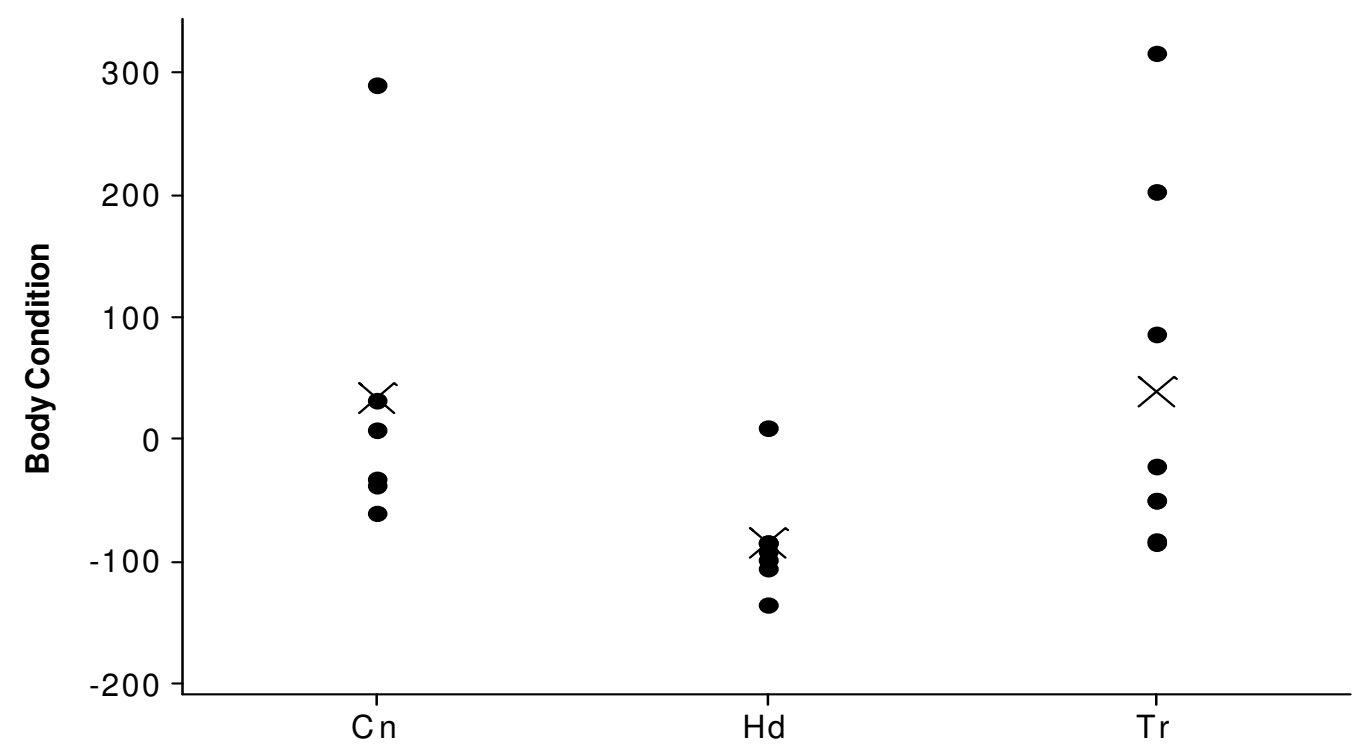

Figure 16: The body condition (BC) following application of translocation, handling, or undisturbed control treatments to 21 adult male $C$. o. oreganus represented as individual values. Body condition was estimated as the residual of a regression of Mass versus SVL for each snake using 68 other males from the same population not involved in the current study. Treatment did not significantly affect BC. The mean BC for each treatment is displayed as an "X".

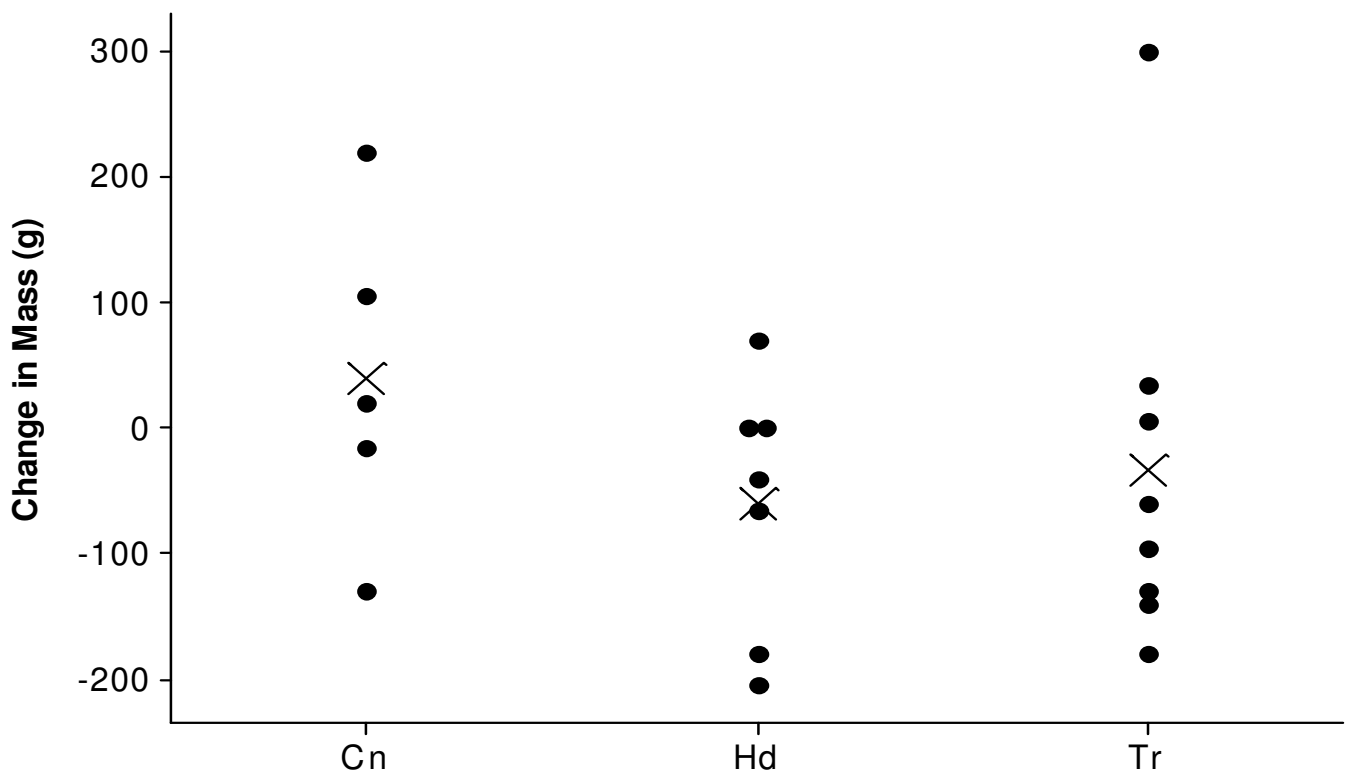

Figure 17: The change in mass from before to after the application of translocation, handling, or undisturbed control treatments to 21 adult male $C$. $o$. oreganus represented as individual values. A positive value indicates that the animal gained mass during the course of the study. Treatment did not significantly affect change in mass. The mean change in mass for each treatment is displayed as an " $\mathrm{X}$ ". 


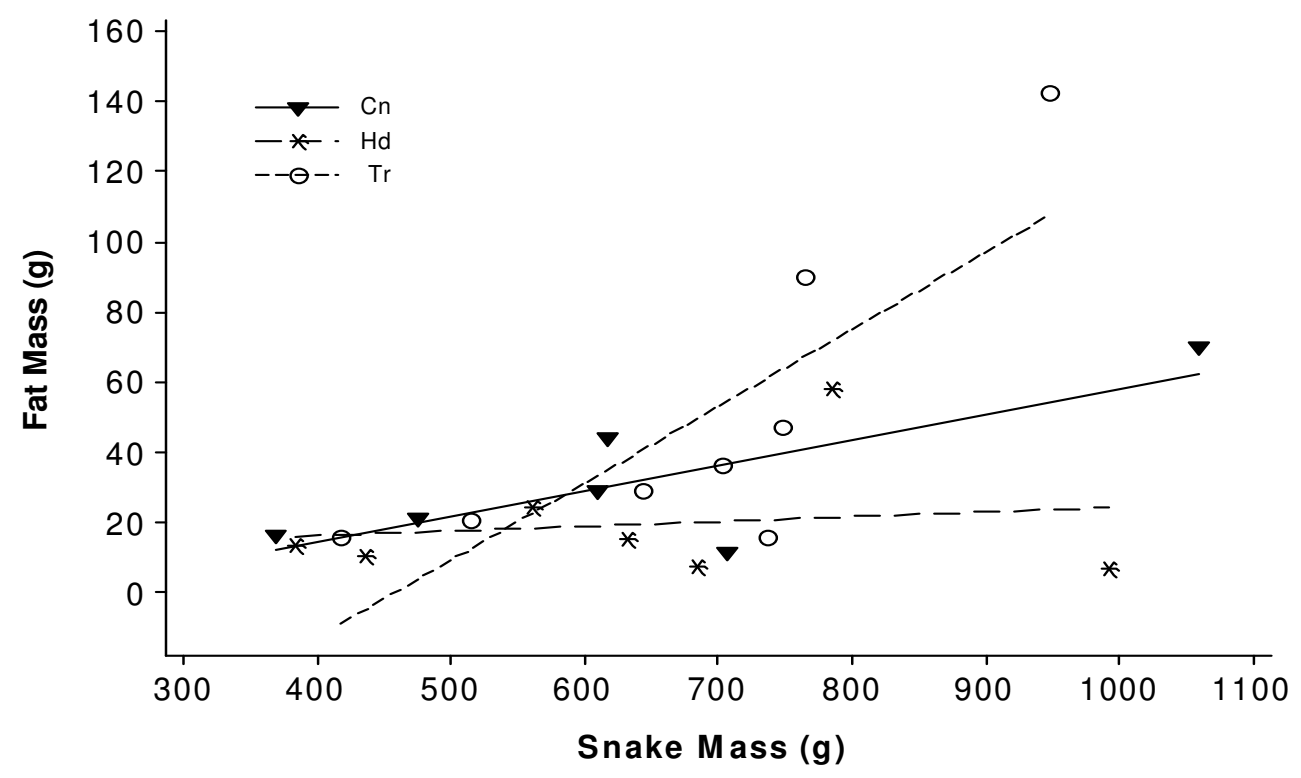

Figure 18: The mass of fat pads following application of translocation, handling, or undisturbed control treatments to 21 adult male $C$. o. oreganus is plotted against the mass of the snakes' bodies minus fat and gut contents to control for the size of the snake. Treatment interacted significantly with snake mass to affect fat mass such that at larger sizes $\operatorname{Tr}$ snakes had more fat than Hd snakes.

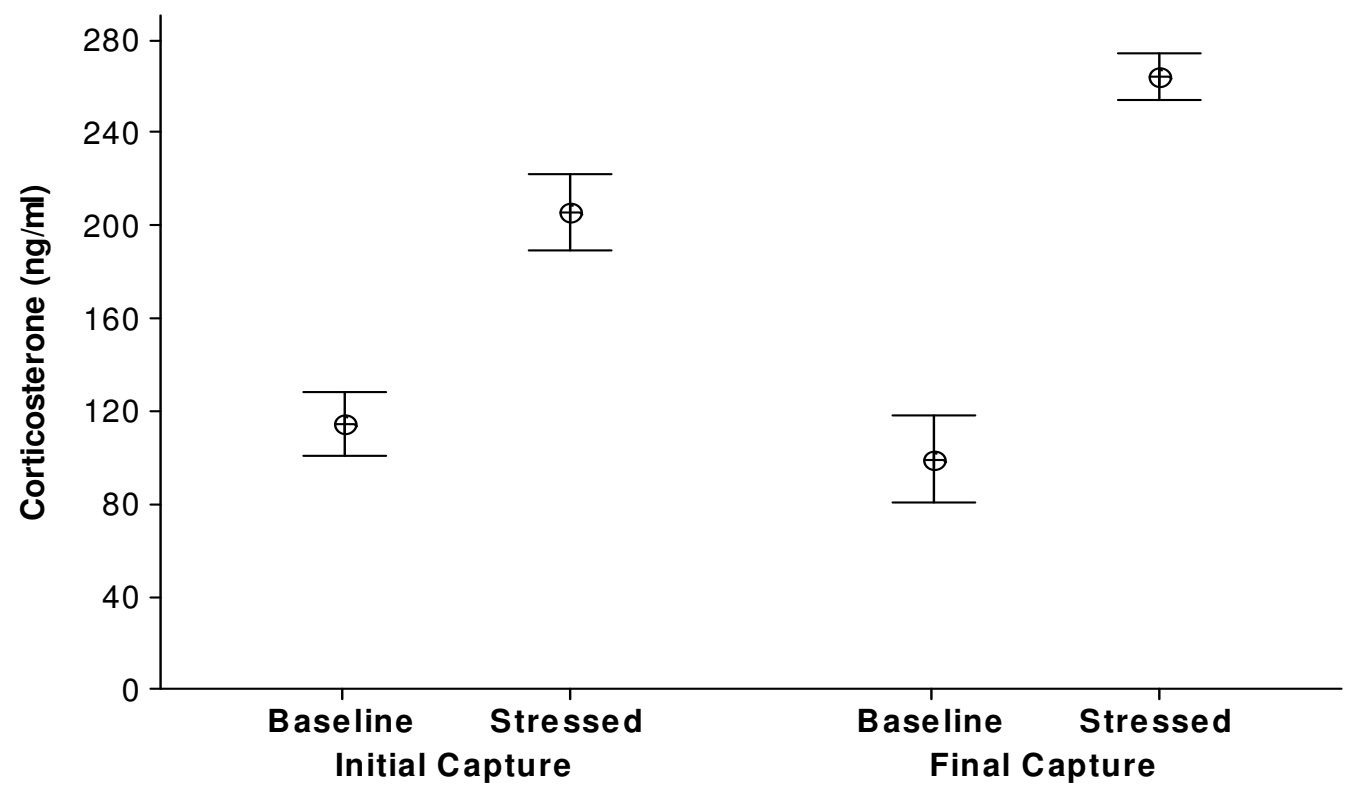

Figure 19: Corticosterone concentrations from the blood of male C. o. oreganus are shown irrespective of treatment (mean $\pm \mathrm{SE}$ ). Blood was obtained upon capture (baseline) and then after one hour in a white plastic bucket (stressed). Snakes exhibited a significant stress response during both initial and final capture.Baseline CORT did not differ significantly between captures, while stressed CORT was significantly higher during the final capture. 


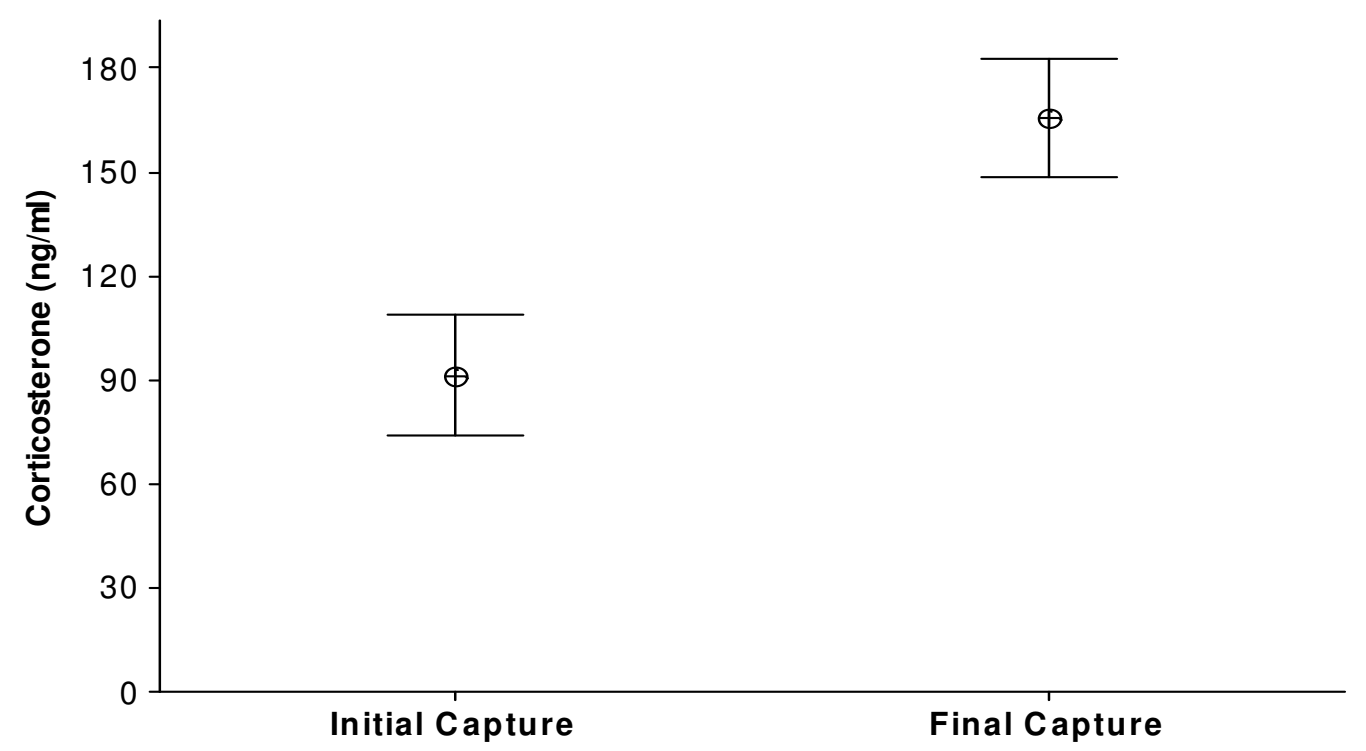

Figure 20: The acute stress response of male C. o. oreganus during initial capture and final capture is shown irrespective of treatment as mean changes in CORT \pm SE. Blood was obtained upon capture (baseline) and then after one hour in a white plastic bucket (stressed) and the CORT response to stress was determined as stressed concentration minus baseline concentration. The magnitude of the change in CORT concentration was significantly greater during the final capture.

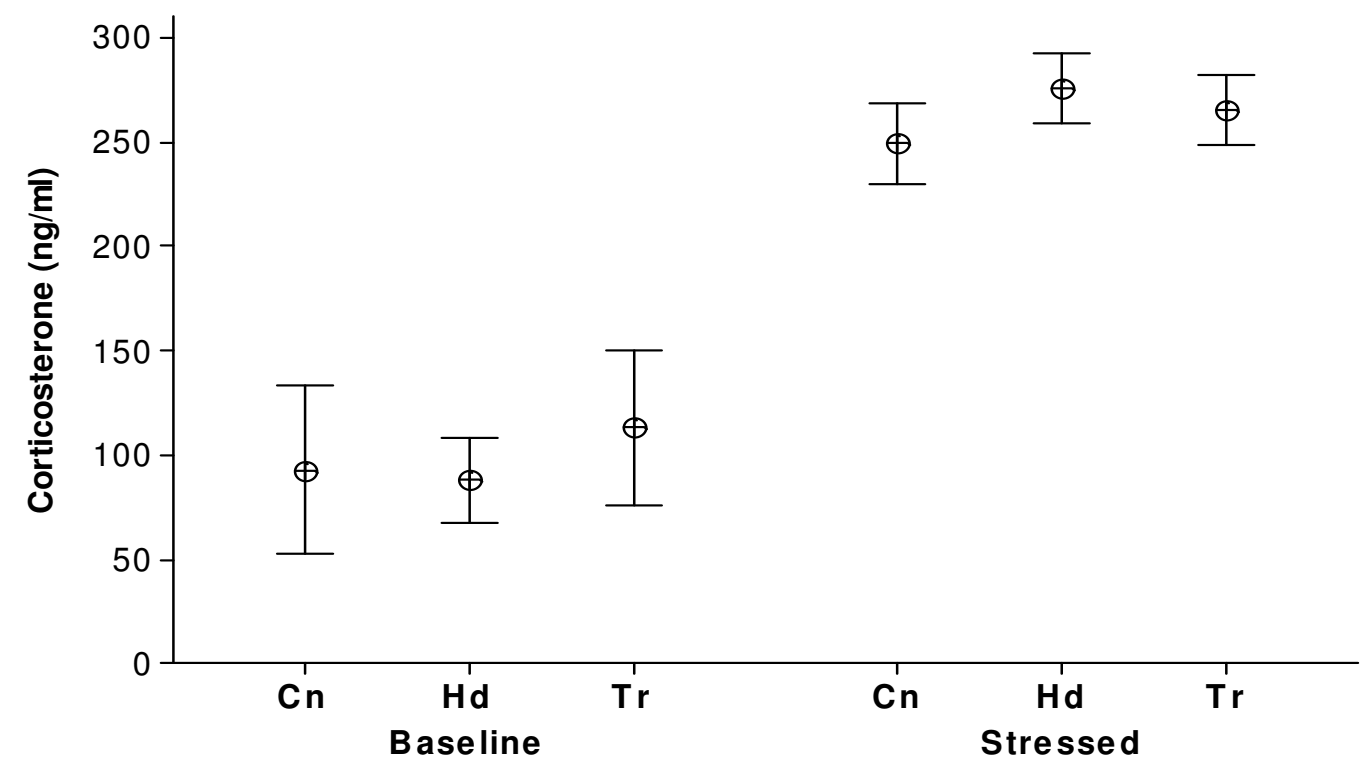

Figure 21: The baseline and stressed CORT concentrations in the blood of male C. 0 . oreganus during final capture is shown as means \pm SE. Blood was obtained upon capture (baseline) and then after one hour in a white plastic bucket (stressed) and the CORT response to stress was determined as stressed concentration minus baseline concentration. Baseline and stressed CORT and the magnitude of the CORT response to acute stress were not affected bv treatment. 


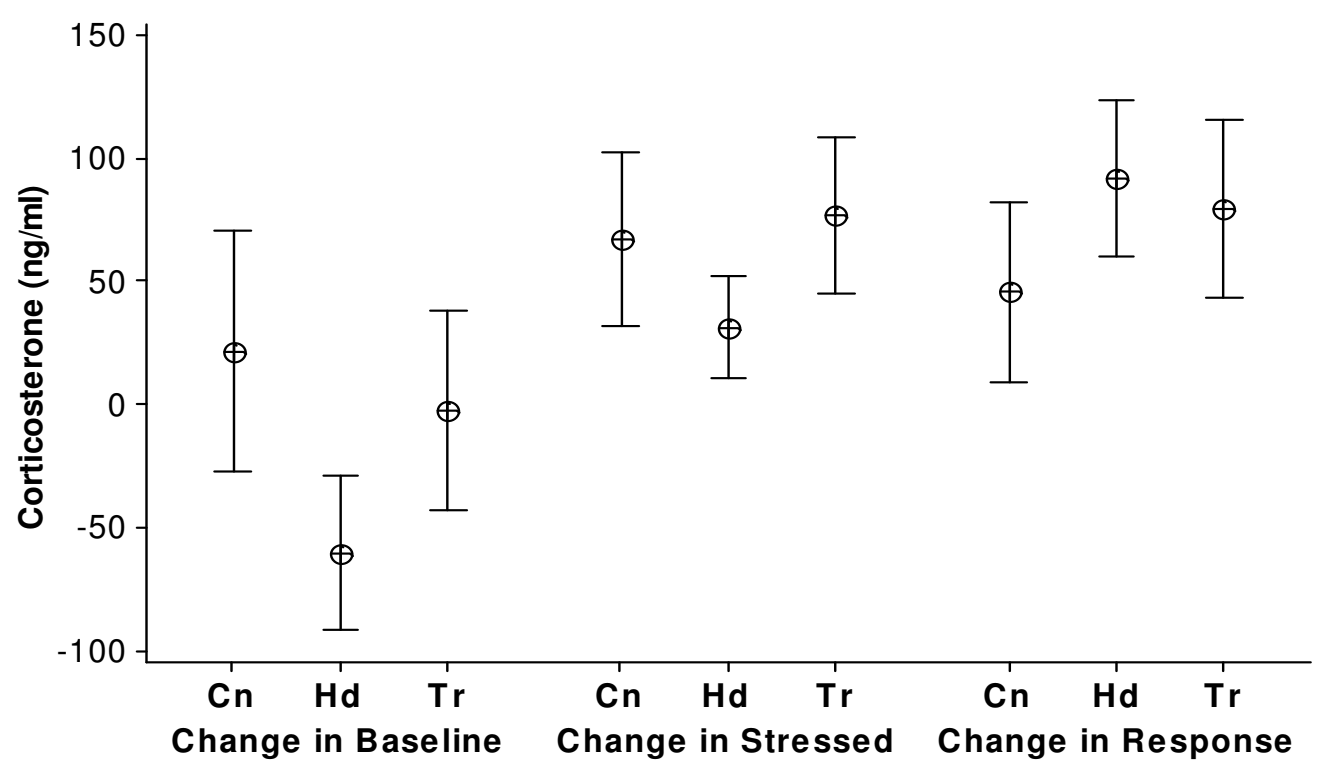

Figure 22: The change in baseline and stressed CORT concentrations in the blood along with the change in the magnitude of the acute stress response of male $C$. $o$. oreganus from initial to final capture is shown as means \pm SE. Blood was obtained upon capture (baseline) and then after one hour in a white plastic bucket (stressed) and the CORT response to stress was determined as stressed concentration minus baseline concentration. Positive values indicate that an increase in that variable occurred from initial capture to final capture. None of these variables were significantly impacted by treatment.

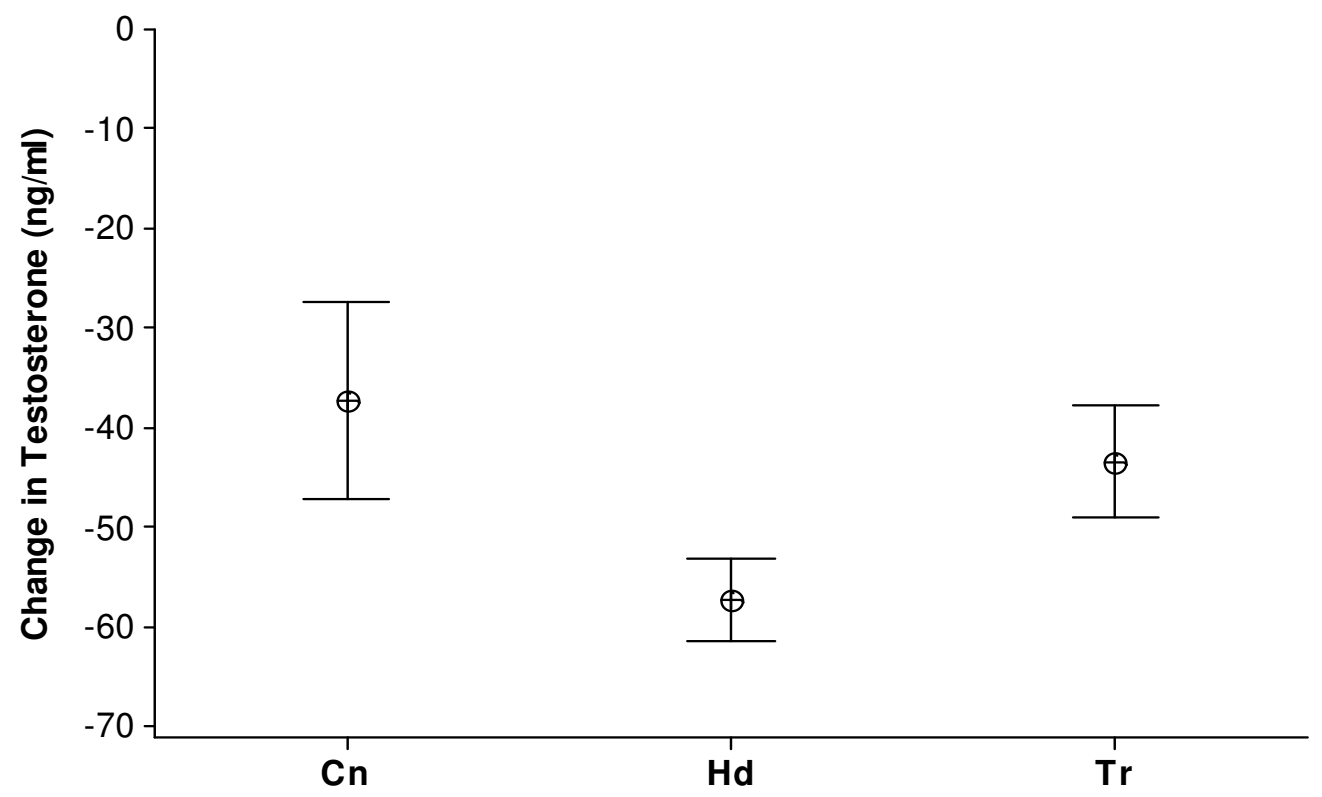

Figure 23: The decrease in baseline T concentrations in the blood of 21 male $C$. $o$. oreganus from initial to final capture (means \pm SE). This decrease was not significantly impacted by treatment. 


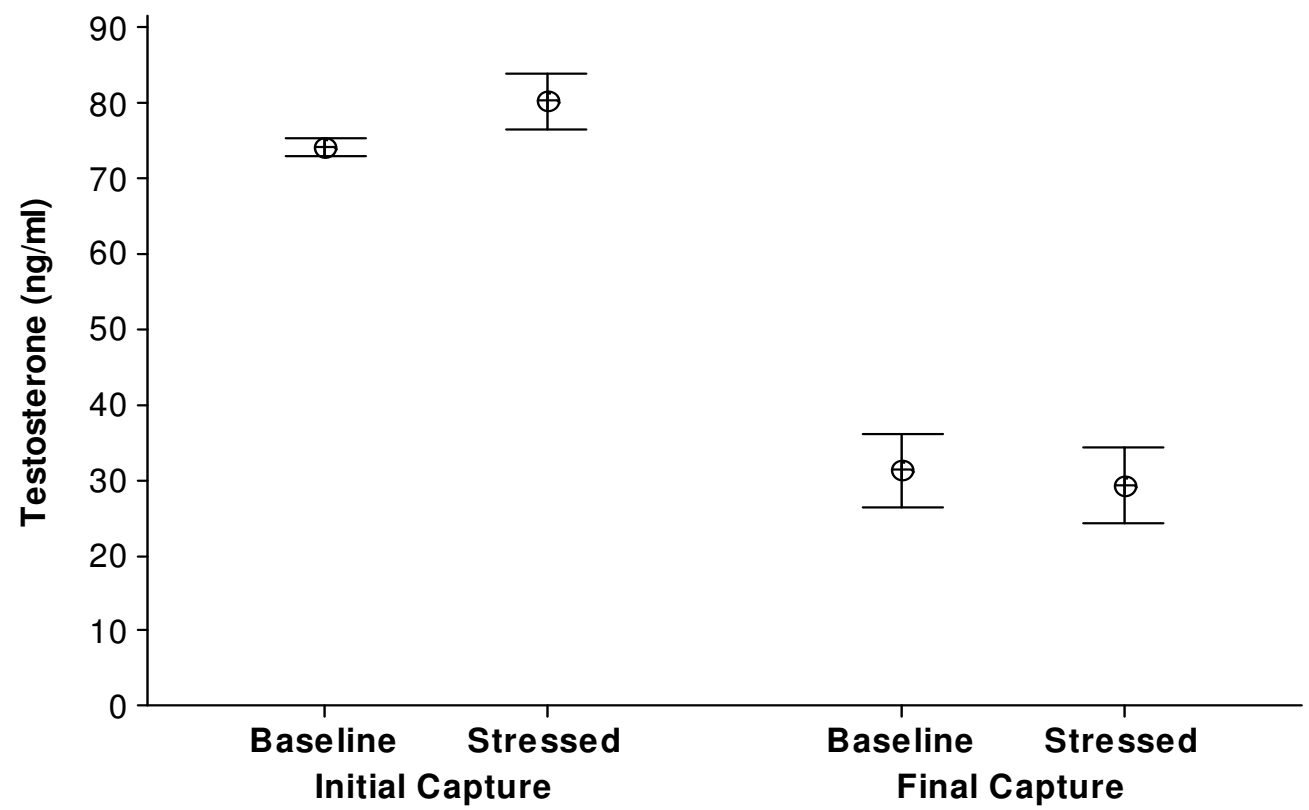

Figure 24: The baseline and stressed T concentrations in the blood male C. 0 . oreganus at initial and final capture are shown as means \pm SE. Blood was obtained upon capture (baseline) and then after one hour in a white plastic bucket (stressed). Baseline and stressed concentrations were not significantly different at initial capture, while stressed $T$ was significantly lower during the stressed bleed compared to the baseline bleed.

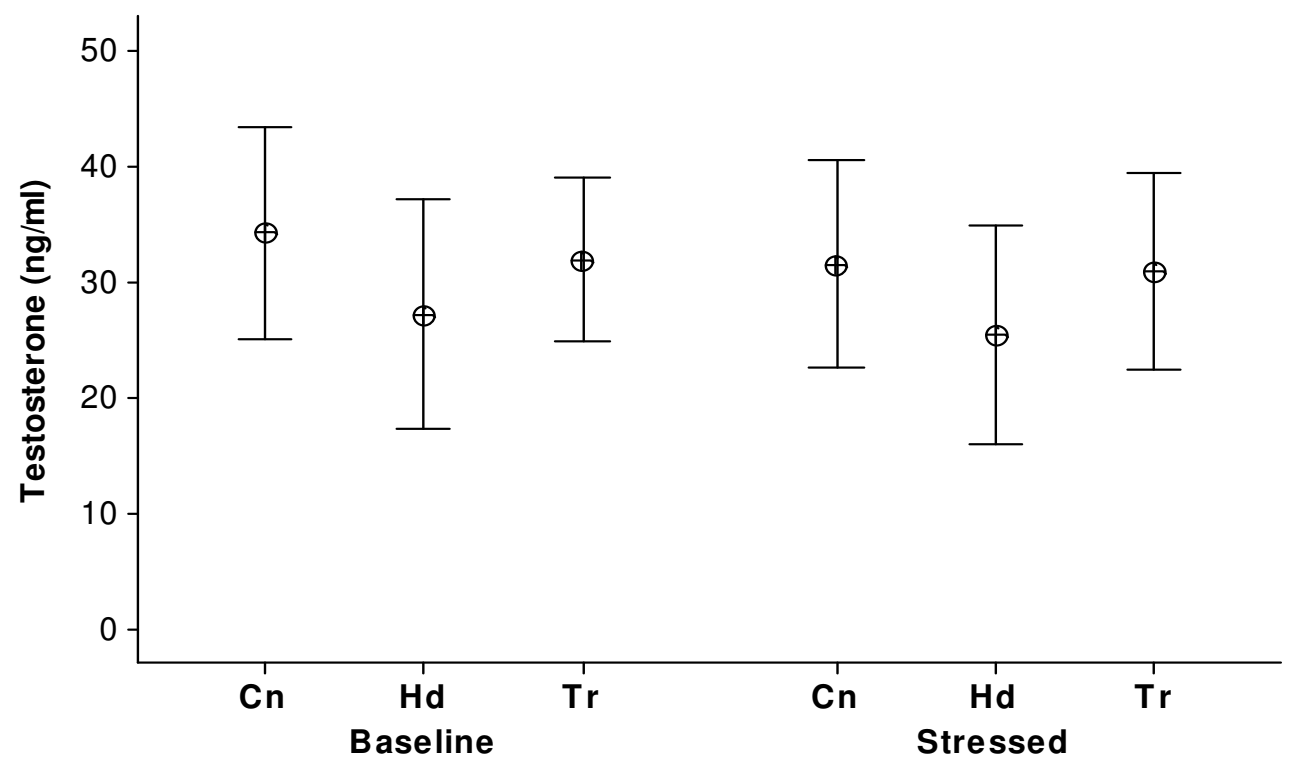

Figure 25: The baseline and stressed T concentrations in the blood male $C$. 0 . oreganus at final capture are separated by $\mathrm{Cn}, \mathrm{Hd}$, and $\mathrm{Tr}$ treatments as means $\pm \mathrm{SE}$. Blood was obtained upon capture (baseline) and then after one hour in a white plastic bucket (stressed). Treatment did not significantly affect baseline T concentration, stressed T concentration, or the magnitude of the change experienced during the acute stressor (stressed T minus baseline T). 


\section{Literature Cited}

Almli, L.M. and Wilczynski, W. 2009. Sex-specific modulation of cell proliferation by socially relevant stimuli in the adult green treefrog (Hyla cinerea). Brain, Behavior, and Evolution 74: 143-154.

Amrein, I., Slomianka, L., Poletaeva, I.I., Bologova, N.V., and Lipp, H. 2004a. Marked species and age-dependent differences in cell proliferation and neurogenesis in the hippocampus of wild-living rodents. Hippocampus 14: 1000-1010.

Amrein, I., Slomianka, L., and Lipp, H. 2004b. Granule cell number, cell death and cell proliferation in the dentate gyrus of wild-living rodents. European Journal of Neuroscience 20: 3342-3350.

Bailey, F.C., Cobb, V.A., Rainwater, T.R., Worrall, T., and Klukowski, M. 2009. Adrenocortical effects of human encounters on free-ranging cottonmouths (Agkistrodon piscivorus). Journal of Herpetology 43: 260-266.

Beaupre, S.J. 1993. An ecological study of oxygen consumption in the mottled rock rattlesnake, Crotalus lepidus lepidus, and black-tailed rattlesnake, Crotalus molossus molossus, from two populations. Physiological Zoology 66: 437-454.

Biegler, R. McGregor, A., Krebs, J.R., and Healy, S.D. 2001. A larger hippocampus is associated with longer-lasting spatial memory. Proceedings of the National Academy of Sciences of the United States of America 98: 6941-6944.

Black, J.E., Isaacs, K.R., Anderson, B.J., Alacantara, A.A., and Greenough, W.T. 1990. Learning causes synaptogenesis, whereas motor activity causes angiogenesis, in cerebellar cortex of adult rats. Proceedings of the National Academy of Sciences of the United States of America 87: 5568-5572.

Brown, J.R., Bishop, C.A., and Brooks, R.J. 2009. Effectiveness of short-distance translocation and its effects on Western Rattlesnakes. Journal of Wildlife Management 73: 419-425.

Brown, T.K., Lemm, J.M., Montagne, J., Tracey, J.A., and Alberts, A.C. 2008. Spatial ecology, habitat use, and survivorship of resident and translocated red diamond rattlesnakes (Crotalus ruber). In Hayes, W.K., Beaman, K.R., Cardwell, M.D., and Bush, S.P. (Eds.).The Biology of the Rattlesnakes. Loma Linda University Press, Loma Linda, California, pp. 377-394.

Bruce, L.L. and Butler, A.B. 1984. Telencephalic connections in lizards. I. Projections to the cortex. The Journal of Comparative Neurology 229: 585-601. 
Burger, J. 2001. The behavioral response of basking Northern water (Nerodia sipedon) and Eastern garter (Thamnophis sirtalis) snakes to pedestrians in a New Jersey park. Urban Ecosystems 5: 119-129.

Butler, A.B. and Hodos, W. 1996. Comparative vertebrate neuroanatomy: Evolution and Adaptation. Wiley-Liss, New York.

Cartledge, V.A and Jones, S. 2007. Does adrenal responsiveness vary with sex and reproductive status in Egernia whitii, a viviparous skink? General and Comparative Endocrinology 150: 132-139.

Cease, A.J., Lutterschmidt, D.I., and Mason, R.T. 2007. Corticosterone and the transition from courtship behavior to dispersal in male red-sided garter snakes (Thamnophis sirtalis parietalis). General and Comparative Endocrinology 150: 124-131.

Clayton, N.S. 1995. The neuroethological development of food-storing memory: a case of use it or lose it. Behavioural Brain Research 70: 95-102.

Clayton, N.S. an d Krebs, J.R. 1994. Hippocampal growth and attrition are affected by experience. Proceedings of the National Academy of Sciences of the United States of America 91: 7410-7414.

Clayton, N.S., Reboreda, J.C., and Kacelnik, A. 1997. Seasonal changes in hippocampus volume in parasitic cowbirds. Behavioural Processes 41: 237-243.

Cote, J., Clobert, J., Poloni, L.M., Haussy, C., and Meylan, S. 2010. Food deprivation modifies corticosterone-dependent behavioral shifts in the common lizard. General and Comparative Endocrinology 166: 142-151.

Cree, A., Amey, A.P., and Whittier, J.M. 2000. Lack of consistent hormonal response to capture during the breeding season of the bearded dragon, Pogona barbata. Comparative Biochemistry and Physiology 126A: 275-285.

Cree, A., Tyrrell, C.L., Preest, M.R., Thorburn, D., and Guillette, L.J. 2003. Protecting embryos from stress: corticosterone effects and the corticosterone response to capture and confinement during pregnancy in a live-bearing lizard (Hoplodactylus maculates). General and Comparative Endocrinology 134: 316-329.

Dauphin-Villemant, C., Leboulenger, F., Xavier, and Vaudry, H. 1990. Adrenal activity in the female lizard Lacerta vivipara Jacquin associated with breeding activities. General and Comparative Endocrinology 78: 399-413.

Day, L.B., Crews, D., and Wilczynski, W. 1999a. Relative medial and dorsal cortex volume in relation to foraging ecology in congeneric lizards. Brain, Behavior and Evolution 54: 314-322. 
Day, L.B., Crews, D., and Wilczynski, W. 1999b. Spatial and reversal learning in congeneric lizards with different foraging strategies. Animal Behaviour 57: 393407.

Day, L.B., Crews, D., and Wilczynski, W. 2001. Effects of medial and dorsal cortex lesions on spatial memory in lizards. Behavioural Brain Research 118: 27-42.

Delgado-González, F.J., Alonso-Fuentes, A., Delgado-Fumero, A., García-Verdugo, J.M., González-Granero, S., Trujillo-Trujillo, C.M., Damas-Hernández, M.C. 2008. Seasonal differences in ventricular proliferation of adult Gallotia galloti lizards. Brain Research 1191: 39-46.

DeNardo, D.F. and Licht, P. 1993. Effects of corticosterone on social behavior of male lizards. Hormones and Behavior 27: 184-199.

Diller, L.V. and Wallace, R.L. 2002. Growth, reproduction, and survival in a population of Crotalus viridis oreganus in north central Idaho. Herpetological Monographs 16: 26-45.

Dodd, C.K. and Seigel, R.A. 1991. Relocation, repatriation, and translocation of amphibians and reptiles: are they conservation strategies that work? Herpetologica 47: 336-350.

Dunlap, K.D. and Wingfield, J.C. 1995. External and internal influences on indices of physiological stress I. Seasonal and population variation in adrenocortical secretion of free-living lizards, Sceloporus occidentalis. The Journal of Experimental Biology 271: 36-46.

Fisher, J., and Lindenmayer, D.B. 2000. An assessment of the published results of animal relocations. Biological Conservation 96: 1-11.

Font, E., Desfilis, E., Pérez-Cañellas, M.M., and García-Verdugo, J.M. 2001. Neurogenesis and neuronal regeneration in the adult reptilian brain.

French, S.S., DeNardo, D.F., Greives, T.J., Strand, C.R., and Demas, G.E. 2010. Human disturbance alters endocrine and immune responses in the Galapagos marine iguana (Amblyrhynchus cristatus).

French, S.S., Fokidis, H.B., and Moore, M.C. 2008. Variation in stress and innate immunity in the tree lizard (Urosaurus ornatus) across and urban-rural gradient. Journal of Comparative Physiology 178: 997-1005.

French, S.S., McLemore, R., Vernon, B., Johnston, G.I.H., and Moore, M.C. 2007. Corticosterone modulation of reproductive and immune systems trade-offs in female tree lizards: long-term corticosterone manipulations via injectable gelling material. The Journal of Experimental Biology 210: 2859-2865. 
Fuenzalida, C.E., Ulrich, G., and Ichikawa, B.T. 1975. Response decrement to repeated shadow stimuli in garter snake, Thamnophis radix. Bulletin of the Psychonomic Society 5: 221-222.

Galea, L.A.M. and McEwen, B.S. 1999. Sex and seasonal differences in the rate of cell proliferation in the dentate gyrus of adult wild meadow voles. Neuroscience 89: 955-964.

Glaudas, X. 2004. Do cottonmouths (Agkistrodon piscivorus) habituate to human confrontation? Southeastern Naturalist 3: 129-138.

Gould, E., McEwen, B.S., Tanapat, P., Galea, L.A.M., and Fuchs, E. 1997. Neurogenesis in the dentate gyrus of the adult tree shrew is regulated by psychosocial stress and NMDA receptor activation. The Journal of Neuroscience.

Gould, E., Beylin, A., Tanapat, P., Reeves, A., and Shors, T. 1999. Learning enhances adult neurogenesis in the hippocampal formation. Nature Neuroscience 2: 260265.

Gould, E., Woolley, C.S., Cameron, H.A., Daniels, D.C., and McEwen, B.S. 1991. Adrenal steroids regulate postnatal development of the rat dentate gyrus: II. Effects of glucocorticoids and mineralocorticoids on cell birth. The Journal of Comparative Neurology 313: 486-493.

Gould, E., Woolley, C.S., Frankfurt, M., and McEwen, B.S. 1990. Adrenal steroids regulate dendritic spine density in hippocampal pyramidal cells in adulthood. The Journal of Comparative Neurology 313: 486-493.

Grassman, M. and Hess, D.L. 1992. Sex differences in adrenal function in the lizard Cnemidophorus sexlineatus: I. Seasonal variation in the field. The Journal of Experimental Zoology 264: 177-182.

Guillette, L.J., Cree, A., and Rooney, A.A. 1995. Biology of stress: interactions with reproduction, immunology, and intermediary metabolism. In: Warwick, C., Frye, F.L., and Murphy, J.B., Eds. Health and Welfare of Captive Reptiles. Chapman and Hall, London. pp. 32-81.

Haenel, G.J., Smith, L.C., and John-Alder, H.B. 2003. Home-range analysis in Sceloporus undulatus (Eastern Fence Lizard). I. Spacing patterns and the context of territorial behavior. Copeia 2003(1): 99-112.

Halpern, M. 1980. The telencephalon of snakes. In Ebbesson, S.O.E. (Ed.).Comparative Neurology of the Telencephalon.Plenium Press, New York, pp. 257-295. 
Hardy, D.L., Greene, H.W., Tomberlin, B., and Webster, M. 2001. Relocation of nuisance rattlesnakes: problems using short-distance translocation in a small rural community. Sonoran Herpetologist 10: 26-31.

Heine, V.M., Maslam, S., Zareno, J., Joëls, M., and Lucassen, P.J. 2004. Suppressed proliferation and apoptotic changes in the rat dentate gyrus after acute and chronic stress are reversible. European Journal of Neuroscience 19: 131-144.

Herzog, H.A., Bowers, B.B., and Burghardt, G.M. 1989. Development of antipredator response in snakes: IV. Interspecific and intraspecific differences in habituation of defensive behavior. Developmental Psychobiology 22: 489-508.

Holtzman, D.A., Harris, T.W., Aranguren, G., and Bostocks, E. 1999. Spatial learning of an escape task by young corn snakes. Animal Behaviour 57: 51-60.

Husak, J.F., Irschick, D.J., Meyers, J.J., Lailvaux, S.P., and Moore, I.T. 2007. Hormones, sexual signals and performance of green anole lizards (Anolis carolinensis). Hormones and Behavior 52: 360-367.

Jacobs, L.F., Gaulin, S.J.C., Sherry, D.F., and Hoffman, G.E. 1990. Evolution of spatial cognition: Sex-specific patterns of spatial cognition behavior predict hippocampal size. Proceedings of the National Academy of Sciences of the United States of America 87: 6349-6352.

Jones, S.M. and Bell, K. 2004. Plasma corticosterone concentrations in males of the skink Egernia whitii during acute and chronic confinement and over a diel period. Comparative Biochemistry and Physiology 137: 105-113.

Klukowski, M. and Nelson, C.E. 1998. The challenge hypothesis and seasonal changes in aggression and steroids in male northern fence lizards (Sceloporus undulatus hyacinthinus). Hormones and Behavior 33: 197-204.

Knapp, R. and Moore, M.C. 1997. Male morphs in tree lizards have different testosterone responses to elevated levels of corticosterone. General and Comparative Endocrinology 107: 273-279.

Langkilde, T. and Shine, R. 2006. How much stress do researchers inflict on their study animals? A case study using a scincid lizard, Eulamprus heatwolei. The Journal of Experimental Biology 209: 1035-1043.

Lind, C.M., Husak, J.F., Eikenaar, C., Moore, I.T., and Taylor, E.N. 2010. The relationship between plasma steroid hormone concentrations and the reproductive cycle in the northern Pacific rattlesnake, Crotalus oreganus. General and Comparative Endocrinology 166: 590-599. 
Lindsey, B.W. and Tropepe, V. 2006. A comparative framework for understanding the biological principles of adult neurogenesis. Progress in Neurobiology 80: 281307.

Lopez-Garcia, C., Molowny, A., Nacher, J., Ponsoda, X., Sancho-Bielsa, F., and AlonsoLlosa, G. 2002. The lizard cerebral cortex as a model to study neuronal regeneration. Annals of the Brazilian Academy of Sciences 74: 85-104.

López, J.C., Vargas, J.P., Gómez, Y., and Salas, C. 2003. Spatial and non-spatial learning in turtles: the role of the medial cortex. Behavioural Brain Research 14: 109-120.

Lutterschmidt, W.I., Lutterschmidt, D.I., Mason, R.T., and Reinert, H.K. 2009. Seasonal variation in hormonal responses of timber rattlesnakes (Crotalus horridus) to reproductive and environmental stressors. Journal of Comparative Physiology B 179: 747-757.

MaCartney, J.M., Gregory, P.T., and Charland, M.B. 1990. Growth and sexual maturity of the western rattlesnake, Crotalus viridis, in British Columbia. Copeia 1990: 528-542.

Maguire, E.A., Gadian, D.G., Johnsrude, I.S., Good, C.D., Ashburner, J., Frackowiak, R.S.J., and Frith, D. 2000. Navigation-related structural change in the hippocami of taxi drivers. Proceedings of the National Academy of Sciences of the United States of America 97: 4398-4403.

Manzo, C., Zerani, M., Gobbetti, A., Di Fiore, M.M., and Angelini, F. 1994. Is corticosterone involved in the reproductive processes of the male lizard, Podarcis sicula sicula? Hormones and Behavior 28: 117-129.

Marchioro, M., de AzevedoMotaNunes, J.M., RabeloRamalho, A.M., Molowny, A., Perez-Martinez, E., Ponsoda, X., and Lopez-Garcia, C.L. 2005. Postnatal neurogenesis in the medial cortex of the tropical lizard Tropidurus hispidus. Neuroscience 134: 407-413.

McCormich, C.M., McNamara, M., Mukhopadhyaya, S., and Kelsey, J.E. 1997. Acute corticosterone replacement reinstates performance on spatial and nonspatial memory tasks 2 months after adrenalectomy despite degeneration in the dentate gyrus. Behavioral Neuroscience 111: 518-531.

Moore, M.C. and Marler, C.A. 1987. Effects of testosterone manipulations on nonbreeding season territorial aggression in free-living male lizards, Sceloporus jarrovi. General and Comparative Endocrinology 65: 225-232.

McEwen, B.S. 2007. Physiology and neurobiology of stress and adaptation: central role of the brain. Physiological Reviews 87: 873-904. 
Moore, M.C., Thompson, C.W., and Marler, C.A. 1991. Reciprocal changes in corticosterone and testosterone levels following acute and chronic handling stress in the tree lizard, Urosaurus ornatus. General and Comparative Endocrinology 81: 217-226.

Moore, I.T., Greene, M.J., and Mason, R.T. 2001. Environmental and seasonal adaptations of the adrenocortical and gonadal responses to stress in two populations of the male garter snake, Thamnophis sirtalis. Journal of Experimental Zoology 289: 90-108.

Moore, I.T., Lemaster, M.P., and Mason, R.T. 2000. Behavioural and hormonal responses to capture stress in the male red-sided garter snakes (Thamnophis sirtalis parietalis). Animal Behaviour 59: 529-534.

Moore, I.T., Lerner, J.P., Lerner, K.T., and Mason, R.T. 2000. Relationships between annual cycles of testosterone, corticosterone, and body condition in male redspotted harter snakes, Thamnophis sirtalis concinnus. Physiological and Biochemical Zoology 73: 307-312.

Moser, M.B., Trommald, M., and Anderson, P. 1994. An increase in dendritic spine density on hippocampal CA1 pyramidal cells following spatial learning in adult rats suggests the formations of new synapses. Proceedings of the National Academy of Sciences of the United States of America 91: 12673-12675.

Moynihan, J.A. 2003. Mechanisms of stress-induced modulation of immunity. Brain, Behavior, and Immunity 17: 11-16.

Nowak, E.M., Hare, T., and McNally, J. 2002. Management of "nuisance" vipers: effects of translocation on western diamond-backed rattlesnakes (Crotalus atrox). In: Schuett, G.W., Hoggren, M., Douglas, M.E., Greene, H.W., (Eds.). Biology of the Vipers. Eagle Mountain Publishing, Eagle Mountain, Utah, pp. 533-560.

Patel, S.N., Clayton, N.S., and Krebs, J.R. 1997. Spatial learning induces neurogenesis in the avian brain. Behavioural Brain Research 89: 115-128.

Pérez-Cañellas, M.M. and García-Verdugo, J.M. 1996. Adult neurogenesis in the telencephalon of a lizard: a $\left[{ }^{3} \mathrm{H}\right]$ thymidineautoradiographic and bromodeoxyuridineimmunocytochemical study. Developmental Brain Research 93: 49-61.

Phuphanich, S. and Levin, V.A. 1985. Bioavailability of Bromodeoxyuridine in dogs and toxicity in rats. Cancer Research 45: 2387-2389. 
Plummer, M.V. and Mills, N.E. 2000. Spatial ecology and survivorship of resident and translocated hognose snakes (Heterodon platirhinos). Journal of Herpetology 34: 565-575.

Pravosudov, V.V. and Omanska, A. 2005. Dominance-related changes in spatial memory are associated with changes in hippocampal cell proliferation rates in mountain chickadees. Journal of Neurobiology 62: 31-41.

Ramirez, C., Nacher, J., Molowny, A., Sanchez-Sanchez, F., Irurzun, A., and LopezGarcia, C. 1997. Photoperiod-temperature and neuroblast proliferation-migration in the adult lizard cortex. NeuroReport 8: 2337-2342.

Ramírez-Amaya, V., Balderas, I., Sandoval, J., Escobar, M.L., and Bermúdez-Rattoni, F. 2001. Spatial long-term memory is related to mossy fiber synaptogenesis. The Journal of Neuroscience 21: 7340-7348.

Reinert, H.K. 1991. Translocation as a conservation strategy for amphibians and reptiles: some comments, concerns, and observations. Herpetologica 47: 357363.

Reinert, H.K. and Rupert Jr., R.R. 1999. Impacts of translocation on behavior and survival of timber rattlesnakes, Crotalus horridus. Journal of Herpetology 33: 4561.

Rödl, T., Berger, S., Romero, M., and Wikelski, M. 2007. Tameness and stress physiology in a predator-naïve island species confronted with novel predation threat. Proceedings of the Royal Society B: 274: 577-582.

Rodríguez, F., López, J.C., Vargas, J.P., Gópez, Y., Broglio, C., and Salas, C. 2002. Conservation of spatial memory function in the pallial forebrain of reptiles and ray-finned fishes. The Journal of Neuroscience 22: 2894-2903.

Roth, E.D., Lutterschmidt, W.I., and Wilson, D.A. 2006. Relative medial and dorsal cortex volume in relation to sex differences in spatial ecology of a snake population. Brain, Behavior and Evolution 67: 103-110.

Sampedro, C., Font, E., and Desfilis, E. 2008. Size variation and cell proliferation in chemosensory brain areas of a lizard (Podarcis hispanica): effects of sex and season. European Journal of Neuroscience 28: 87-98.

Schuett, G.W., Taylor, E.N., Van Kirk, E.A., and Murdoch, W.J. 2004. Handling stress and plasma corticosterone levels in captive male western diamond-backed rattlesnakes (Crotalus atrox). Herpetological Review 35: 229-233.

Sherry, D.F., Forbes, M.R.L., Khurgel, M., and Ivy, G.O. 1993. Females have a larger hippocampus than males in the brood-parasitic brown-headed cowbird. 
Proceedings of the National Academy of Sciences of the United States of America 90: 7839-7843.

Siwak-Tapp, C.T., Head, E., Muggenburg, B.A., Milgram, N.W., and Cotman, C.W. 2007. Neurogenesis decreases with age in the canine hippocampus and correlates with cognitive function. Neurobiology of Learning and Memory 88: 249-259.

Snyder, J.S., Glover, L.R., Sanzone, K.M., Kamhi, J.F., and Cameron, H.A. 2009. The effects of exercise and stress on the survival and maturation of adult-generated granule cells. Hippocampus 19: 898-906.

Summer, C.H. and Norman, M.F. 1988. Chronic low humidity-stress in the lizard Anolis carolinensis: changes in diurnal corticosterone rhythms. The Journal of Experimental Zoology 247: 271-278.

Sykes, K.L. and Klukowski, M. 2009. Effects of acute temperature change, confinement, and housing on plasma corticosterone in water snakes, Nerodia sipedon (Colubridae: Natricinae). Journal of Experimental Zoology 311A: 172181.

Tanapat, P., Hastings, N.B., Rydel, T.A., Galea, L.A.M., and Gould, E. 2001. Exposure to fox odor inhibits cell proliferation in the hippocampus of adult rats via an adrenal hormone-dependent mechanism. The Journal of Comparative Neurology 437: 496-504.

Taylor, E.N. and Schuett, G.W. 2004. Effect of temperature and storage duration on the stability of steroid hormones in blood samples from western diamond-backed rattlesnakes (Crotalus oreganus). Herpetological Review 35: 14-17.

Tracy, C.R., Nussear, K.E., Esque, T.C., Dean-Bradley, K., Tracy, C.R., DeFalco, L.A., Castle, K.T., Zimmerman, L.C., Espinoza, R.E., and Barber, A.M. 2006. The importance of physiological ecology in conservation biology. Integrative and Comparative Biology 46: 1191-1205.

Tokarz, R.R. 1987. Effects of corticosterone treatment on male aggressive behavior in a lizard (Anolis sagrei). Hormones and Behavior 21: 358-370.

Wada, H., Hahn, T.P., Breuner, C.W. 2007. Development of stress reactivity in whitecrowned sparrow nestlings: total corticosterone response increases with age, while free corticosterone response remains low. General and Comparative Endocrinology 150: 405-413.

Watt, M.J., Forster, G.L., and Joss, M.P. 2003. Steroid correlates of territorial behavior in male jacky dragons, Amphibolurus muricatus. Brain, Behavior, and Evolution 61: 184-194. 
Wingfield, J.C. and Farner, D.S. 1975. The determination of five steroids in avian plasma by radioimmunoassay and competitive protein binding. Steroids 26: 311327.

Wingfield, J.C., Maney, D.L., Breuner, C.W., Jacobs, J.D., Lynn, S., Ramenofsky, M., and Richardson, R.D. 1998. Ecological bases of hormone-behavior interactions: the "emergency life history stage:. American Journal of Zoology 38: 191-206.

Woodley, S.K. and Moore, M.C. 2002. Plasma corticosterone response to an acute stressor varies according to reproductive condition in female tree lizards (Urosaurus ornatus). General and Comparative Endocrinology 128: 143-148.

Yajurvedi, H.N. and Menon, S. 2005. Influence of stress on gonadotrophin induced testicular recrudescence in the lizard Mabuya carinata. Journal of Experimental Zoology 303A: 534-540.

Yajurvedi, H.N. and Nijagal, B.S. 2000. Corticosterone inhibits normal and FSHinduced testicular recrudescence in the lizard, Mabuya carinata. General and Comparative Endocrinology 120: 283-288.

Zuri, I. and Bull, C.M. 2000. The use of visual cues for spatial orientation in the sleepy lizard (Tiliqua rugosa). The Canadian Journal of Zoology 78: 515-520. 